NISTIR 7365

\title{
Results from Field Testing of Embedded Air Handling Unit and Variable Air Volume Box Fault Detection Tools
}

Jeffrey Schein 
NISTIR 7365

\title{
Results from Field Testing of Embedded Air Handling Unit and Variable Air Volume Box Fault Detection Tools
}

\author{
Jeffrey Schein \\ Building Environment Division \\ Building and Fire Research Laboratory \\ National Institute of Standards and Technology \\ Gaithersburg, MD 20899-8530
}

October 2006

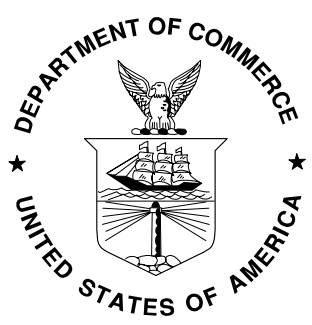

U.S. Department of Commerce

Carlos M. Gutierrez, Secretary

Technology Administration

Robert Cresanti, Under Secretary of Commerce for Technology

National Institute of Standards and Technology

William Jeffrey, Director 


\section{Executive Summary}

Fault detection and diagnostic (FDD) methods that can detect common mechanical faults and control errors in air-handling units (AHUs) and variable-air-volume (VAV) boxes were developed and commercialized. The tools are sufficiently simple that they can be embedded in commercial building automation and control systems and rely only upon the sensor data and control signals that are commonly available in these systems. AHU Performance Assessment Rules (APAR) is a diagnostic tool that uses a set of expert rules derived from mass and energy balances to detect faults in air-handling units. VAV box Performance Assessment Control Charts (VPACC) is a diagnostic tool that uses statistical quality control measures to detect faults or control problems in VAV boxes.

This report describes the transfer of the FDD methods from research to commercial use. An interface between the FDD tools and the building operator is introduced. Results are presented from a multiple site field demonstration in which APAR and VPACC were embedded in commercial AHU and VAV box controllers. Robust FDD parameters are tabulated for both APAR and VPACC. The parameters, which eliminate the need for site-specific configuration, were developed based on experience from the field demonstration.

Key words: BACnet, building automation and control, cybernetic building systems, direct digital control, energy management systems, fault detection and diagnostics

\section{Acknowledgments}

This work was supported in part by the California Energy Commission. 


\section{Table of Contents}

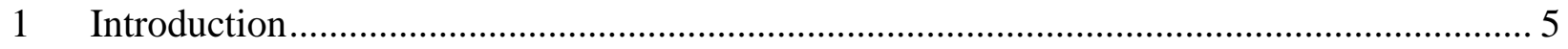

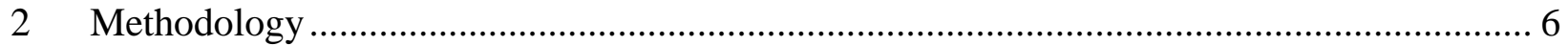

2.1 AHU Performance Assessment Rules (APAR) ........................................................ 6

2.2 VAV Box Performance Assessment Control Charts - VPACC.................................... 11

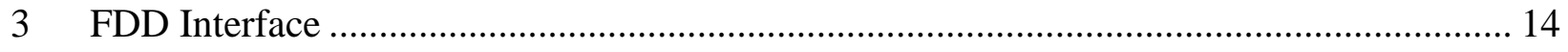

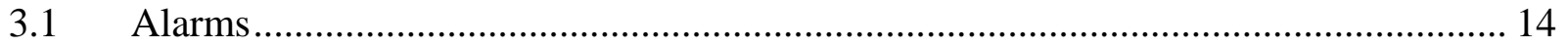

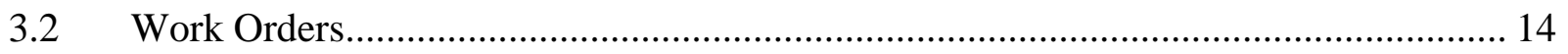

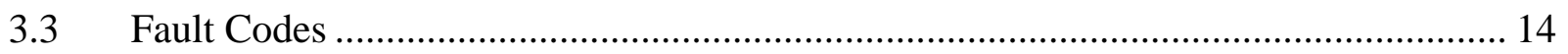

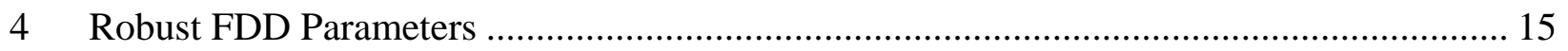

4.1 Tuning FDD Parameters for Optimum Performance ............................................ 17

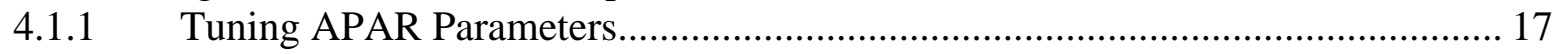

4.1.2 Tuning VPACC Parameters ............................................................................ 18

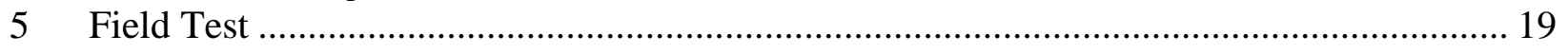

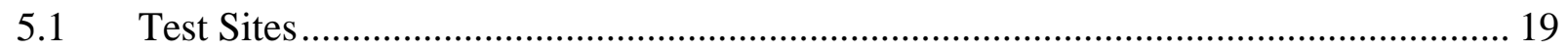

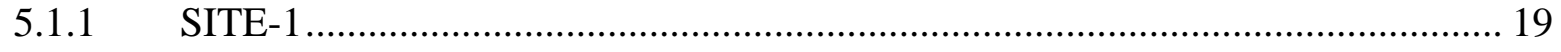

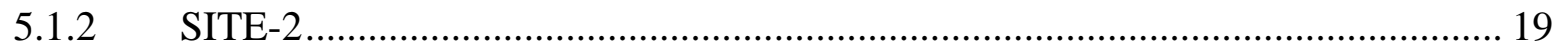

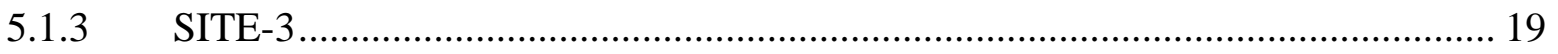

5.1.4 SITE-4

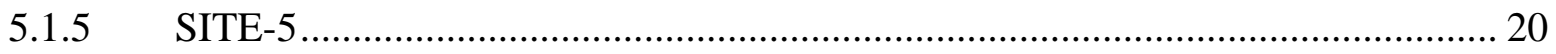

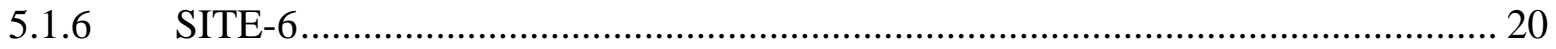

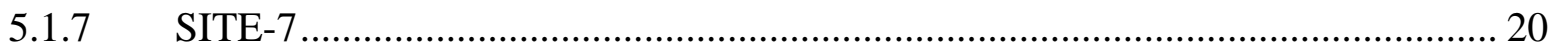

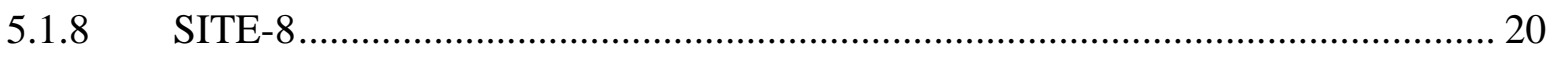

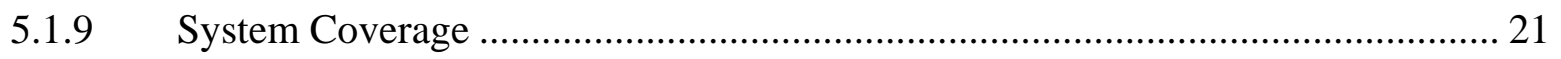

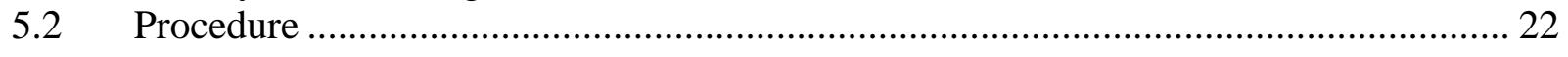

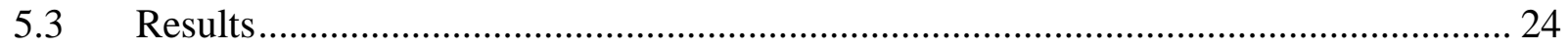

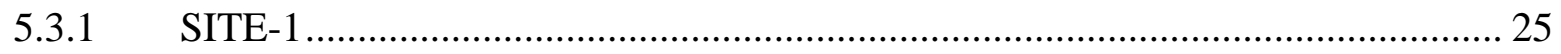

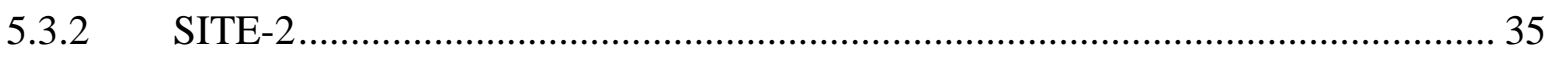

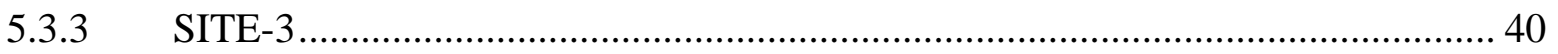

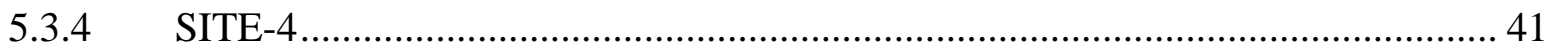

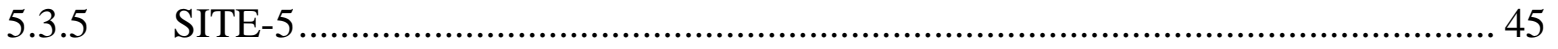

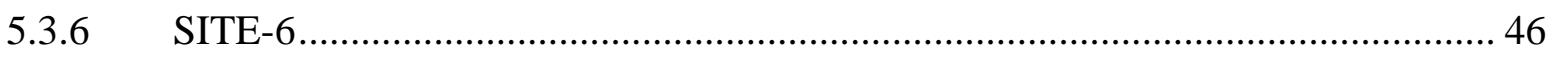

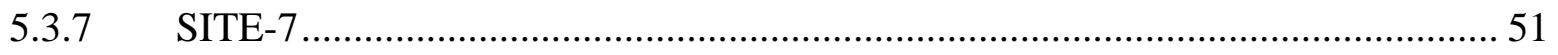

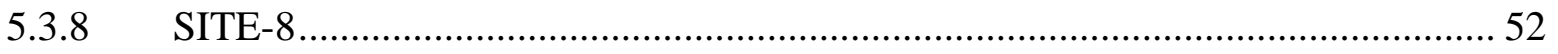

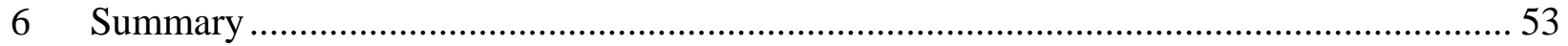

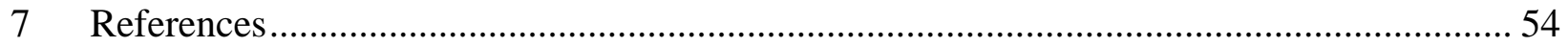

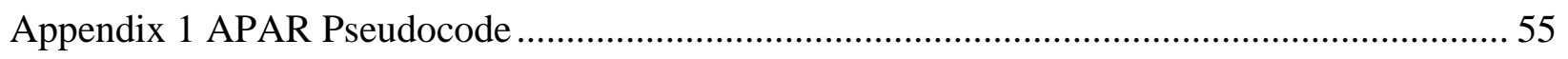

Appendix 2 VPACC Pseudocode .................................................................................. 70 


\section{Introduction}

Building HVAC equipment routinely fails to satisfy performance expectations envisioned at design. Such failures often go unnoticed for extended periods of time. Additionally, higher expectations are being placed on a combination of different and often conflicting performance measures, such as energy efficiency, indoor air quality, comfort, reliability, limiting peak demand on utilities, etc. To meet these expectations, the processes, systems, and equipment used in both commercial and residential buildings are becoming increasingly sophisticated. This development both necessitates the use of automated diagnostics to ensure fault-free operation and enables diagnostic capabilities for the various building systems by providing a distributed platform that is powerful and flexible enough to perform fault detection and diagnostics (FDD).

Most of today's emerging FDD tools are stand-alone software products that do not reside in a building control system. Thus, trend data files must be processed off-line, or an interface to the building control system must be developed to enable on-line analysis. This does not scale well because all of the data must be obtained at a single point. A better solution is to embed FDD in the local controller for each piece of equipment, so that the FDD algorithm is executed as a component of the control logic. NIST has developed FDD methods that can detect common mechanical faults and control errors in air-handling units (AHUs) and variable-air-volume (VAV) boxes. The tools are sufficiently simple that they can be embedded in commercial building control systems and only rely upon sensor data and control signals that are commonly available in commercial building automation and control systems.

In previous research, software tools have been developed to implement APAR and VPACC, then tested and refined using data generated by simulation, emulation, and laboratory testing [1] and data collected from real buildings [2]. APAR and VPACC have also been embedded in commercial AHU and VAV box controllers from several manufacturers and tested in emulation and laboratory environments [3].

The project described in this report was designed to move the FDD algorithms from the research environment to commercial HVAC control products. Several methods to communicate the results of the FDD calculations to the system operator were developed. Robust FDD parameters for both APAR and VPACC were developed to eliminate the need for site-specific configuration. APAR and VPACC were embedded in commercial AHU and VAV box controllers for a multiple site field demonstration which was conducted to establish confidence in automated diagnostics and to familiarize potential vendors and users with FDD. 


\section{Methodology}

\subsection{AHU Performance Assessment Rules (APAR)}

The basis for the air handling unit fault detection methodology is a set of expert rules used to assess the performance of the AHU. The tool developed from these rules is APAR (AHU Performance Assessment Rules). A brief overview of APAR is presented here; a detailed description is available elsewhere [5].

APAR is applicable to single duct VAV and constant volume AHUs with airside economizers. The operation of this type of AHU during occupied periods can be classified into a number of modes, depending on the heating/cooling load and outdoor air conditions. Each mode of operation can be characterized by a different range of values for each of three control signals: the heating coil valve, cooling coil valve, and mixing box dampers. For convenience, the operating modes are summarized below:

- Mode 1: heating

- Mode 2: cooling with outdoor air

- Mode 3: mechanical cooling with $100 \%$ outdoor air

- Mode 4: mechanical cooling with minimum outdoor air

- Mode 5: unknown

Once the mode of operation has been established, rules based on conservation of mass and energy can be evaluated using the sensor and control signal information that is typically available from AHUs. APAR has a total of 28 rules (see Table 2.1). Each rule is expressed as a logical statement that, if true, indicates the presence of a fault. Because the mass and energy balances are different for each mode of operation, a different subset of the rules applies to each mode. There are also some rules that are independent of the operating mode and are always evaluated. A list of possible causes is associated with each rule (see Table 2.2).

Several modifications to the basic APAR algorithm were made to enhance usability and reduce nuisance alarms. Each rule can be individually disabled by the user in order to eliminate nuisance alarms caused by fault conditions that are known to the maintenance staff, but will not be repaired immediately. Since the rules are based on steady state assumptions, there are several delays, during which the rules are not evaluated, to ensure that quasi-steady state conditions exist. There is a delay at the beginning of occupancy and another delay after each mode switch. A third delay establishes the length of time a rule must be satisfied before an alarm is reported. Furthermore, the rules are evaluated using exponentially weighted moving averages of the raw data rather than the current values [5].

The rules in Table 2.1 are generic, not tightly linked to a specific sequence of operations. The rule set was developed for AHUs with hydronic heating and cooling coils and relative enthalpybased economizers, however, it can easily be adapted for different types of AHUs. For example, Rules 9 and 15 will change based on the type of economizer, whether it is temperature- or enthalpy-based, and whether it compares outdoor conditions to return or to a fixed changeover condition, or some combination thereof. If the cooling coil uses direct expansion instead of chilled water, Rules 13, 14, 19, and 20 do not apply. Also, the causes in Table 2.2 related to the 
cooling coil valve (valve stuck or leaking) or the chilled water system (chilled water supply temperature too high, problem with chilled water circulating pump, chilled water not available) are interpreted as problems with the mechanical refrigeration system. If some form of staged heating (electric or combustion) is used instead of hydronic heating, Rules 3 and 4 do not apply. Also, the causes in Table 2.2 related to the heating coil valve (valve stuck or leaking) or the hot water system (hot water supply temperature too low, problem with hot water circulating pump) are interpreted as problems with the staged heating system. For single zone or other AHUs with no supply air temperature setpoint, Rules 5, 8, 13, 19, and 25 do not apply. If there is no mixed air temperature sensor, delete Rules 1, 2, 7, 10, 11, 16, 18, 26, and 27 cannot be evaluated and therefore do not apply. 
Table 2.1: APAR Rule Set

\begin{tabular}{|c|c|c|}
\hline Mode & Rule \# & Rule Expression (true implies existence of a fault) \\
\hline \multirow{4}{*}{$\begin{array}{l}\text { Heating } \\
\text { (Mode 1) }\end{array}$} & 1 & $T_{s a}<T_{m a}+\Delta T_{s f^{-}} \varepsilon_{t}$ \\
\hline & 2 & For $\left|T_{r a}-T_{o a}\right| \geq \Delta T_{\min }:\left|Q_{o a} / Q_{s a}-\left(Q_{o a} / Q_{s a}\right)_{\min }\right|>\varepsilon_{f}$ \\
\hline & 3 & $\left|u_{h c}-1\right| \leq \varepsilon_{h c} \quad$ and $\quad T_{s a, s}-T_{s a} \geq \varepsilon_{t}$ \\
\hline & 4 & $\left|u_{h c}-1\right| \leq \varepsilon_{h c}$ \\
\hline \multirow{3}{*}{$\begin{array}{l}\text { Cooling with } \\
\text { Outdoor Air } \\
\text { (Mode 2) }\end{array}$} & 5 & $T_{o a}>T_{s a, s}-\Delta T_{s f}+\varepsilon_{t}$ \\
\hline & 6 & $T_{s a}>T_{r a}-\Delta T_{r f}+\varepsilon_{t}$ \\
\hline & 7 & $\left|T_{s a}-\Delta T_{s f}-T_{m a}\right|>\varepsilon_{t}$ \\
\hline \multirow{7}{*}{$\begin{array}{l}\text { Mechanical } \\
\text { Cooling with } \\
\text { 100\% Outdoor } \\
\text { Air } \\
\text { (Mode 3) }\end{array}$} & 8 & $T_{o a}<T_{s a, s}-\Delta T_{s f}-\varepsilon_{t}$ \\
\hline & 9 & $T_{o a}>T_{c o}+\varepsilon_{t}$ \\
\hline & 10 & $\left|T_{o a}-T_{m a}\right|>\varepsilon_{t}$ \\
\hline & 11 & $T_{s a}>T_{m a}+\Delta T_{s f}+\varepsilon_{t}$ \\
\hline & 12 & $T_{s a}>T_{r a}-\Delta T_{r f}+\varepsilon_{t}$ \\
\hline & 13 & $\left|u_{c c}-1\right| \leq \varepsilon_{c c} \quad$ and $\quad T_{s a}-T_{s a, s} \geq \varepsilon_{t}$ \\
\hline & 14 & $\left|u_{c c}-1\right| \leq \varepsilon_{c c}$ \\
\hline \multirow{6}{*}{$\begin{array}{l}\text { Mechanical } \\
\text { Cooling with } \\
\text { Minimum } \\
\text { Outdoor Air } \\
\text { (Mode 4) }\end{array}$} & 15 & $T_{o a}<T_{c o}-\varepsilon_{t}$ \\
\hline & 16 & $T_{s a}>T_{m a}+\Delta T_{s f}+\varepsilon_{t}$ \\
\hline & 17 & $T_{s a}>T_{r a}-\Delta T_{r f}+\varepsilon_{t}$ \\
\hline & 18 & For $\left|T_{r a}-T_{o a}\right| \geq \Delta T_{\text {min }}:\left|Q_{o a} / Q_{s a}-\left(Q_{o a} / Q_{s a}\right)_{\min }\right|>\varepsilon_{f}$ \\
\hline & 19 & $\left|u_{c c}-1\right| \leq \varepsilon_{c c} \quad$ and $\quad T_{s a}-T_{s a, s} \geq \varepsilon_{t}$ \\
\hline & 20 & $\left|u_{c c}-1\right| \leq \varepsilon_{c c}$ \\
\hline \multirow{4}{*}{$\begin{array}{l}\text { Unknown } \\
\text { Occupied } \\
\text { Modes } \\
\text { (Mode 5) }\end{array}$} & 21 & $u_{c c}>\varepsilon_{c c}$ and $u_{h c}>\varepsilon_{h c}$ and $\varepsilon_{d}<u_{d}<1-\varepsilon_{d}$ \\
\hline & 22 & $u_{h c}>\varepsilon_{h c}$ and $u_{c c}>\varepsilon_{c c}$ \\
\hline & 23 & $u_{h c}>\varepsilon_{h c}$ and $u_{d}>\varepsilon_{d}$ \\
\hline & 24 & $\varepsilon_{d}<u_{d}<1-\varepsilon_{d}$ and $u_{c c}>\varepsilon_{c c}$ \\
\hline \multirow{4}{*}{$\begin{array}{l}\text { All Occupied } \\
\text { Modes } \\
\text { (Mode 1, 2, 3, 4, } \\
\text { or 5) }\end{array}$} & 25 & $\left|T_{s a}-T_{s a, s}\right|>\varepsilon_{t}$ \\
\hline & 26 & $T_{m a}<\min \left(T_{r a}, T_{o a}\right)-\varepsilon_{t}$ \\
\hline & 27 & $T_{m a}>\max \left(T_{r a}, T_{o a}\right)+\varepsilon_{t}$ \\
\hline & 28 & Number of mode transitions per hour $>M T_{\max }$ \\
\hline
\end{tabular}




\begin{tabular}{|c|c|c|}
\hline \multicolumn{3}{|l|}{ Where } \\
\hline$M T_{\max }$ & $=$ & maximum number of mode changes per hour \\
\hline$T_{s a}$ & $=$ & supply air temperature \\
\hline$T_{m a}$ & $=$ & mixed air temperature \\
\hline$T_{r a}$ & $=$ & return air temperature \\
\hline$T_{o a}$ & $=$ & outdoor air temperature \\
\hline$T_{c o}$ & $=$ & changeover air temperature for switching between Modes 3 and 4 \\
\hline$T_{s a, s}$ & $=$ & supply air temperature set point \\
\hline$\Delta T_{s f}$ & $=$ & temperature rise across the supply fan \\
\hline$\Delta T_{r f}$ & $=$ & temperature rise across the return fan \\
\hline$\Delta T_{\min }$ & $=$ & $\begin{array}{l}\text { threshold on the minimum temperature difference between the return and } \\
\text { outdoor air }\end{array}$ \\
\hline$Q_{o a} / Q_{s a}$ & $=$ & outdoor air fraction $=\left(T_{m a}-T_{r a}\right) /\left(T_{o a}-T_{r a}\right)$ \\
\hline$\left(Q_{o a} / Q_{s a}\right)_{\min }$ & $=$ & threshold on the minimum outdoor air fraction \\
\hline$u_{h c}$ & $=$ & $\begin{array}{l}\text { normalized heating coil valve control signal }[0,1] \text { where } u_{h c}=0 \text { indicates } \\
\text { the valve is closed and } u_{h c}=1 \text { indicates it is } 100 \% \text { open }\end{array}$ \\
\hline$u_{c c}$ & $=$ & $\begin{array}{l}\text { normalized cooling coil valve control signal }[0,1] \text { where } u_{c c}=0 \text { indicates } \\
\text { the valve is closed and } u_{c c}=1 \text { indicates it is } 100 \% \text { open }\end{array}$ \\
\hline$u_{d}$ & $=$ & $\begin{array}{l}\text { normalized mixing box damper control signal }[0,1] \text { where } u_{d}=0 \text { indicates } \\
\text { the outdoor air damper is closed and } u_{d}=1 \text { indicates it is } 100 \% \text { open }\end{array}$ \\
\hline$\varepsilon_{t}$ & $=$ & threshold for errors in temperature measurements \\
\hline$\varepsilon_{f}$ & $=$ & $\begin{array}{l}\text { threshold parameter accounting for errors related to airflows (function of } \\
\text { uncertainties in temperature measurements) }\end{array}$ \\
\hline$\varepsilon_{h c}$ & $=$ & threshold parameter for the heating coil valve control signal \\
\hline$\varepsilon_{c c}$ & $=$ & threshold parameter for the cooling coil valve control signal \\
\hline$\varepsilon_{d}$ & $=$ & threshold parameter for the mixing box damper control signal \\
\hline
\end{tabular}


Table 2.2: APAR Diagnoses

Rule \#

Alarm Description

Possible Diagnoses

\begin{tabular}{|c|c|c|c|c|c|c|c|c|c|c|c|c|c|c|c|c|c|c|}
\hline & & & & & & & & & & & & & & & & & & \\
\hline 1 & In heating mode, supply air temp should be greater than mixed air temp. & $\mathrm{X}$ & & $\mathrm{X}$ & & \begin{tabular}{c|c}
$x$ & $\lambda$ \\
\end{tabular} & $\mathrm{X}$ & & & & & $\mathrm{x}$ & \begin{tabular}{l|l} 
\\
\end{tabular} & $\mathrm{X}$ & $\mathrm{X}$ & $\mathrm{X}$ & & \\
\hline 2 & Outdoor air fraction (percentage of outdoor air) is too low or too high. & & $\mathrm{X}$ & $\mathrm{X}$ & $\mathrm{X}$ & & & & & & & & & & & & $\mathrm{X}$ & $\mathrm{X}$ \\
\hline 3 & Heating coil valve command is fully open and supply air temp error exists. & $\mathrm{x}$ & & & & 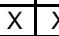 & $\mathrm{X}$ & & & & & $\mathrm{x}$ & \begin{tabular}{l|l|l} 
& $x$ \\
\end{tabular} & $\mathrm{x}$ & $\mathrm{X}$ & $\mathrm{x}$ & & \\
\hline 4 & Heating coil valve command is fully open. If heating load increases, supply air temp will drift from setpoint. & $\mathrm{x}$ & & & & \begin{tabular}{c|ccc}
$x$ & $\lambda$ & $r$
\end{tabular} & $\mathrm{X}$ & & & & & $\mathrm{x}$ & 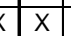 & $\mathrm{x}$ & $\mathrm{X}$ & $\mathrm{X}$ & & \\
\hline 5 & Outdoor air temp is too warm for cooling with outdoor air. & $\mathrm{x}$ & & & $\mathrm{X}$ & & & & & & & & & & & & & \\
\hline 6 & Supply air temp should be less than return air temp. & $\mathrm{x}$ & $\mathrm{x}$ & & & & & & & & & \begin{tabular}{l|l}
$X$ & $X$
\end{tabular} & & & & & & \\
\hline 7 & Supply and mixed air temp should be nearly the same. & $\mathrm{x}$ & & $\mathrm{X}$ & & \begin{tabular}{c|ccc}
$x$ & $x$ \\
\end{tabular} & $\mathrm{X}$ & & & & & \begin{tabular}{l|ll}
$X$ & $X$ \\
\end{tabular} & & & & & & \\
\hline 8 & Outdoor air temperature is too cool for mechanical cooling with $100 \%$ outdoor air. & $\mathrm{x}$ & & & $\mathrm{X}$ & & & & & & & \begin{tabular}{l|l}
$X$ & $X$
\end{tabular} & & & & & $\mathrm{x}$ & $\mathrm{X}$ \\
\hline 9 & Outdoor air enthalpy is too great for mechanical cooling with $100 \%$ outdoor air. & & & & & & & & & & & & & & & & & \\
\hline 10 & Outdoor and mixed air temp should be nearly the same. & & & $\mathrm{X}$ & $\mathrm{X}$ & & & & & & & & & & & & $\mathrm{x}$ & $\mathrm{X}$ \\
\hline 11 & Supply air temp should be less than mixed air temp. & $\mathrm{x}$ & & $\mathrm{X}$ & & & \begin{tabular}{l|lll}
$x$ & $x$ \\
\end{tabular} & 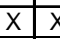 & \begin{tabular}{l|l}
$x$ & $x$ \\
\end{tabular} & \begin{tabular}{c|c|cc}
$x$ & $x$ \\
\end{tabular} & $\mathrm{X}$ & \begin{tabular}{l|l}
$X$ & $X$
\end{tabular} & & & & & & \\
\hline 12 & Supply air temp should be less than return air temp. & $\mathrm{x}$ & $\mathrm{x}$ & & & & 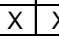 & 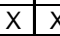 & \begin{tabular}{l|l}
$X$ & $x$
\end{tabular} & 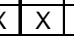 & $\mathrm{X}$ & \begin{tabular}{l|ll}
$X$ & $X$ \\
\end{tabular} & & & & & & \\
\hline 13 & Cooling coil valve command is fully open and supply air temp error exists. & $\mathrm{x}$ & & & & & 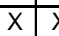 & 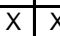 & \begin{tabular}{l|l}
$x$ & $x$
\end{tabular} & \begin{tabular}{l|l|l}
$x$ & $x$ & $r$ \\
\end{tabular} & $\mathrm{X}$ & \begin{tabular}{l|l}
$X$ & $X$
\end{tabular} & & & & & & \\
\hline 14 & Cooling coil valve command is fully open. If cooling load increases, supply air temp will drift from setpoint. & $\mathrm{X}$ & & & & & \begin{tabular}{c|ccc}
$x$ & $\lambda$ & $r$
\end{tabular} & 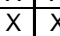 & \begin{tabular}{l|l}
$x$ & $x$
\end{tabular} & 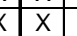 & $\mathrm{x}$ & \begin{tabular}{l|l}
$X$ & $X$
\end{tabular} & & & & & & \\
\hline 15 & Outdoor air enthalpy is too low for mechanical cooling with minimum outdoor air. & & & & & & & & & & & & & & & & & \\
\hline 16 & Supply air temp should be less than mixed air temp. & $\mathrm{x}$ & & $\mathrm{X}$ & & & 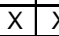 & 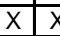 & \begin{tabular}{l|l}
$X$ & $x$ \\
\end{tabular} & $\mathrm{x}$ & $\mathrm{X}$ & \begin{tabular}{l|ll}
$X$ & $X$ \\
\end{tabular} & & & & & & \\
\hline 17 & Supply air temp should be less than return air temp. & $\mathrm{x}$ & $\mathrm{x}$ & & & & \begin{tabular}{l|lll}
$x$ & $\lambda$ \\
$x$
\end{tabular} & \begin{tabular}{l|l}
$x$ & $x$ \\
\end{tabular} & \begin{tabular}{l|l}
$x$ & $x$ \\
\end{tabular} & $\mathrm{x}$ & $\mathrm{X}$ & \begin{tabular}{l|l}
$x$ & $x$ \\
\end{tabular} & & & & & & \\
\hline 18 & Outdoor air fraction (percentage of outdoor air) is too low or too high. & & $\mathrm{x}$ & $\mathrm{X}$ & $\mathrm{X}$ & & & & & & & & & & & & $\mathrm{x}$ & $\mathrm{X}$ \\
\hline 19 & Cooling coil valve command is fully open and supply air temp error exists. & $\mathrm{x}$ & & & & & \begin{tabular}{c|c}
$x$ & $x$ \\
\end{tabular} & 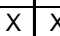 & \begin{tabular}{l|ll}
$x$ & $x$
\end{tabular} & $|x|$ & $\mathrm{X}$ & \begin{tabular}{l|ll}
$X$ & $x$
\end{tabular} & & & & & & \\
\hline 20 & Cooling coil valve command is fully open. If cooling load increases, supply air temp will drift from setpoint. & $\mathrm{x}$ & & & & & 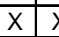 & 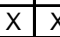 & \begin{tabular}{l|l}
$x$ & $x$
\end{tabular} & $\mathrm{x}$ & 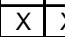 & \begin{tabular}{l|l}
$x$ & $x$ \\
\end{tabular} & & & & & & \\
\hline 21 & Heating coil valve, cooling coil valve, and mixing box dampers are all modulating simultaneously. & & & & & & & & & & & & & & & & & \\
\hline 22 & Heating coil valve and cooling coil valve are both modulating simultaneously. & & & & & & & & & & & & & & & & & \\
\hline 23 & Heating coil valve and mixing box dampers are both modulating simultaneously. & & & & & & & & & & & & & & & & & \\
\hline 24 & Cooling coil valve and mixing box dampers are both modulating simultaneously. & & & & & & & & & & & & & & & & & \\
\hline 25 & Persistent supply air temp error exists. & & & & & & & & & & & & & & & & & \\
\hline 26 & Mixed air temp should be between return and outdoor air temp (mixed air temp too great). & & $\mathrm{x}$ & $\mathrm{X}$ & $\mathrm{X}$ & & & & & & & & & & & & & \\
\hline 27 & Mixed air temp should be between return and outdoor air temp (mixed air temp too low). & & $\mathrm{x}$ & $\mathrm{X}$ & $\mathrm{X}$ & & & & & & & & & & & & & \\
\hline 28 & Too many mode switches per hour. & & & & & & & & & & & & & & & & & \\
\hline
\end{tabular}




\subsection{VAV Box Performance Assessment Control Charts - VPACC}

The challenges presented in detecting and diagnosing faults in VAV boxes are similar to those encountered with other pieces of HVAC equipment. Generally there are very few sensors, making it difficult to determine what is happening in the device. Limitations associated with controller memory and communication capabilities further complicate the task. The number of different types of VAV boxes and lack of standardized control sequences add a final level of complexity to the challenge. These needs and constraints led to the development of VAV Box Performance Assessment Control Charts (VPACC), a fault detection tool that uses a small number of control charts to assess the performance of VAV boxes. A brief overview of VPACC is presented here; a detailed description is available elsewhere [6].

VPACC implements an algorithm known as a CUSUM (cumulative sum) chart [7]. The basic concept behind CUSUM charts is to accumulate the error between a process output and the expected value of the output. Large values of the accumulated error indicate an out of control process. Mathematically, the technique can be expressed as:

$$
z_{i}=\left(x_{i}-x_{\text {exp }}\right) / \sigma_{\exp }
$$

where $z_{i}$ is the normalized error at time $i, x_{i}$ is the error at time $i, x_{\exp }$ is the expected value of the error, and $\sigma_{\text {exp }}$ is the expected variation of the error. Separate positive $(S)$ and negative $(T)$ sums are then accumulated. The slack parameter, $k$, is defined as the amount of variation that is considered normal, and therefore ignored. The cumulative positive and negative sums are calculated by:

$$
\begin{aligned}
& S_{i}=\max \left[0, z_{i}-k+S_{i-1}\right] \\
& T_{i}=\max \left[0,-z_{i}-k+T_{i-1}\right]
\end{aligned}
$$

The final step is to compare $S$ and $T$ to the alarm limit, $h$, to determine whether the process is out of control.

In order to make VPACC independent of the control strategy used in a particular controller/VAV box application, four generic errors were identified: the airflow rate error, the absolute value of the airflow rate error, the temperature error, and the discharge air temperature error. As long as the VAV box controller has an airflow setpoint, as well as heating and cooling temperature setpoints, VPACC will function independently of the specific control strategy used. Common mechanical and control faults will result in a positive or negative deviation of one or more of these errors from its value during normal operation, which can be detected by a CUSUM chart. A list of possible causes is associated with each alarm (see Table 2.3).

The airflow rate error, $Q_{\text {error }}$, is defined as the difference between the measured airflow rate and the airflow rate set point. The absolute value of the airflow rate error, $\left|Q_{\text {error }}\right|$, is defined simply as the absolute value of the difference between the measured airflow rate and the airflow rate set point. Only one CUSUM value is defined for this error since it is never negative. 
The zone temperature error, $T_{\text {error }}$, is defined as

$$
\begin{array}{ll}
T_{\text {error }}=T_{\text {zone }}-C S P & : \text { If } T_{\text {zone }}>C S P \\
T_{\text {error }}=0 & : \text { If } H S P \leq T_{\text {zone }} \leq C S P \\
T_{\text {error }}=T_{\text {zone }}-H S P & : \text { If } T_{\text {zone }}<H S P
\end{array}
$$

where

$$
\begin{aligned}
& T_{\text {zone }}=\text { zone temperature } \\
& C S P=\text { cooling set point } \\
& H S P=\text { heating set point }
\end{aligned}
$$

The discharge air temperature error, $D A T_{\text {error }}$, is only applied to VAV boxes with hydronic reheat. The $D A T_{\text {error }}$ is calculated only when the reheat coil valve is fully closed, otherwise it is set equal to zero. It is defined as the difference between the VAV box discharge air temperature and the entering air temperature. The supply air temperature from the AHU serving the VAV box can be used as a surrogate for the entering air temperature. This value is generally obtained via the building control network.

The errors and CUSUMs are only calculated during occupied periods. During unoccupied periods, the errors are not computed and the CUSUMs are reset to zero. There is a delay at the onset of the occupied period to allow quasi-steady state conditions to develop. Also, the CUSUMs are periodically reset to zero to prevent alarms from being reported due to small steady state errors. Each alarm can be individually disabled by the user in order to eliminate nuisance alarms caused by fault conditions that are known to the maintenance staff, but will not be repaired immediately.

VPACC was developed for pressure independent VAV boxes with hydronic reheat coils, however, it can easily be adapted for different types of VAV boxes. For cooling only VAV boxes or boxes that do not have discharge air temperature sensors, the discharge air temperature error $\left(\Delta T_{\text {error }}\right)$ does not apply. For dual duct boxes, two airflow errors $\left(Q_{\text {error,hot }}\right.$ and $\left.Q_{\text {error,cold }}\right)$ and two absolute value airflow errors $\left(\left|Q_{\text {error, hot }}\right|\right.$ and $\left.\left|Q_{\text {error, cold }}\right|\right)$ are needed, and the discharge air temperature error $\left(\Delta T_{\text {error }}\right)$ does not apply. Although VPACC was originally tested using VAV boxes without fans $[1,2,3,5]$, the algorithm is independent of fan configuration and can be applied to boxes with series or parallel fans without modification. 
Table 2.3. VPACC Diagnoses.

Possible Diagnoses

Alarm Description

\begin{tabular}{|c|c|c|c|c|c|c|c|c|c|c|c|c|c|c|c|c|c|c|c|c|}
\hline High zone temperature alarm & $\mathrm{X}$ & $x$ & & & & $\mathrm{X}$ & $\mathrm{X}$ & $\mathrm{X}$ & & & $\mathrm{X}$ & $\mathrm{X}$ & $\mathrm{X}$ & $\mathrm{X}$ & $\mathrm{X}$ & & & $\mathrm{X}$ & & $\mathrm{X}$ \\
\hline Low zone temperature alarm & $\mathrm{X}$ & $\mathrm{X}$ & & & & $\mathrm{X}$ & $\mathrm{X}$ & & $\mathrm{X}$ & & $\mathrm{X}$ & $\mathrm{X}$ & $\mathrm{X}$ & $\mathrm{X}$ & $\mathrm{X}$ & & $\mathrm{x}$ & & & $\mathrm{X}$ \\
\hline High airflow alarm & & $\mathrm{X}$ & & $\mathrm{X}$ & $\mathrm{X}$ & & & & & & $\mathrm{X}$ & & $\mathrm{X}$ & & & & & & & $\mathrm{x}$ \\
\hline Low airflow alarm & & $\mathrm{X}$ & & $\mathrm{X}$ & $\mathrm{X}$ & & & & & $\mathrm{X}$ & $\mathrm{X}$ & $\mathrm{X}$ & $\mathrm{X}$ & & & & & & $\mathrm{X}$ & $\mathrm{X}$ \\
\hline Unstable airflow alarm & & $\mathrm{x}$ & & $\bar{x}$ & $\mathrm{X}$ & & & & & $\mathrm{X}$ & $\mathrm{X}$ & $\mathrm{X}$ & $\mathrm{X}$ & & & $\mathrm{X}$ & & & & $\mathrm{x}$ \\
\hline High discharge temperature alarm & & & $\mathrm{x}$ & & & $\mathrm{X}$ & $\mathrm{X}$ & & & & & & & & & & & & & \\
\hline Low discharge temperature alarm & & & $\mathrm{x}$ & & & $\mathrm{X}$ & $\mathrm{X}$ & & & & & & & & & & & & & \\
\hline
\end{tabular}




\section{FDD Interface}

In addition to providing access to the data that the algorithms need and a platform to perform the calculations, the BAS also provides an interface between the results of the FDD algorithms and the operator. The results of APAR and VPACC consist, within the controller, of a set of fault conditions as shown in Tables 2.2 (APAR) and 2.3 (VPACC). There are several different ways to communicate the results to the operator.

\subsection{Alarms}

Most BASs provide some alarm or event handling capability. Each FDD fault condition can be configured as a BAS alarm point with the appropriate text message from Table 2.2 or 2.3. When a rule is satisfied (APAR) or a CUSUM exceeds the alarm limit (VPACC), a BAS alarm is reported. There are various options for instantaneous notification via the operator workstation, printer, email, fax, or pager. Alarms are also logged in an alarm history file or database. If an alarm is investigated at the time it occurs, diagnosis and troubleshooting are aided by observation of the system during faulty operation. An alternative is to review the alarm history for each piece of equipment before performing scheduled maintenance. If any faults have been recorded since the previous maintenance, corrective action can be taken.

\subsection{Work Orders}

Facilities that use a computerized maintenance management system (CMMS) can have work orders generated automatically when faults are detected. Interfacing the CMMS with FDD is typically done by having the CMMS periodically query the AHU and VAV box controllers for fault status, then generate a work order for each device with one or more faults. The work order would identify the piece of equipment, the time and date the fault was detected, and include descriptive information about the fault(s) detected from Table 2.2 or 2.3. Implementation requires some configuration of the CMMS to communicate with the AHU and VAV box controllers including drivers for the network communication protocol used by the BAS. The greater persistence and visibility of work orders compared to BAS alarms is the primary benefit of this approach, but it means that the potential harm caused by false alarms is also greater. In order to minimize the danger of false alarms, the building operator should have the capability of disabling the FDD-work order process when certain conditions exist that are likely to cause false alarms. There should also be a provision to delete erroneous work orders.

\subsection{Fault Codes}

Rather than reporting faults as BAS alrms or work orders, trend logs could be used to monitor the equipment fault status. To reduce the number of trend logs, several binary fault statuses for a particular piece of equipment could be combined using a bitmask into a single analog fault code. This approach can be useful as a service tool. It could also be used in an initial installation of FDD to verify its performance before enabling the generation of alarms or work orders. 


\section{Robust FDD Parameters}

There are a wide variety of disturbances that can cause an HVAC system to deviate from ideal, "normal operation" conditions, but are not actual faults and should not be reported as such [4]. These include variations in outdoor temperature, wind velocity and direction, solar radiation, internal heat sources, and changes in system mode of operation or schedule. Normal nonidealities of the HVAC system, such as minor sensor drift, errors due to analog-to-digital or digital-to-analog converter resolution, electronic noise, small deviations from setpoint, actuator hysteresis, etc., also should not be reported as faults. Many FDD methods, including APAR and VPACC, employ a set of parameters that collectively define the severity of a fault needed in order to report an alarm. If the cutoff severity needed to trigger an alarm is too great, real faults will remain undetected (false negatives). However, if the cutoff severity is too small, false alarms (false positives) will be generated. FDD parameters must be selected carefully to minimize both false positives and false negatives.

In previous research, the FDD parameters for APAR and VPACC were determined on a sitespecific basis. For each data source, whether it was a simulation, emulation, laboratory, or field test site, initial guess values of the parameters were refined through trial and error [1,2,3,5,6]. It is expected that for most control system integrators and building owners, the need to develop a site-specific set of parameters presents a major barrier to the adoption of FDD, both in terms of a detailed understanding of the APAR and VPACC algorithms as well as the time and resources required. To overcome this obstacle, a set of robust FDD parameters was developed. These parameters were found to be effective for a variety of mechanical system types, building uses, and weather conditions based on application to previous work [2] as well as to multiple test sites in a field demonstration of APAR and VPACC concurrent with the study described in this report.

In the development of any set of FDD parameters, there is an inherent tradeoff between false negatives (real faults remain undetected) and false positives (false alarms). For the tabulated set of parameters, this tradeoff is biased toward minimizing false alarms, if necessary at the expense of missing some real faults. Most facilities have limited manpower available to follow up on reported faults, so by reporting only relatively severe faults, technician productivity is maximized as repairs are made to the most serious problems. Minimizing false alarms is crucial since too many false alarms will cause O\&M staff to waste time and lose confidence in the FDD algorithms, ultimately causing real faults to be ignored. Furthermore, a large number of fault reports, whether real or false, may be more information than the O\&M staff can process.

The recommended FDD parameters are presented in Tables 3.1 for APAR and 3.2 for VPACC. 
Table 4.1. APAR Recommended Parameters.

\begin{tabular}{|c|c|}
\hline Parameter & Value \\
\hline Heating Coil Valve Control Signal Threshold & 0.02 \\
\hline Cooling Coil Valve Control Signal Threshold & 0.02 \\
\hline Mixing Box Damper Threshold & 0.02 \\
\hline Temperature Threshold & $2.0^{\circ} \mathrm{C}\left(3.6^{\circ} \mathrm{F}\right)$ \\
\hline Flow Threshold & 0.3 \\
\hline Enthalpy Threshold & $3.0 \mathrm{~kJ} / \mathrm{kg}(1.3 \mathrm{Btu} / \mathrm{lbm})$ \\
\hline Supply Fan Temperature Rise & $1.1^{\circ} \mathrm{C}\left(2.0^{\circ} \mathrm{F}\right)$ \\
\hline Return Fan Temperature Rise & $1.1^{\circ} \mathrm{C}\left(2.0^{\circ} \mathrm{F}\right)$ \\
\hline Minimum Temperature Difference for Ventilation Rules & $5.6^{\circ} \mathrm{C}\left(10.0^{\circ} \mathrm{F}\right)$ \\
\hline Maximum Number of Mode Switches Per Hour & 7 \\
\hline Occupancy Delay & $90 \mathrm{~min}$ \\
\hline Mode Switch Delay & $60 \mathrm{~min}$ \\
\hline Rule Delay & $60 \mathrm{~min}$ \\
\hline Smoothing Constant for APAR Input Data & 0.1 \\
\hline
\end{tabular}

Table 4.2. VPACC Recommended Parameters.

\begin{tabular}{|l|l|}
\hline Parameter & Value \\
\hline Expected Zone Temperature Error & $0.0^{\circ} \mathrm{C}\left(0.0^{\circ} \mathrm{F}\right)$ \\
\hline Zone Temperature Error Standard Deviation & $0.6^{\circ} \mathrm{C}\left(1.0^{\circ} \mathrm{F}\right)$ \\
\hline Expected Airflow Rate Error & $0 \mathrm{~m}^{3} / \mathrm{s}(0 \mathrm{cfm})$ \\
\hline Airflow Rate Error Standard Deviation & $0.02^{*} \mathrm{VAV}$ Box Maximum Airflow Rate ${ }^{1}$ \\
\hline Expected Discharge Temperature Error & $1.1^{\circ} \mathrm{C}\left(2.0^{\circ} \mathrm{F}\right)$ \\
\hline Discharge Temperature Error Standard Deviation & $1.1^{\circ} \mathrm{C}\left(2.0^{\circ} \mathrm{F}\right)$ \\
\hline Slack Parameter & 3 \\
\hline Alarm Limit & 1000 \\
\hline Occupancy Delay & $90 \mathrm{~min}$ \\
\hline CUSUM Reset Interval & $360 \mathrm{~min}$ \\
\hline
\end{tabular}

${ }^{1}$ By scaling the airflow rate error standard deviation to the maximum airflow rate through the box, the same code can be used for any size VAV box. 


\subsection{Tuning FDD Parameters for Optimum Performance}

In most cases it is expected that the tabulated FDD parameters will be used. However, some building operators may need to develop their own parameter values. For example, a particular facility may find that, although the faults that are reported are legitimate, there are too many for the operations and maintenance (O\&M) staff to handle. In this case, the parameters will be adjusted so that the threshold severity for a fault to be reported is increased. Or, in a facility that has more resources available and is particularly interested in reducing energy consumption, the parameters might be adjusted so that the threshold severity is reduced. To enable users to make these adjustments, guidelines for tuning the FDD parameters are included.

\subsubsection{Tuning APAR Parameters}

Some of the parameters can be determined directly by evaluating the mechanical system. The values for supply and return fan temperature rise can be determined from design data or field measurements.

The minimum temperature difference for ventilation rules can be determined by evaluating trendlogs of the return, outdoor, and mixed air temperatures, and the mixing box damper control signal. For each logged data sample, the actual outdoor air fraction can be compared with the calculated outdoor air fraction based on the temperature data. Correlating the accuracy of the calculated outdoor air fraction with the difference between the return and outdoor air temperatures will yield the minimum temperature difference for ventilation rules.

The occupancy delay can be determined by evaluating trendlogs of the supply air temperature and setpoint. The occupancy delay parameter should be set equal to the time from the onset of the occupancy until the supply air temperature is reasonably close to the setpoint. Then a margin of safety should be added. The mode switch delay can be determined similarly, by observing the time for the system to "settle out" after a change from one mode of operation to another.

The heating coil, cooling coil, mixing box damper, temperature, flow, and enthalpy thresholds, and the maximum number of mode switches per hour are best determined by analysis of particular rules that are causing false alarms or are not reporting actual faults when the recommended parameter values are used. Although it is possible to apply a standard uncertainty analysis as described in [8] to the rule, better results are obtained from trial and error. Trendlogs of the data relevant to the rule combined with a spreadsheet analysis of the rule can be very helpful for understanding why a particular rule is or is not reporting a fault, and then to help select better parameter values.

A detailed analysis of a particular rule will also reveal incorrect results that are due to poor values of the rule delay or the smoothing constant. If the rule delay is too short, transient conditions that are not true faults will cause false alarms, while a rule delay that is too long will cause real faults to be missed. If the smoothing constant is too great, noisy data or transient conditions that are not true faults will cause false alarms, while a smoothing constant that is too small will not allow real faults to be reported. A smoothing constant that is too small can also cause false alarms if the smoothed data still reflect the transient conditions from the most recent mode switch. 


\subsubsection{Tuning VPACC Parameters}

Ideally, initial guesses for the expected value and standard deviation of the zone temperature, airflow, and discharge temperature errors should be calculated from data collected from the VAV boxes at the site. Data from unoccupied periods and from the first two hours of occupied periods should be removed from the set before computing the statistics. It is important to use data that is equally representative of heating and cooling conditions. If data are not available, the initial guesses for the expected zone temperature or airflow errors should both be set equal to zero. The initial guess for the expected discharge temperature should be set equal to the duct heat gain, which can be determined from the design documents or from measurements from a few typical VAV boxes. Sensor accuracies or typically observed variations can be used as initial guesses for the standard deviations. The recommended values from Table 3.2 can serve as initial guesses for the remaining parameters.

Once initial guesses have been determined, the parameters can be tuned by observing the faults reported by VPACC compared to the actual performance of the system. If there are false alarms or missed faults from two or more of the errors, the alarm limit should be increased or decreased, respectively. If the missed faults or false alarms are from one error only, the standard deviation of that error should be adjusted instead. To eliminate false alarms early in the occupied period of the day, the occupancy delay should be increased. If false alarms occur late in the day, the CUSUM reset interval should be decreased.

The following example demonstrates the relationships between the parameters. In this example, the recommended values from Table 3.2 are used. Consider a VAV box with a maximum airflow rate of $0.472 \mathrm{~m}^{3} / \mathrm{s}(1000 \mathrm{cfm})$ and a constant airflow rate error of $0.07 \mathrm{~m}^{3} / \mathrm{s}(150 \mathrm{cfm})$. The expected airflow rate error is zero and the airflow rate error standard deviation is equal to 0.02 multiplied by the maximum airflow rate, or $0.009 \mathrm{~m}^{3} / \mathrm{s}(20 \mathrm{cfm})$. The normalized error will be constant:

$$
\begin{aligned}
& z_{i}=\left(x_{i}-x_{\text {exp }}\right) / \sigma_{\text {exp }}=\left(0.07 \mathrm{~m}^{3} / \mathrm{s}-0 \mathrm{~m}^{3} / \mathrm{s}\right) / 0.009 \mathrm{~m}^{3} / \mathrm{s}=(150 \mathrm{cfm}-0 \mathrm{cfm}) / 20 \mathrm{cfm} \\
& z_{i}=7.5
\end{aligned}
$$

Since the error is positive, only the positive $(S)$ sum is accumulated. $S$ is defined as:

$$
S_{i}=\max \left[0, z_{i}-k+S_{i-1}\right]
$$

The expression is evaluated once per minute beginning 90 min (the occupancy delay) after the beginning of occupancy. Since all the terms are constant, $S$ increases by

$$
z-k=7.5-3=4.5
$$

each minute. After 223 minutes, $S$ reaches a value of 1003.5, which is greater than the alarm limit of 1000 . The CUSUM reset interval is $360 \mathrm{~min}$, which is greater than the time to reach the alarm limit, so the alarm will be reported before $S$ is reset to zero. 


\section{Field Test}

\subsection{Test Sites}

Previous research has established the performance of APAR and VPACC [1, 2, 3, 4, 5]. However, the primary goal of the field test was to evaluate the practicality and usability of embedding these FDD algorithms in commercial AHU and VAV box controllers. By involving controls manufacturers and dealers as well as building engineers in the study, the tools were evaluated under conditions as close as possible to those in which they will be used commercially. This approach was selected to ensure that any obstacles to commercialization would be revealed during the course of the test. Another goal was to evaluate modifications to APAR and VPACC for different system types. The field sites are described below.

\subsubsection{SITE-1}

SITE-1 is a private office building. APAR was embedded in the controllers of two VAV rooftop AHUs with hydronic heating coils and staged direct-expansion (DX) cooling coils. VPACC was embedded in 53 VAV box controllers, including 20 pressure independent, single-duct, parallel fan powered VAV boxes with hydronic reheat and 33 pressure independent, single-duct, throttling (no fan), cooling-only VAV boxes. Trendlogs of selected raw data, APAR rule violations, and VPACC alarms were configured. The trendlogs were archived and reviewed monthly. Personnel at the site responded to investigate and verify any reported faults.

\subsubsection{SITE-2}

SITE-2 is a large federal government office building in California. APAR was embedded in the controllers of two constant-volume AHUs with hydronic heating and cooling coils. VPACC was embedded in 1000 pressure independent, dual-duct VAV box controllers. Rather than configuring trendlogs, a computerized maintenance management system (CMMS) was configured to automatically generate a work order whenever a fault was detected. The building engineers responded to investigate, verify, and repair any faults reported through the CMMS.

\subsubsection{SITE-3}

SITE-3 is a private office building with some light industrial spaces. APAR was embedded in one VAV AHU with staged (combustion) heating and DX cooling coils. VPACC was embedded in the controllers of 46 pressure independent, single-duct, throttling (no fan), cooling-only VAV boxes. Trendlogs of selected raw data, APAR rule violations, and VPACC alarms were configured. The trendlogs were archived and reviewed periodically. Also, the building automation system's alarm/event handling function was configured to alert the operator whenever an APAR rule violations or VPACC alarm occurred. Each FDD event was also recorded in an alarm history database. Personnel at the site responded to investigate and verify any reported faults.

\subsubsection{SITE-4}

SITE-4 is a federal government building with a combination of office and laboratory spaces. APAR was embedded in the controller of one constant-volume AHUs with hydronic heating and 
cooling coils. Since the AHU controller operated in stand-alone mode (not connected to a network), selected raw data and APAR rule violations were logged by a stand-alone datalogging software tool running on a computer physically connected to the AHU controller. The trendlogs were archived and reviewed weekly. Personnel at the site responded to investigate and verify any faults that were detected.

\subsubsection{SITE-5}

SITE-5 is a large federal government office building. APAR was embedded in the controllers of two VAV AHUs with hydronic heating and cooling coils. VPACC was embedded in two pressure independent, single-duct, throttling (no fan) VAV boxes with hydronic reheat and two pressure independent, single-duct, throttling (no fan), cooling-only VAV boxes. Trendlogs of selected raw data, APAR rule violations, and VPACC alarms were configured. The trendlogs were archived and reviewed periodically. Also, the building automation system's alarm/event handling function was configured to record each FDD event in an alarm history database. Personnel at the site responded to investigate and verify any reported faults.

\subsubsection{SITE-6}

SITE-6 is a classroom building on a community college campus. APAR was embedded in the controllers of two VAV AHUs with hydronic heating and cooling coils. VPACC was embedded in 101 pressure independent, single-duct, series fan-powered VAV boxes with hydronic reheat. Trendlogs of selected raw data, APAR rule violations, and VPACC alarms were configured. The trendlogs were archived and reviewed periodically. Personnel at the site responded to investigate and verify any reported faults.

\subsubsection{SITE-7}

SITE-7 is a museum building on a university campus. A specialized HVAC system maintains precise temperature and humidity conditions for the museum's artifacts; however, there is also a general purpose HVAC system for office and visitor spaces. APAR was embedded in the controllers of two VAV rooftop AHUs with hydronic heating coils and DX cooling coils. VPACC was embedded in nine pressure independent, single-duct, throttling (no fan) VAV boxes with hydronic reheat. Trendlogs of selected raw data, APAR rule violations, and VPACC alarms were configured. The trendlogs were archived and reviewed weekly. Personnel at the site responded to investigate and verify any reported faults.

\subsubsection{SITE-8}

SITE-8 is a classroom and office building on a community college campus. APAR was embedded in the controllers of one VAV AHU with hydronic heating and cooling coils. VPACC was embedded in 11 VAV box controllers, including 10 pressure independent, single-duct, parallel fan powered VAV boxes with electric reheat and one pressure independent, single-duct, throttling (no fan), cooling-only VAV box. The building automation system's alarm/event handling function was configured to to alert the operator whenever an APAR rule violations or VPACC alarm occurred. Each FDD event was also recorded in an alarm history database. Personnel at the site responded to investigate and verify any reported faults. 


\subsubsection{System Coverage}

Tables 3.1 and 3.2 show the extent of AHU and VAV box system types that will be studied, as well as the coverage of those system types by the four field sites already identified.

Table 5.1. AHU System Types.

\begin{tabular}{|c|c|c|c|c|c|c|}
\hline & \multicolumn{2}{|c|}{ Cooling Medium } & \multicolumn{2}{c|}{ Heating Medium } & \multicolumn{2}{c|}{ Volume Control } \\
\cline { 2 - 8 } Site & $\begin{array}{c}\text { Chilled } \\
\text { Water }\end{array}$ & $\mathrm{DX}$ & $\begin{array}{c}\text { Hot water / } \\
\text { Steam }\end{array}$ & $\begin{array}{c}\text { Staged (Electric } \\
\text { Resistance or } \\
\text { Combustion) }\end{array}$ & $\begin{array}{c}\text { Variable } \\
\text { Volume }\end{array}$ & $\begin{array}{c}\text { Constant } \\
\text { Volume }\end{array}$ \\
\hline SITE-1 & & $\mathrm{X}$ & $\mathrm{X}$ & & $\mathrm{X}$ & \\
\hline SITE-2 & $\mathrm{X}$ & & $\mathrm{X}$ & & & $\mathrm{X}$ \\
\hline SITE-3 & & $\mathrm{X}$ & & $\mathrm{X}$ & $\mathrm{X}$ & \\
\hline SITE-4 & $\mathrm{X}$ & & $\mathrm{X}$ & & & $\mathrm{X}$ \\
\hline SITE-5 & $\mathrm{X}$ & & $\mathrm{X}$ & & $\mathrm{X}$ & \\
\hline SITE-6 & $\mathrm{X}$ & & $\mathrm{X}$ & & $\mathrm{X}$ & \\
\hline SITE-7 & & $\mathrm{X}$ & $\mathrm{X}$ & & $\mathrm{X}$ & \\
\hline SITE-8 & $\mathrm{X}$ & & $\mathrm{X}$ & & $\mathrm{X}$ & \\
\hline
\end{tabular}

Table 5.2. VAV Box System Types.

\begin{tabular}{|c|c|c|c|c|c|c|c|c|}
\hline & System Type & \multicolumn{3}{|c|}{ Fan Configuration } & \multicolumn{3}{c|}{ Reheat Medium } \\
\cline { 2 - 9 } Site & $\begin{array}{c}\text { Single } \\
\text { Duct }\end{array}$ & $\begin{array}{c}\text { Dual } \\
\text { Duct }\end{array}$ & $\begin{array}{c}\text { Throttling } \\
\text { (No Fan) }\end{array}$ & $\begin{array}{c}\text { Parallel Fan- } \\
\text { Powered }\end{array}$ & $\begin{array}{c}\text { Series Fan- } \\
\text { Powered }\end{array}$ & $\begin{array}{c}\text { No } \\
\text { Reheat }\end{array}$ & $\begin{array}{c}\text { Electric } \\
\text { Reheat }\end{array}$ & $\begin{array}{c}\text { Hydronic } \\
\text { Reheat }\end{array}$ \\
\hline SITE-1 (Type 1) & $\mathrm{X}$ & & & $\mathrm{X}$ & & & & $\mathrm{X}$ \\
\hline SITE-1 (Type 2) & $\mathrm{X}$ & & $\mathrm{X}$ & & & $\mathrm{X}$ & & \\
\hline SITE-2 (Type 1) & $\mathrm{X}$ & & $\mathrm{X}$ & & & $\mathrm{X}$ & & \\
\hline SITE-2 (Type 2) & & $\mathrm{X}$ & $\mathrm{X}$ & & & $\mathrm{X}$ & & \\
\hline SITE-3 & $\mathrm{X}$ & & $\mathrm{X}$ & & & $\mathrm{X}$ & & \\
\hline SITE-4 & & & & & & & & \\
\hline SITE-5 (Type 1) & $\mathrm{X}$ & & $\mathrm{X}$ & & & & & $\mathrm{X}$ \\
\hline SITE-5 (Type 2) & $\mathrm{X}$ & & $\mathrm{X}$ & & & $\mathrm{X}$ & & \\
\hline SITE-6 & $\mathrm{X}$ & & & & $\mathrm{X}$ & & & $\mathrm{X}$ \\
\hline SITE-7 & $\mathrm{X}$ & & & & & & & \\
\hline SITE-8 (Type 1) & $\mathrm{X}$ & & & $\mathrm{X}$ & & & $\mathrm{X}$ & \\
\hline SITE-8 (Type 2) & $\mathrm{X}$ & & $\mathrm{X}$ & & & $\mathrm{X}$ & & \\
\hline
\end{tabular}




\subsection{Procedure}

The following procedure was applied to each field site, except as noted in $3.1-3.9$ :

1. Collect the HVAC control system points list and the relevant control application programs from the site.

2. Modify the control application programs to incorporate the FDD algorithms.

3. Download the modified control application programs to the appropriate controllers at the site.

4. Establish trend logs of selected raw data along with the results of the FDD algorithms.

For each AHU, trend the following data points:

- AHU run status (on - off)

- Supply air temperature setpoint

- Supply air temperature

- Return air temperature

- Outdoor air temperature

- Mixed air temperature

- Return air enthalpy or humidity, if used in economizer control sequence

- Outdoor air enthalpy or humidity, if used in economizer control sequence

- Cooling coil valve control signal, if chilled water is used for cooling; or mechanical cooling status, if DX cooling is used

- Heating coil valve control signal, if hot water or steam is used for cooling; or heating status, if electric resistance or combustion heating is used

- Mixing box dampers control signal

- Status of each APAR rule (on - off)

For each VAV box, trend the following data points:

- Occupancy status (on - off)

- Zone temperature

- Heating setpoint

- Cooling setpoint

- Airflow rate (if box is dual duct, then trend both hot and cold airflow rates)

- Airflow rate setpoint (if box is dual duct, then trend both hot and cold airflow rate setpoints)

- Damper control signal

- Reheat coil valve control signal, if reheat coil is present

- Discharge air temperature, if sensor is present

- Supply air temperature from the AHU serving the VAV box, only if a discharge air temperature sensor is present

- Status of each VPACC alarm (on - off)

5. Once per week, collect and analyze the trend data to evaluate the performance of the FDD algorithms. The data can be made available by either enabling online access to the building control system's trend log database, or by exporting the trend logs to text files 
and submitting them via email or CD.

6. Follow up with the facility maintenance staff to verify the presence of any faults detected by either of the FDD algorithms. Verify whether the actual cause of the fault is one of the causes listed by the FDD algorithm.

7. Record the presence and cause of any faults reported through any other means that were not detected by the FDD algorithms. 


\subsection{Results}

A representative subset of faults that were detected during the study are presented in the following pages. Table 5.3 summarizes the faults and their impact on the facility.

Table 5.3. Fault Summary and Impact.

Fault Impact

Site

Fault Description

\begin{tabular}{|l|l|}
\hline SITE-1 & Mixed Air Temperature Sensor Error
\end{tabular}

\begin{tabular}{|l|l|}
\hline SITE-1 & Leaking Heating Coil Valve \\
\hline
\end{tabular}

\begin{tabular}{|l|l|}
\hline SITE-1 & Outdoor Air Temperature Sensor Error \\
\hline
\end{tabular}

\begin{tabular}{|l|l|}
\hline SITE-1 & Mechanical Cooling Fault \\
\hline
\end{tabular}

\begin{tabular}{|l|l|}
\hline SITE-1 & Stuck VAV Box Damper Actuator \\
\hline
\end{tabular}

\begin{tabular}{|l|l|}
\hline SITE-1 & VAV Box Maximum Airflow Setpoint Too High \\
\hline
\end{tabular}

\begin{tabular}{|l|l|}
\hline SITE-1 & Slipping Supply Fan Drive Belt \\
\hline
\end{tabular}

\begin{tabular}{|l|l|}
\hline SITE-1 & Communication Failure \\
\hline
\end{tabular}

\begin{tabular}{|l|l|}
\hline SITE-1 & Undersized Supply Duct \\
\hline
\end{tabular}

\begin{tabular}{|l|l|}
\hline SITE-1 & Disconnected Zone Temperature Sensor \\
\hline
\end{tabular}

\begin{tabular}{|l|l}
\hline SITE-2 & Outdoor Air Temperature Sensor Error \\
\hline SITE-2
\end{tabular}

\begin{tabular}{|l|l|}
\hline SITE-2 & Chilled Water Not Available \\
\hline
\end{tabular}

\begin{tabular}{l|l}
\hline SITE-2 & Airflow (DP) Sensor Drift \\
\hline
\end{tabular}

\begin{tabular}{l|l}
\hline SITE-2 & Zone Temperature Sensor Failure \\
\hline
\end{tabular}

\begin{tabular}{|l|l|}
\hline SITE-2 & Damper Actuator Failure \\
\hline
\end{tabular}

\begin{tabular}{|l|l}
\hline SITE-2 & Zone Temperature PID Loop Tuning Error \\
\hline
\end{tabular}

\begin{tabular}{|l|l|}
\hline SITE-3 & Supply Air Temperature Error \\
\hline
\end{tabular}

\begin{tabular}{|l|l|}
\hline SITE-4 & Hot Water Converter Offline \\
\hline
\end{tabular}

\begin{tabular}{|l|l}
\hline SITE-4 & Manual Override of Outdoor Air Damper \\
\hline
\end{tabular}

\begin{tabular}{|l|l|}
\hline SITE-4 & Steam Outage \\
\hline
\end{tabular}

\begin{tabular}{|l|l}
\hline SITE-4 & Incorrect Cooling Coil Valve Actuator Configuration
\end{tabular}

\begin{tabular}{|l|l|}
\hline SITE-5 & Simultaneous Mechanical Cooling and Economizing \\
\hline
\end{tabular}

\begin{tabular}{l|l} 
SITE-6 & Simultaneous Mechanical Cooling and Economizing
\end{tabular}

\begin{tabular}{lll}
\hline SITE-6 & Outdoor Air Temperature Sensor Error
\end{tabular}

\begin{tabular}{l|l}
\hline SITE-6 & VAV Box Controller Hardware Failure \\
\hline
\end{tabular}

\begin{tabular}{|l|l|}
\hline SITE-6 & Disconnected VAV Box Supply Air Duct \\
\hline
\end{tabular}

\begin{tabular}{|l|l|}
\hline SITE-6 & VAV Box Damper Actuator Failure \\
\hline
\end{tabular}

\begin{tabular}{l|l}
\hline SITE-6 & Disconnected VAV Box Flow Sensor Tubing
\end{tabular}

\begin{tabular}{|l|l|}
\hline SITE-6 & Zone Temperature Sensor Error \\
\hline
\end{tabular}

\begin{tabular}{|l|l|}
\hline SITE-6 & Undersized VAV Box \\
\hline
\end{tabular}

\begin{tabular}{l|l}
\hline SITE-6 & Undersized Supply Fan \\
\hline
\end{tabular}

\begin{tabular}{l|l} 
SITE-7 & AHU PID Loop Tuning Error \\
\hline
\end{tabular}

\begin{tabular}{l|l}
\hline SITE-8 & Zone Temperature Setpoint Too High \\
\hline
\end{tabular}

\begin{tabular}{|c|c|c|c|c|}
\hline 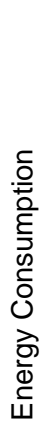 & 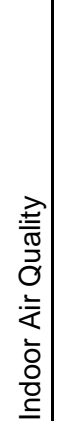 & 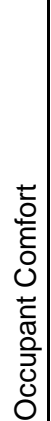 & 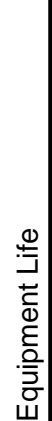 & 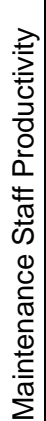 \\
\hline$x$ & & & & \\
\hline$X$ & & & & \\
\hline$X$ & & & & \\
\hline & & $\mathrm{X}$ & & \\
\hline$X$ & & & & \\
\hline & & & & $X$ \\
\hline & & & $\mathrm{X}$ & \\
\hline$X$ & & & & $X$ \\
\hline & & $\mathrm{x}$ & & \\
\hline$X$ & & $\mathrm{x}$ & & $X$ \\
\hline$X$ & & & & \\
\hline & & $X$ & & \\
\hline $\mathrm{X}$ & $\mathrm{X}$ & $x$ & & \\
\hline$X$ & & $\mathrm{X}$ & & \\
\hline$X$ & & $x$ & & \\
\hline & & & $X$ & \\
\hline & & $\mathrm{X}$ & & \\
\hline & & $\mathrm{X}$ & & \\
\hline$X$ & & & & \\
\hline & & $x$ & & \\
\hline & & $X$ & & \\
\hline $\mathrm{X}$ & & & & \\
\hline$X$ & & & & \\
\hline$X$ & & & & \\
\hline & & $\mathrm{X}$ & & $\mathrm{X}$ \\
\hline & & $\mathrm{X}$ & & $x$ \\
\hline$X$ & & & & \\
\hline$X$ & $\mathrm{X}$ & $\mathrm{X}$ & & \\
\hline$X$ & & $X$ & & \\
\hline & & $x$ & & \\
\hline & & $\mathrm{X}$ & & \\
\hline & & & $X$ & \\
\hline$X$ & & $\mathrm{X}$ & & \\
\hline
\end{tabular}




\subsubsection{SITE-1}

\subsubsection{Mixed Air Temperature Sensor Error}

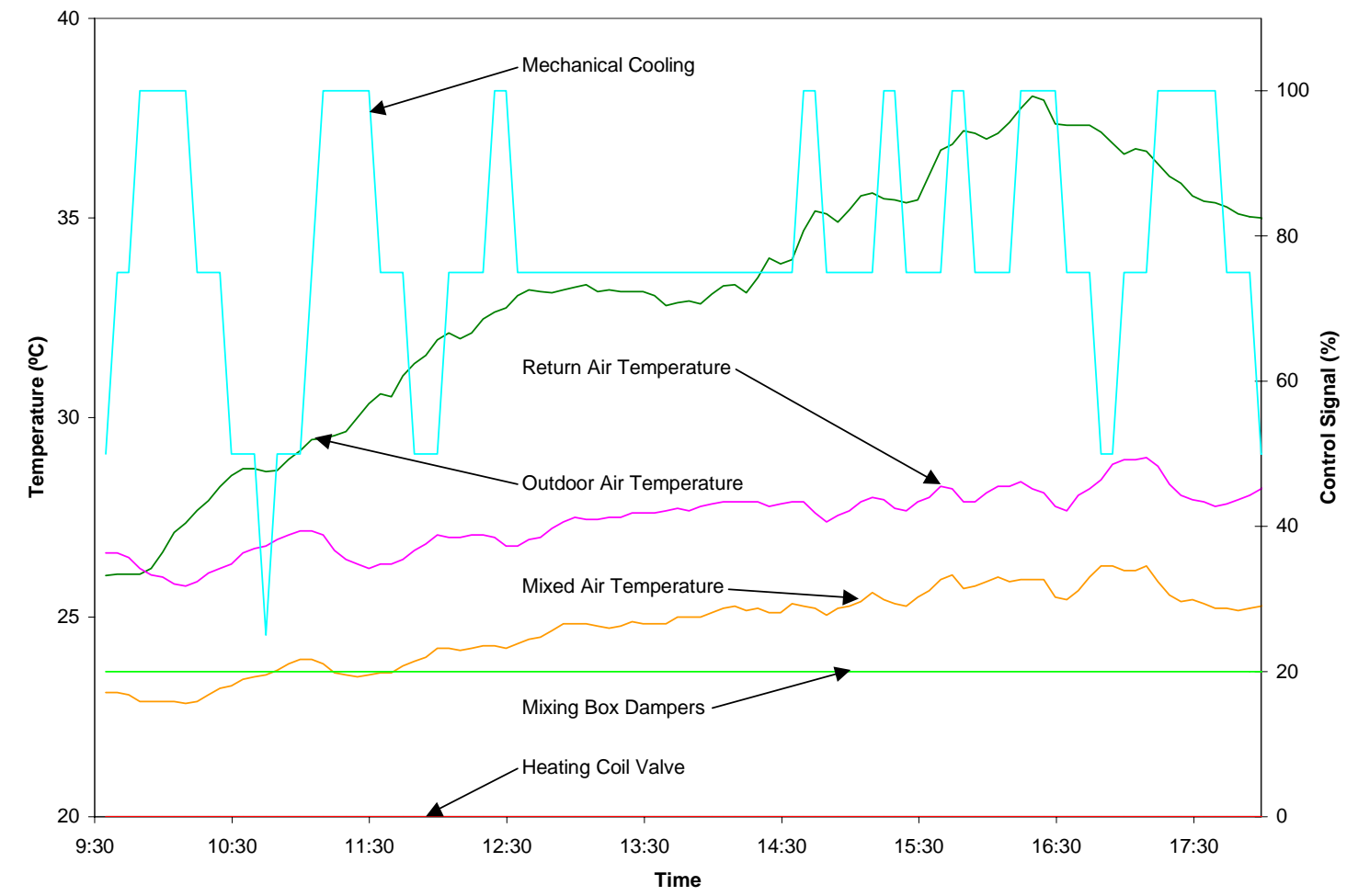

Figure 5.1. Mixed Air Temperature Sensor Error.

Figure 5.1 shows a plot of temperature and control signal data vs. time of day from one of the rooftop AHUs at SITE-1. The heating coil valve is fully closed and the mixing box dampers are positioned for the minimum outdoor air fraction needed to meet ventilation requirements (20\%). Stages of mechanical cooling are energized based on cooling requests from the terminal units served by the AHU. This combination of control signals corresponds to Mode 4: mechanical cooling with minimum outdoor air. In addition to the set of rules specific to Mode 4, there is a set of rules that applies to all occupied modes of operation (see Table 2.1). One rule which applies to all occupied modes is Rule 26, which states that the mixed air temperature should be greater than the minimum of the return and outdoor air temperatures. For nearly the entire time period shown in Figure 5.1, the return air temperature is less than the outdoor air temperature, so according to Rule 26, the mixed air temperature should be greater than the return air temperature. However, Figure 5.1 shows that the mixed air temperature is less than the return air temperature by approximately $3{ }^{\circ} \mathrm{C}$. A trendlog showed that the APAR algorithm embedded in the AHU controller had generated a fault report due to Rule 26. As shown in Table 2.2, the possible causes of this fault are a return, mixed, or outdoor air temperature sensor error. Onsite personnel investigated, determined that the mixed air temperature sensor had drifted out of calibration, and recalibrated it. 


\subsubsection{Leaking Heating Coil Valve}

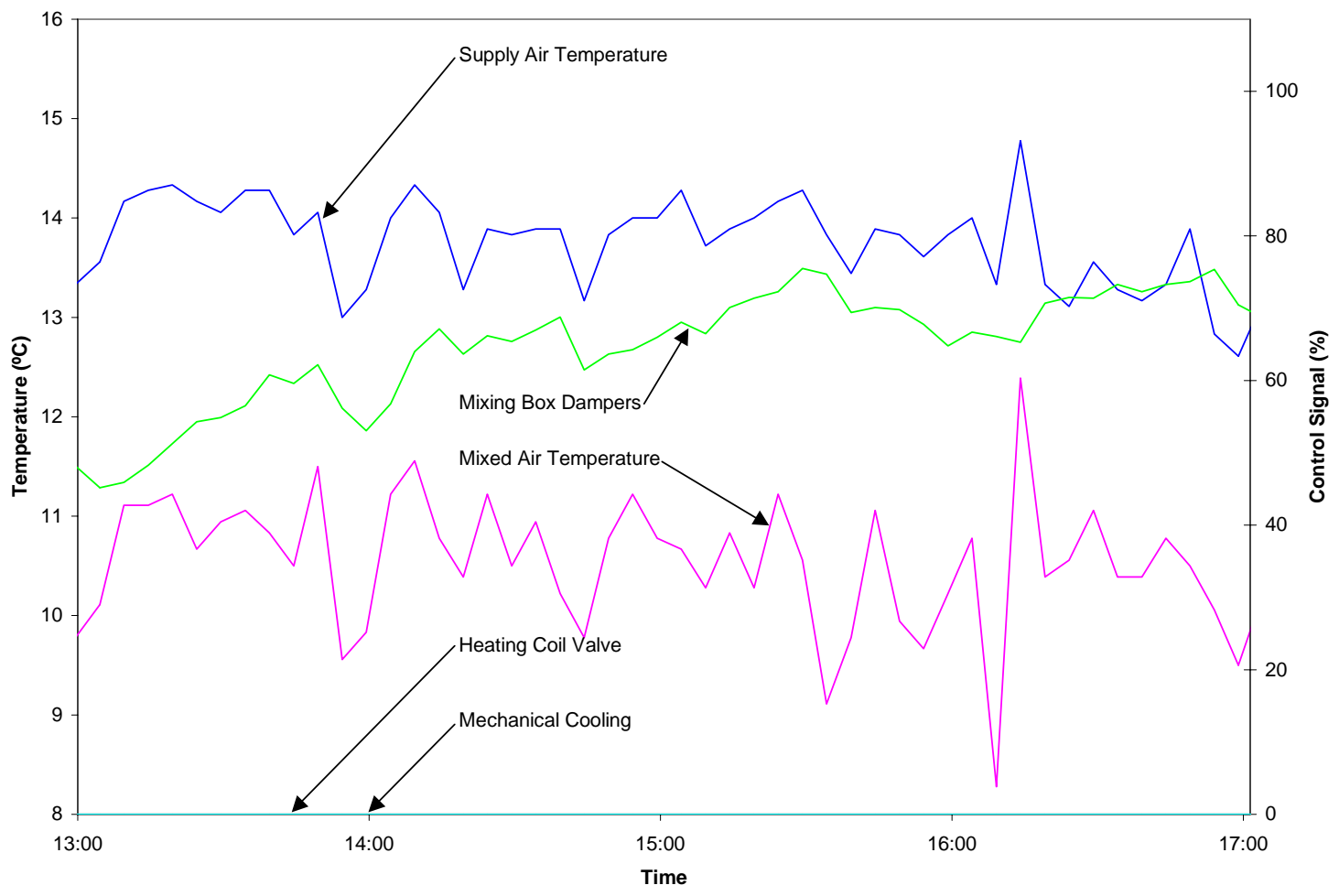

Figure 5.2. Leaking Heating Coil Valve.

Figure 5.2 shows a plot of temperature and control signal data vs. time of day from one of the rooftop AHUs at SITE-1. The heating coil valve is fully closed and all stages of mechanical cooling are de-energized. The mixing box dampers modulate to maintain the supply air temperature at its setpoint (not shown). This combination of control signals corresponds to Mode 2: cooling with outdoor air. One of the rules for Mode 2 is Rule 7, which states that the supply air and mixed air temperatures should be nearly the same. Figure 5.2 shows that the supply air temperature is greater than the mixed air temperature by approximately $3^{\circ} \mathrm{C}$. A trendlog showed that the APAR algorithm embedded in the AHU controller had generated a fault report due to Rule 7. As shown in Table 2.2, the possible causes of this fault are a supply or mixed air temperature sensor error, a problem with the mechanical cooling system (since chilled water is not used), or a stuck or leaking heating coil valve. Onsite personnel investigated and determined that there was a leak in the heating coil valve. 


\subsubsection{Outdoor Air Temperature Sensor Error}

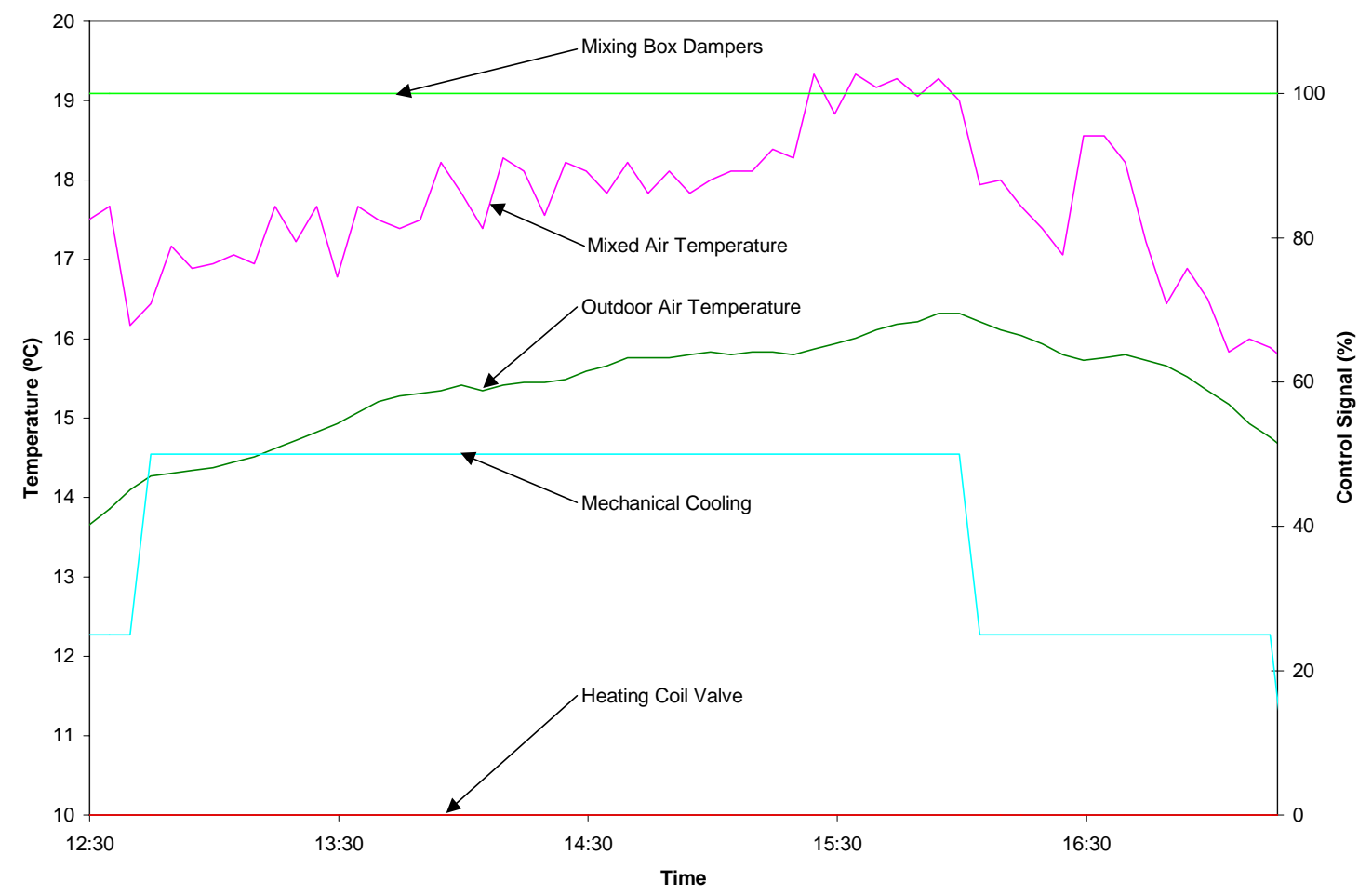

Figure 5.3. Outdoor Air Temperature Sensor Error.

Figure 5.3 shows a plot of temperature and control signal data vs. time of day from one of the rooftop AHUs at SITE-1. The heating coil valve is fully closed and the mixing box dampers are positioned for $100 \%$ outdoor air. Stages of mechanical cooling are energized based on cooling requests from the terminal units served by the AHU. This combination of control signals corresponds to Mode 3: mechanical cooling with $100 \%$ outdoor air. One of the rules for Mode 3 is Rule 10, which states that the outdoor air and mixed air temperatures should be nearly the same. Figure 5.3 shows that the mixed air temperature is greater than the outdoor air temperature by 2 to $3{ }^{\circ} \mathrm{C}$. A trendlog showed that the APAR algorithm embedded in the AHU controller had generated a fault report due to Rule 10. As shown in Table 2.2, the possible causes of this fault are an outdoor or mixed air temperature sensor error or a stuck or leaking mixing box damper. Onsite personnel investigated and determined that the fault was due to an outdoor air temperature sensor error caused by a difference in temperature between the location of the outdoor air temperature sensor and the AHU's outdoor air intake. 


\subsubsection{Mechanical Cooling Fault}

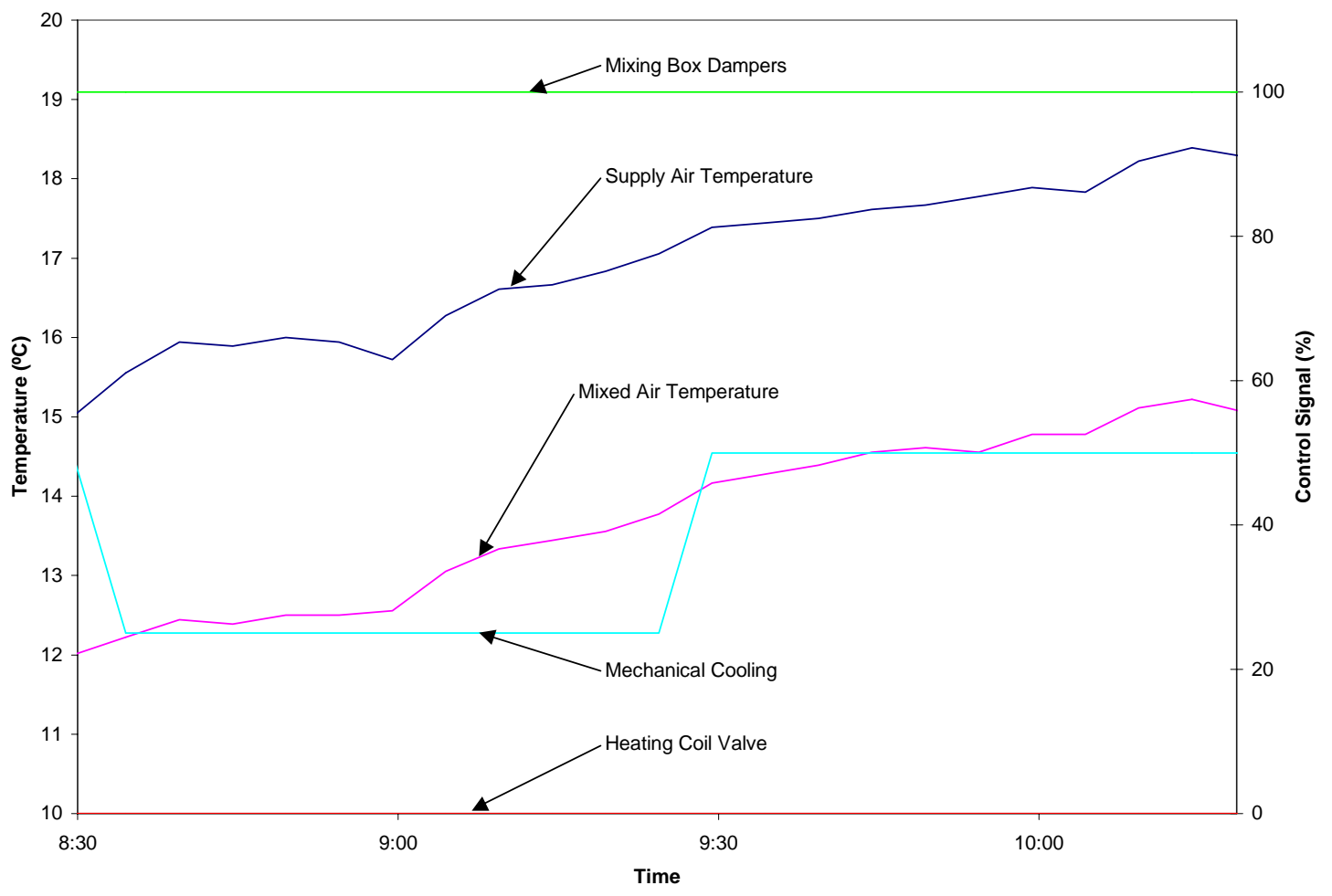

Figure 5.4. Mechanical Cooling Fault.

Figure 5.4 shows a plot of temperature and control signal data vs. time of day from one of the rooftop AHUs at SITE-1. The heating coil valve is fully closed and the mixing box dampers are positioned for $100 \%$ outdoor air. Stages of mechanical cooling are energized based on cooling requests from the terminal units served by the AHU. This combination of control signals corresponds to Mode 3: mechanical cooling with $100 \%$ outdoor air. One of the rules for Mode 3 is Rule 11, which states that the supply air temperature should be less than the mixed air temperature. Figure 5.4 shows that the supply air temperature is $3{ }^{\circ} \mathrm{C}$ to $4{ }^{\circ} \mathrm{C}$ greater than the mixed air temperature. A trendlog showed that the APAR algorithm embedded in the AHU controller had generated a fault report due to Rule 11. Table 2.2 lists the possible causes of this fault including a supply or mixed air temperature sensor error, a fouled or undersized heating or cooling coil, and problems associated with mechanical cooling system. Onsite personnel investigated, determined that the fault was due to a problem with the mechanical cooling system, and added it to a list of tasks that was prepared for a maintenance contractor. 


\subsubsection{Stuck VAV Box Damper Actuator}

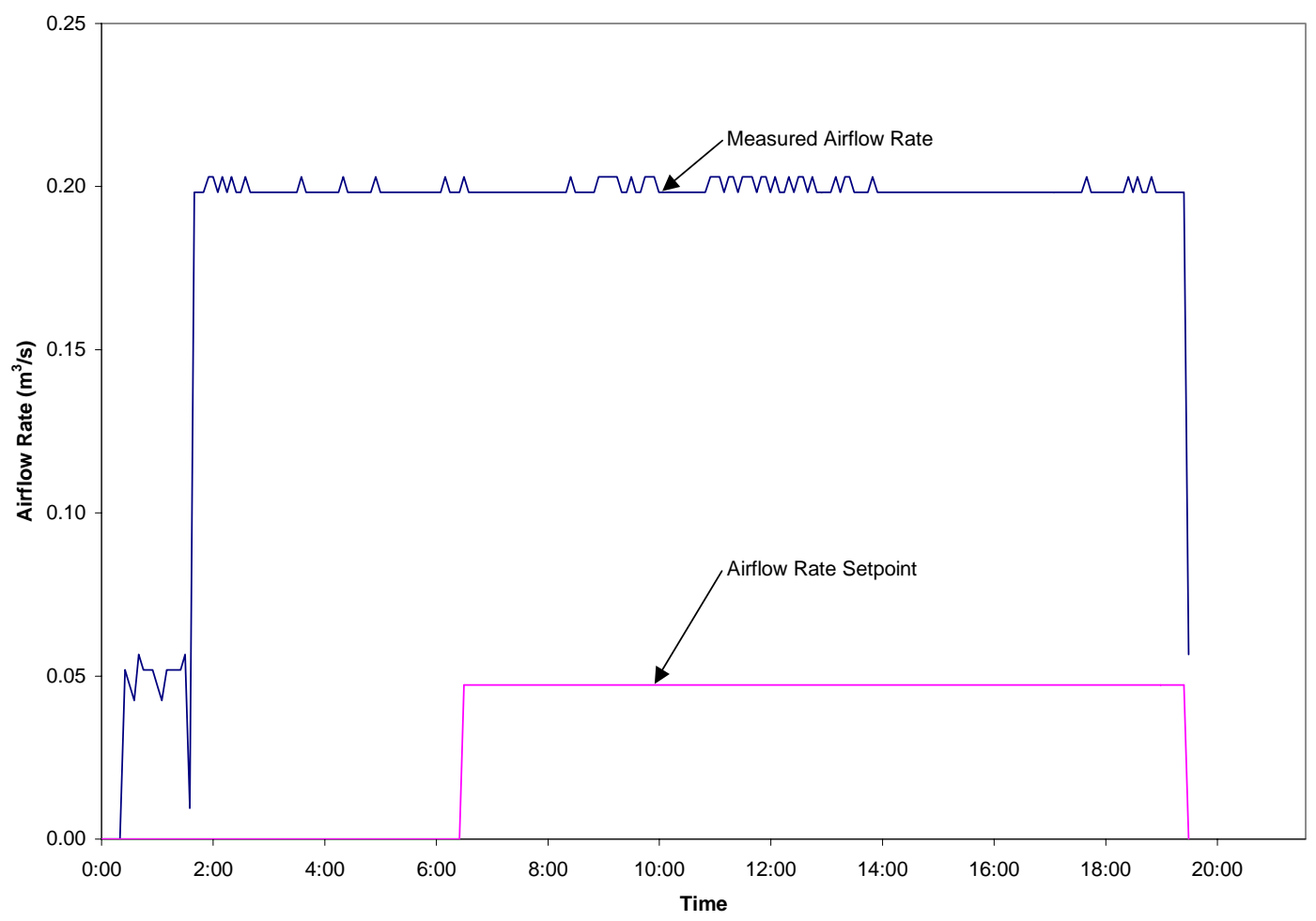

Figure 5.5. Stuck VAV Box Damper Actuator.

Figure 5.5 shows a plot of airflow data vs. time of day from one of the fan powered VAV boxes at SITE-1. The plot shows that there was a large positive airflow error, since the measured airflow rate was substantially greater than the airflow rate setpoint. A trendlog showed that the VPACC algorithm embedded in the VAV box controller reported a high airflow alarm. Table 2.3 lists the possible causes of this fault including an airflow (DP) sensor error, a stuck or failed damper or damper actuator, a scheduling conflict with the AHU, a tuning problem with the airflow control PID loop, and a sequencing logic error. Onsite personnel investigated and determined that the fault was due to a stuck damper actuator. 


\subsubsection{VAV Box Maximum Airflow Setpoint Too High}

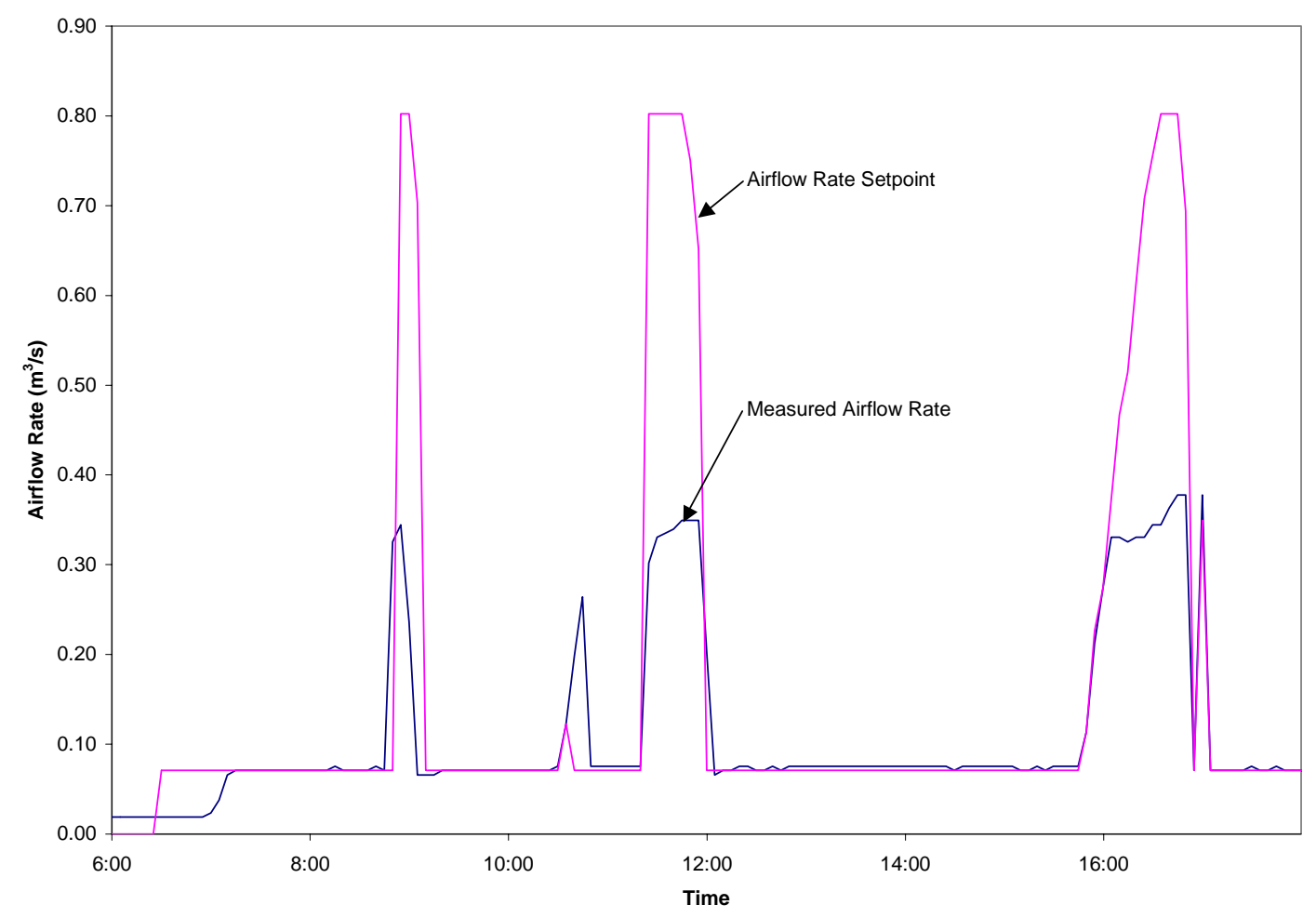

Figure 5.6. VAV Box Airflow Parameter Error.

Figure 5.6 shows a plot of airflow data vs. time of day from one of the fan-powered VAV boxes at SITE-1. The plot shows that whenever the airflow setpoint increased above the minimum, there was a large negative airflow error, since the measured airflow rate was substantially less than the airflow rate setpoint. A trendlog showed that the VPACC algorithm embedded in the VAV box controller reported a low airflow alarm. Table 2.3 lists the possible causes of this fault, including an airflow (DP) sensor error, a stuck or failed damper or damper actuator, low static pressure in the supply air duct, a scheduling conflict with the AHU, an undersized VAV box, a tuning problem with the airflow control PID loop, a maximum airflow setpoint that is too high, and a sequencing logic error. Onsite personnel investigated and determined that the fault was due to a maximum airflow setpoint that was too high. The VAV box controller was originally installed on a larger VAV box. During a building renovation, the controller was moved to a smaller VAV box, but the maximum airflow parameter was not changed. As a result, even when the damper was fully open, the airflow rate never reached the nominal maximum value. 


\subsubsection{Slipping Supply Fan Drive Belt}

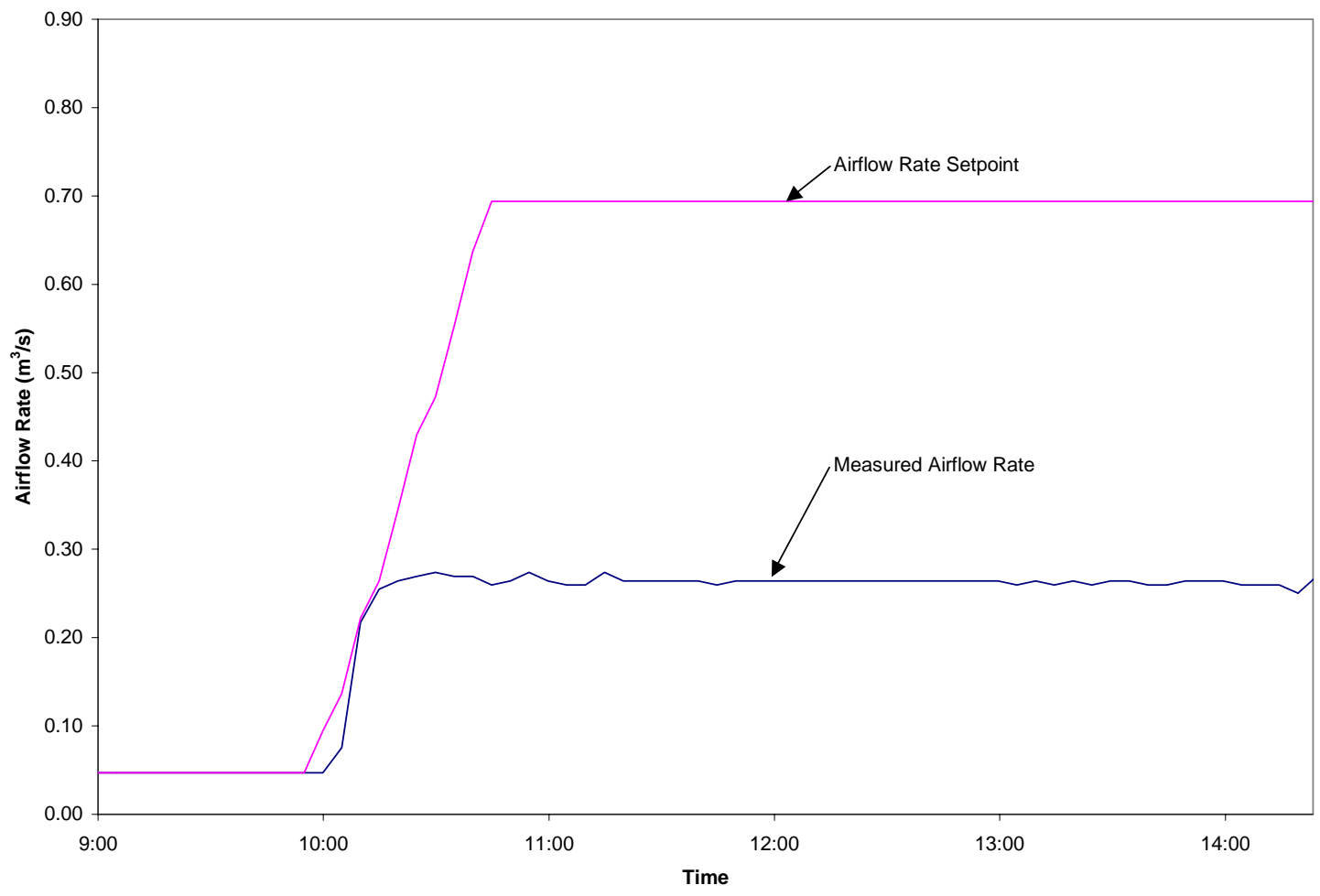

Figure 5.7. Slipping Supply Fan Drive Belt.

Figure 5.7 shows a plot of airflow data vs. time of day from one of the fan-powered VAV boxes at SITE-1. The occupied period was from 06:30 until 19:30. During occupancy, the VAV box had a minimum airflow rate setpoint of $0.047 \mathrm{~m}^{3} / \mathrm{s}$ to meet ventilation requirements. The plot shows that whenever the airflow setpoint increased above the minimum, there was a large negative airflow error, since the measured airflow rate was substantially less than the airflow rate setpoint. A trendlog showed that the VPACC algorithm embedded in the VAV box controller reported a low airflow alarm. Table 2.3 lists the possible causes of this fault, including an airflow (DP) sensor error, a stuck or failed damper or damper actuator, low static pressure in the supply air duct, a scheduling conflict with the AHU, an undersized VAV box, a tuning problem with the airflow control PID loop, a maximum airflow setpoint that is too high, and a sequencing logic error. Onsite personnel investigated and determined that the fault was due to low static pressure caused by a slipping supply fan drive belt in the AHU that serves this VAV box. Figure 5.7 illustrates that early in the day, the airflow rate setpoint was at the minimum and the supply fan was able to maintain sufficient static pressure. When the airflow setpoint increased later in the day, the actual airflow fell below the setpoint as the supply fan was not able to maintain the static pressure at the setpoint due to the slipping belt. 


\subsubsection{Communication Failure}

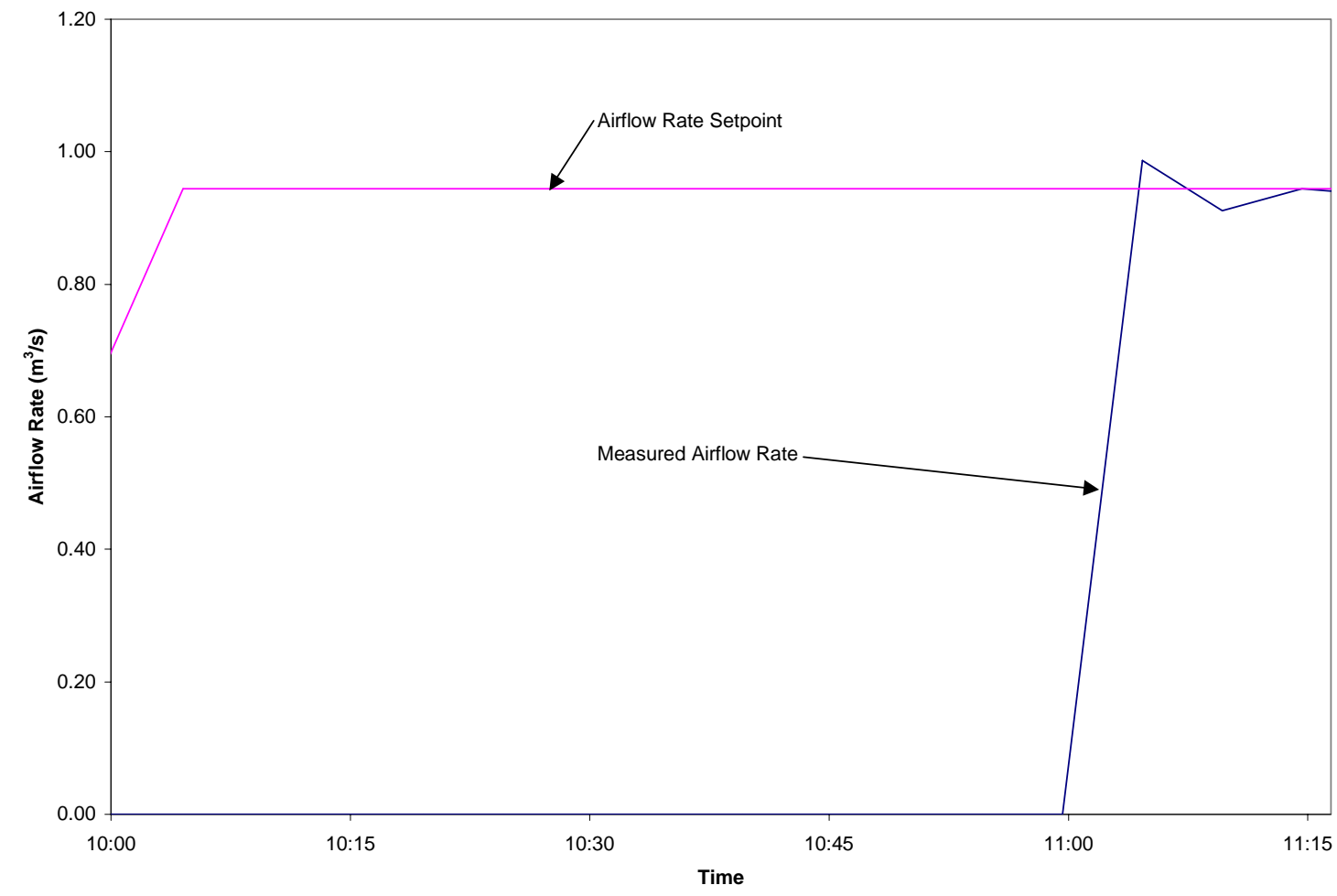

Figure 5.8. Communication Failure.

Figure 5.8 shows a plot of airflow data vs. time of day from one of the throttling (no fan) VAV boxes at SITE-1. It shows a large negative airflow error, since the measured airflow rate was substantially less than the airflow rate setpoint. A trendlog showed that the VPACC algorithm embedded in the VAV box controller reported a low airflow alarm. Table 2.3 lists the possible causes of this fault, including an airflow (DP) sensor error, a stuck or failed damper or damper actuator, low static pressure in the supply air duct, a scheduling conflict with the AHU, an undersized VAV box, a tuning problem with the airflow control PID loop, a maximum airflow setpoint that is too high, and a sequencing logic error. Onsite personnel investigated and determined that the fault was due to low static pressure caused by a temporary communication failure of the building control network. The AHUs at SITE-1 are scheduled based on the number of run requests received from the VAV boxes they serve. Since the AHU serving this VAV box did not receive any run requests, the supply fan was not energized and the static pressure in the supply air duct was too low. Figure 5.8 also shows that the fault disappeared when network communications were restored at approximately 11:00. 


\subsubsection{Undersized Supply Duct}

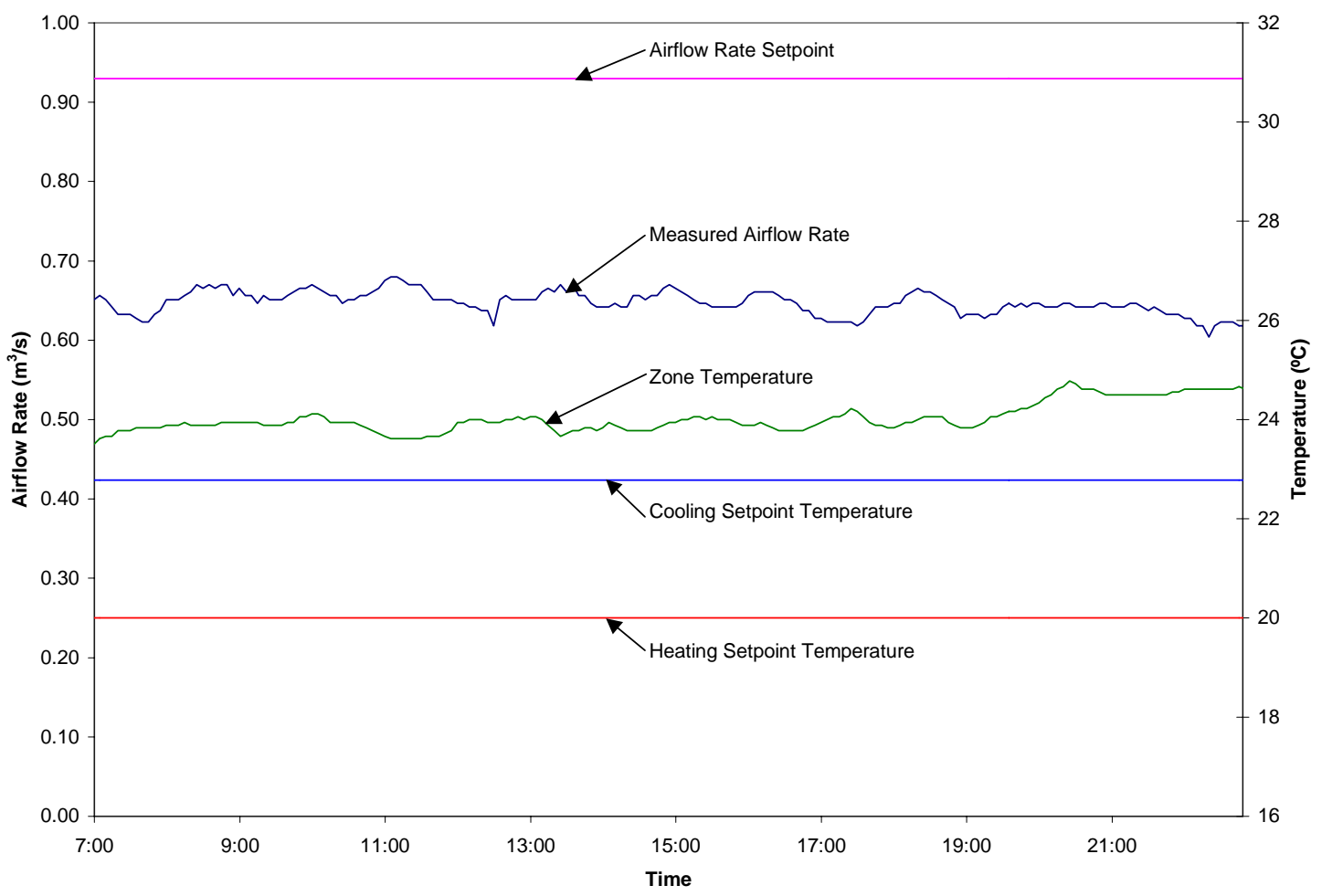

Figure 5.9. Undersized Supply Duct.

Figure 5.9 shows a plot of airflow and temperature data vs. time of day from one of the throttling (no fan) VAV boxes at SITE-1. It shows a large negative airflow error, since the measured airflow rate was substantially less than the airflow rate setpoint. There is also a large positive zone temperature error, since the zone temperature is greater than the cooling setpoint temperature. A trendlog showed that the VPACC algorithm embedded in the VAV box controller reported a low airflow alarm and a high zone temperature alarm. Table 2.3 lists the possible causes of this fault, including a zone temperature sensor error, an airflow (DP) sensor error, a stuck or failed damper or damper actuator, supply air too warm, low static pressure in the supply air duct, a scheduling conflict with the AHU, an undersized VAV box, a tuning problem with the airflow control or zone temperature control PID loop, a maximum airflow setpoint that is too low or too high, an inappropriate zone temperature setpoint, and a sequencing logic error. This VAV box does not have a reheat coil, so the possible causes of reheat coil valve or actuator stuck or failed shown in Table 2.3 do not apply. Onsite personnel investigated and determined that the fault was due to low static pressure in the supply duct. This is a large VAV box at the distant end of the supply duct from the serving AHU. The duct is undersized so under high load conditions this VAV box is starved of supply air. When this happens, the airflow rate drops below the airflow rate setpoint, and the zone temperature rises above the cooling setpoint temperature, since there is not enough airflow to meet the cooling load. 


\subsubsection{Disconnected Zone Temperature Sensor}

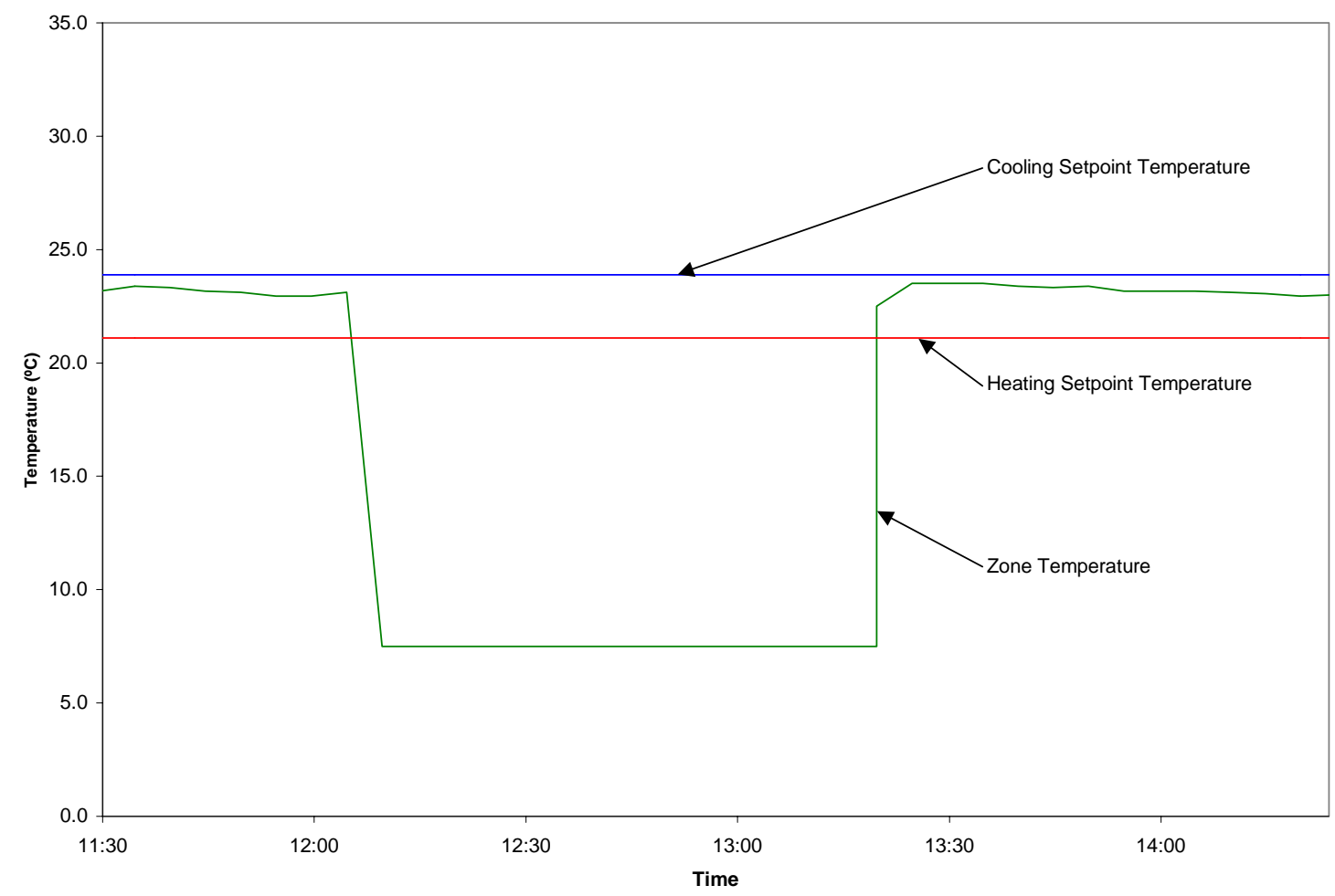

Figure 5.10. Disconnected Zone Temperature Sensor.

Figure 5.10 shows a plot of temperature data vs. time of day from one of the throttling (no fan) VAV boxes at SITE-1. It shows a large negative zone temperature error, since the zone temperature is less than the heating setpoint temperature. A trendlog showed that the VPACC algorithm embedded in the VAV box controller reported a low zone temperature alarm. Table 2.3 lists the possible causes of this fault, including a zone temperature sensor error, airflow (DP) sensor error, supply air too cool, a scheduling conflict with the AHU, an undersized VAV box, a tuning problem with the airflow control or zone temperature control PID loop, an inappropriate zone temperature setpoint, a minimum airflow setpoint that is too high, and a sequencing logic error. This VAV box does not have a reheat coil, so the possible causes of reheat coil valve or actuator stuck or failed shown in Table 2.3 do not apply. Onsite personnel investigated and determined that the fault was due to a zone temperature sensor error which occurred when the zone temperature sensor was inadvertently disconnected during maintenance. The sensor was configured for $0-10 \mathrm{~V}$ with a value of $7.5^{\circ} \mathrm{C}$ at $0 \mathrm{~V}$. When the sensor was disconnected, $0 \mathrm{~V}$ was read at the input on the VAV box controller, so a value of $7.5^{\circ} \mathrm{C}$ was recorded, as shown in Figure 5.10. The figure also shows that the fault disappeared when the sensor was reconnected. 


\subsubsection{SITE-2}

At SITE-2, the computerized maintenance management system (CMMS) was configured to automatically generate a work order whenever a fault was detected. The building engineer responded to investigate and verify any faults reported through the MMS. Since no trendlogs of the raw data were established for the AHUs, there are no plots to illustrate the AHU faults described in this section. Supplemental trendlogs were configured for some of the VAV boxes, so plots are shown where data were available.

\subsubsection{Outdoor Air Temperature Sensor Error}

The APAR algorithm embedded in one of the AHU controllers at SITE-2 reported faults due to Rules 8 and 10. Rule 8 states that, in mechanical cooling with $100 \%$ outdoor air mode, the outdoor air temperature should be greater than the supply air temperature setpoint (otherwise, the AHU should be operating in cooling with outdoor mode). As shown in Table 2.2, the possible causes associated with Rule 8 are a supply or outdoor air temperature sensor error, a stuck or leaking heating coil valve, a stuck or leaking mixing box damper, or a controller logic error. Rule 10 states that, in mechanical cooling with $100 \%$ outdoor air mode, the outdoor and mixed air temperatures should be nearly the same. Table 2.2 shows that the possible causes associated with Rule 10 are a mixed or outdoor air temperature sensor error and a stuck or leaking mixing box damper. Onsite personnel investigated and determined that the fault was due to an outdoor air temperature sensor error caused by the AHUs taking outdoor air from a plenum which was consistently 5 to $10{ }^{\circ} \mathrm{C}$ warmer than the actual outdoor air temperature. A project was undertaken to retrofit the outdoor air plenum with ventilation fans to bring the plenum temperature closer to the the actual outdoor air temperature, thus reducing the chilled water load and the number of hours of chiller operation.

\subsubsection{Chilled Water Not Available}

The APAR algorithm embedded in one of the AHU controllers at SITE-2 reported faults due to Rule 12, while another AHU controller reported faults due to Rule 13. Rule 12 states that, in mechanical cooling with $100 \%$ outdoor air mode, the supply air temperature should be less than the return air temperature. As shown in Table 2.2, the possible causes associated with Rule 12 are a supply or return air temperature sensor error, a stuck cooling coil valve, an undersized cooling coil, a fouled cooling coil, chilled water too warm, a problem with one of the chilled water pumps, chilled water not available, a stuck or leaking heating coil valve, and a controller tuning error. Rule 13 observes that the cooling coil valve is saturated fully open and a persistent supply air temperature error exists. Table 2.2 shows that the possible causes associated with Rule 13 are a supply air temperature sensor error, a stuck cooling coil valve, an undersized cooling coil, a fouled cooling coil, chilled water too warm, a problem with one of the chilled water pumps, chilled water not available, a stuck or leaking heating coil valve, and a controller tuning error. Onsite personnel investigated and determined that the fault was due to chilled water not being available. The current sequence of operations for the chiller specifies that the chiller is only operated if several AHUs require chilled water. A project is being developed at the site to modify the chiller plant sequence of operations to ensure that chilled water is available when needed. 


\subsubsection{Airflow (DP) Sensor Drift}

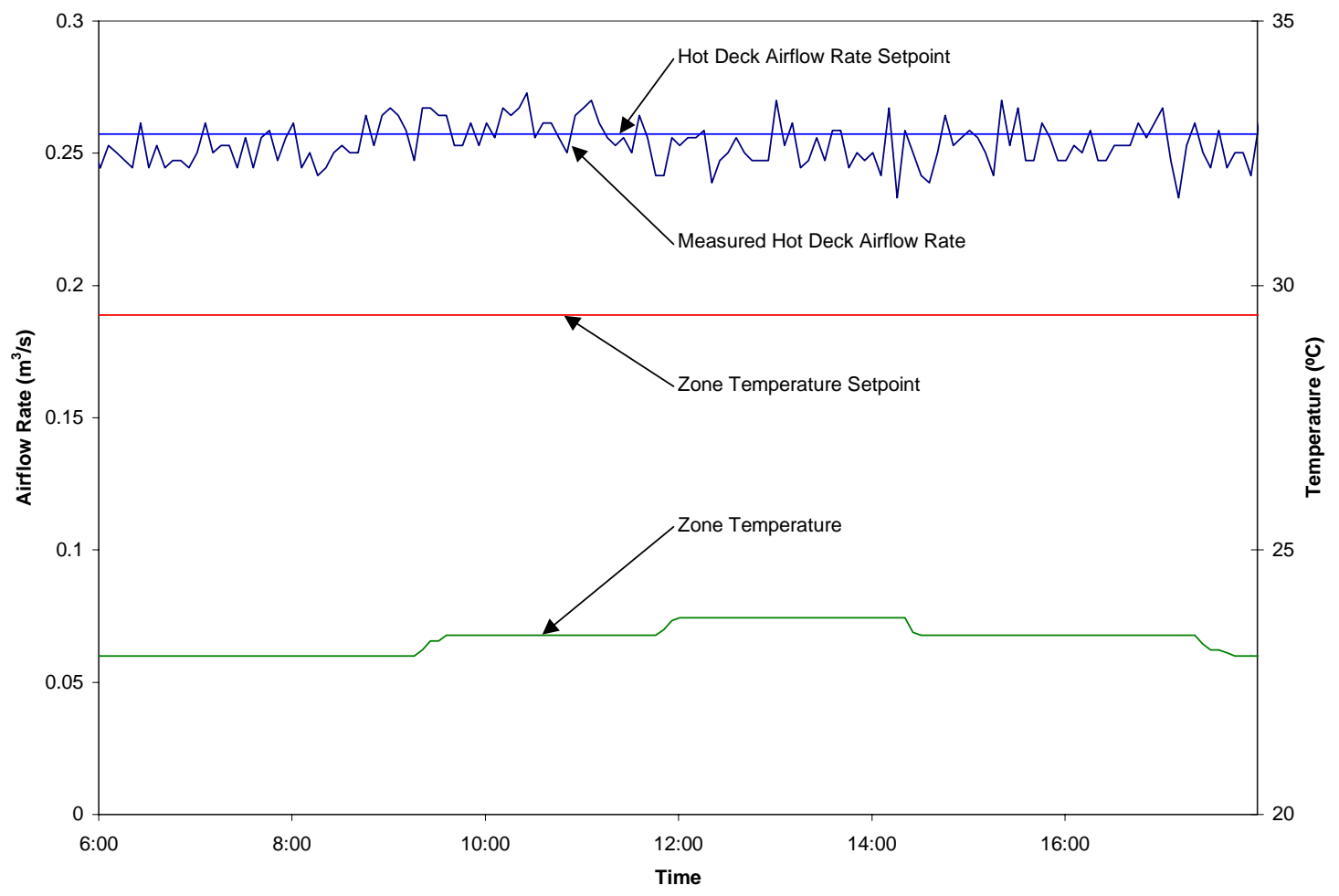

Figure 5.11. Airflow (DP) Sensor Drift.

Figure 5.11 shows a plot of airflow and temperature data from vs. time of day one of the dualduct VAV boxes at SITE-2. It shows a large negative zone temperature error, since the zone temperature is less than the zone temperature setpoint. A trendlog showed that the VPACC algorithm embedded in the VAV box controller reported a low zone temperature alarm. Table 2.3 lists the possible causes of this fault, including a zone temperature sensor error, airflow (DP) sensor drift or failure, supply air too cool, a scheduling conflict with the AHU, an undersized VAV box, a tuning problem with the airflow control or zone temperature control PID loop, an inappropriate zone temperature setpoint, a minimum airflow setpoint that is too high, and a sequencing logic error. This VAV box does not have a reheat coil, so the possible causes of reheat coil valve or actuator stuck or failed shown in Table 2.3 do not apply. Onsite personnel investigated and determined that the fault was due to an airflow sensor error which occurred due to debris buildup in the tubing connecting the pressure probes in the hot deck inlet to the differential pressure senor onboard the VAV box controller. Figure 5.11 shows that the measured hot deck airflow rate was at the setpoint, which was also the maximum hot deck airflow rate for the VAV box. However, the actual hot deck airflow rate was less than the measured value due to the sensor drift. Insufficient warm airflow was provided to the zone, causing the zone temperature to drift well below the setpoint. The fault was repaired by removing the debris from the tubing. 


\subsubsection{Zone Temperature Sensor Failure}

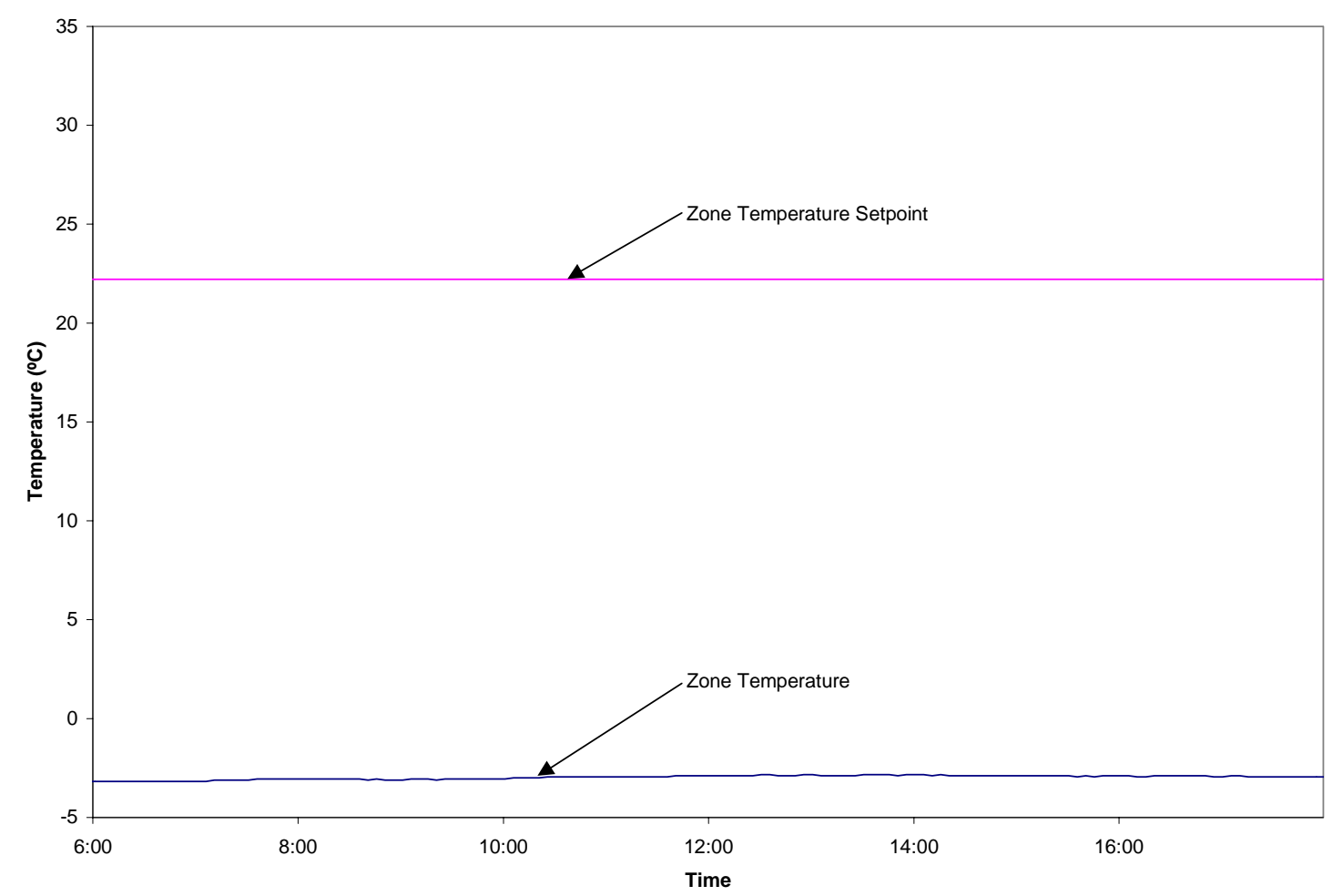

Figure 5.12. Zone Temperature Sensor Failure.

Figure 5.12 shows a plot of temperature data vs. time of day from one of the dual-duct VAV boxes at SITE-2. It shows a large negative zone temperature error, since the zone temperature is less than the zone temperature setpoint. A trendlog showed that the VPACC algorithm embedded in the VAV box controller reported a low zone temperature alarm. Table 2.3 lists the possible causes of this fault, including a zone temperature sensor error, airflow (DP) sensor drift or failure, supply air too cool, a scheduling conflict with the AHU, an undersized VAV box, a tuning problem with the airflow control or zone temperature control PID loop, an inappropriate zone temperature setpoint, a minimum airflow setpoint that is too high, and a sequencing logic error. This VAV box does not have a reheat coil, so the possible causes of reheat coil valve or actuator stuck or failed shown in Table 2.3 do not apply. Onsite personnel investigated and determined that the fault was due to a zone temperature sensor failure. The zone temperature shown in Figure 5.12 is close to the minimum of the range for the sensor, so this fault is not a complete failure, but an extreme sensor drift. The fault was repaired by replacing the sensor. 


\subsubsection{Damper Actuator Failure}

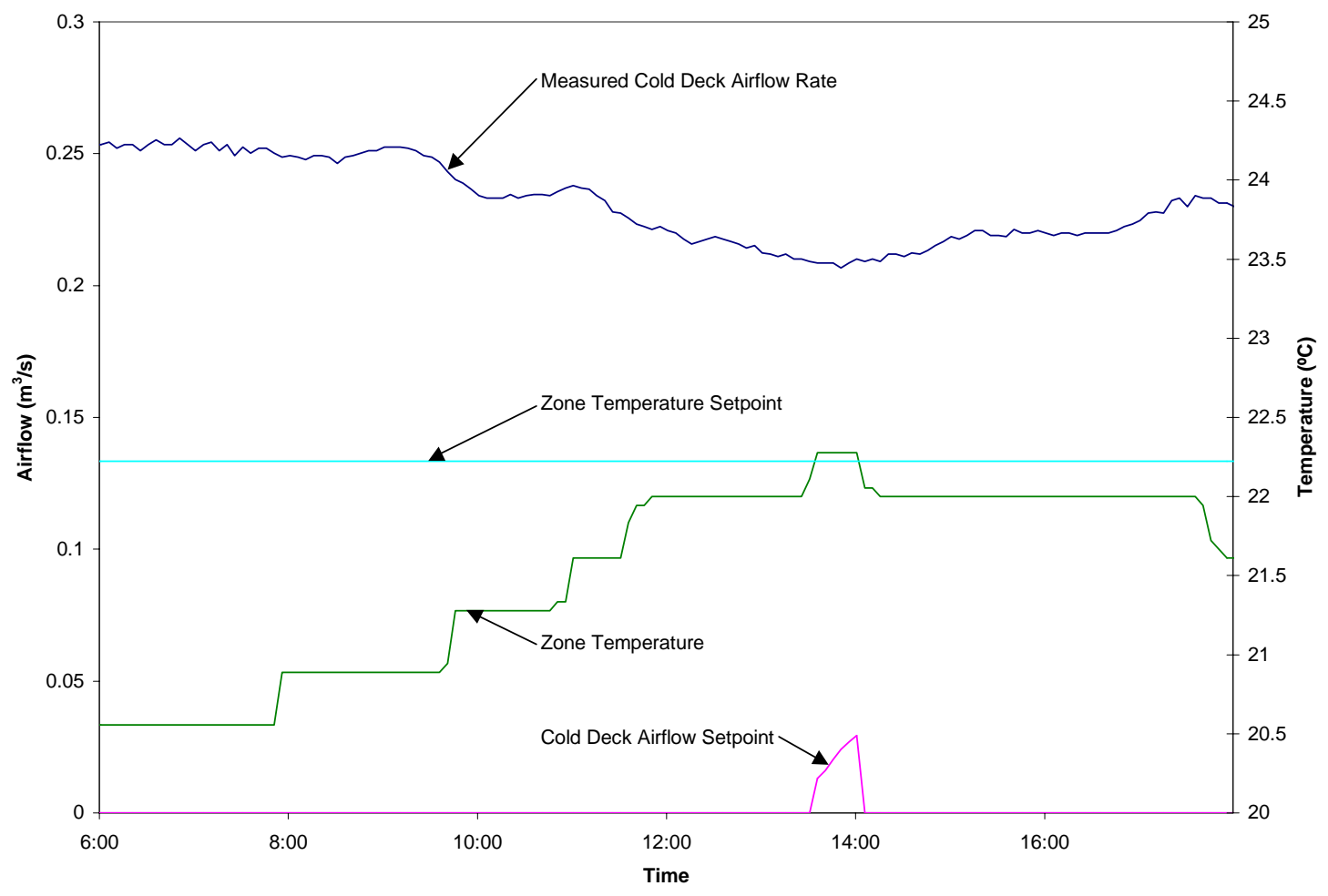

Figure 5.13. Damper Actuator Failure.

Figure 5.13 shows a plot of airflow and temperature data vs. time of day from one of the dualduct VAV boxes at SITE-2. It shows a positive cold deck airflow rate error and a negative zone temperature error. A trendlog showed that the VPACC algorithm embedded in the VAV box controller reported a high cold deck airflow alarm and a low zone temperature alarm. Table 2.3 lists the possible causes of these faults, including a zone temperature sensor error, airflow (DP) sensor drift or failure, cold deck damper or actuator stuck or failed, supply air too cool, a scheduling conflict with the AHU, an undersized VAV box, a tuning problem with the airflow control or zone temperature control PID loop, an inappropriate zone temperature setpoint, a minimum airflow setpoint that is too high, and a sequencing logic error. This VAV box does not have a reheat coil, so the possible causes of reheat coil valve or actuator stuck or failed shown in Table 2.3 do not apply. Onsite personnel investigated and determined that the fault was due to a failed cold deck damper actuator. The damper failure allowed uncontrolled cold deck airflow to the zone, causing the zone temperature to fall well below the setpoint. The fault was repaired by replacing the broken actuator. 


\subsubsection{Zone Temperature PID Loop Tuning Error}

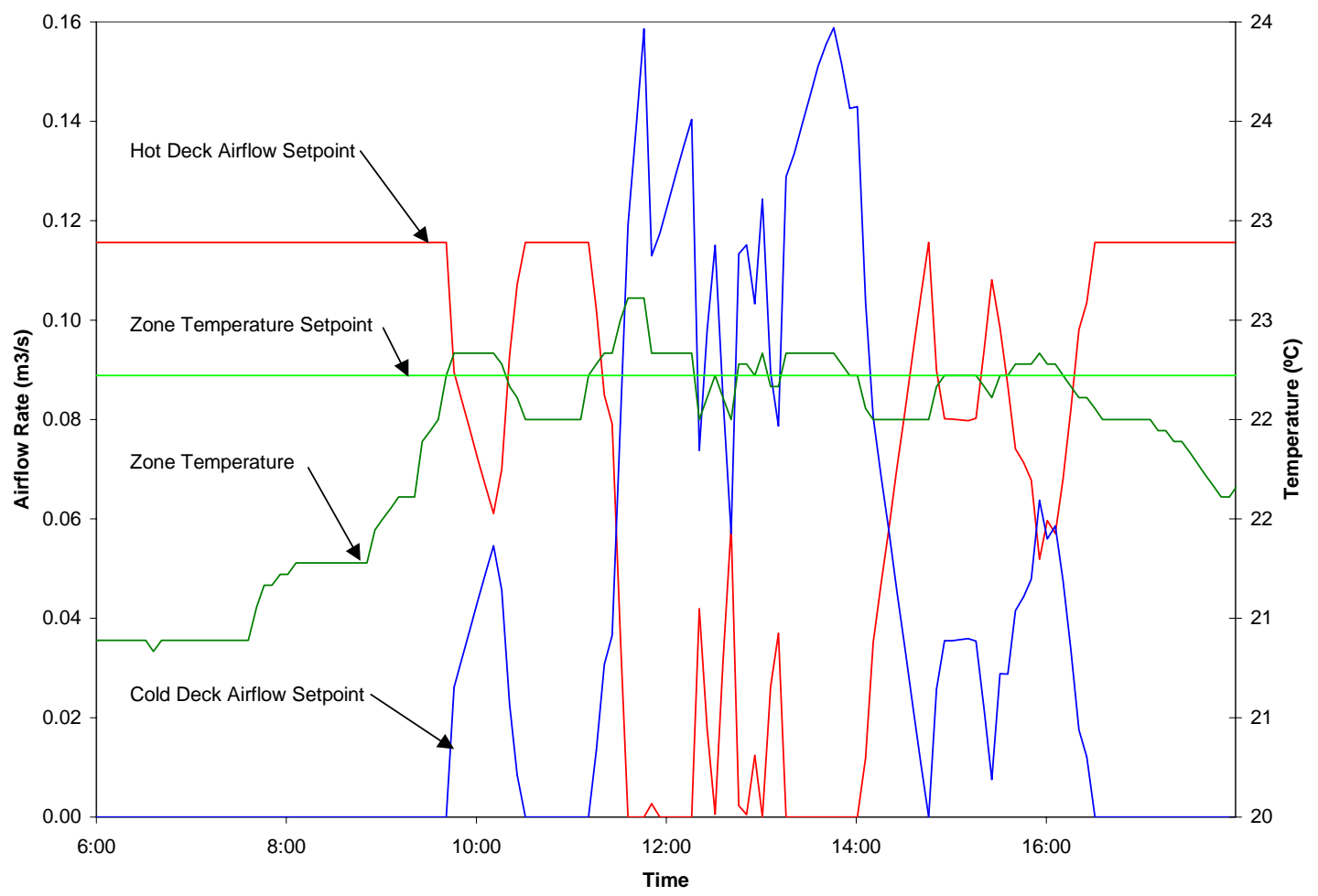

Figure 5.14. Zone Temperature Control Loop Tuning Problem.

Figure 5.14 shows a plot of airflow and temperature data vs. time of day from one of the dualduct VAV boxes at SITE-2. It shows a negative zone temperature error, since the zone temperature is less than the zone temperature setpoint. A trendlog showed that the VPACC algorithm embedded in the VAV box controller reported a low zone temperature alarm. Table 2.3 lists the possible causes of this faults, including a zone temperature sensor error, airflow (DP) sensor drift or failure, supply air too cool, a scheduling conflict with the AHU, an undersized VAV box, a tuning problem with the airflow control or zone temperature control PID loop, an inappropriate zone temperature setpoint, a minimum airflow setpoint that is too high, and a sequencing logic error. This VAV box does not have a reheat coil, so the possible causes of reheat coil valve or actuator stuck or failed shown in Table 2.3 do not apply. Onsite personnel investigated and determined that the fault was due to an underdamped temperature control PID loop. The outputs of the zone temperature control loop are the hot and cold deck airflow setpoints. The hot and cold deck airflow control loops successfully maintained the hot and cold airflow rates (not shown) at their respective setpoints. Figure 5.14 shows that as the zone temperature approached the setpoint, the temperature control loop oscillated, as seen in the varying hot and cold deck airflow setpoints. 


\subsubsection{SITE-3}

\subsubsection{Supply Air Temperature Error}

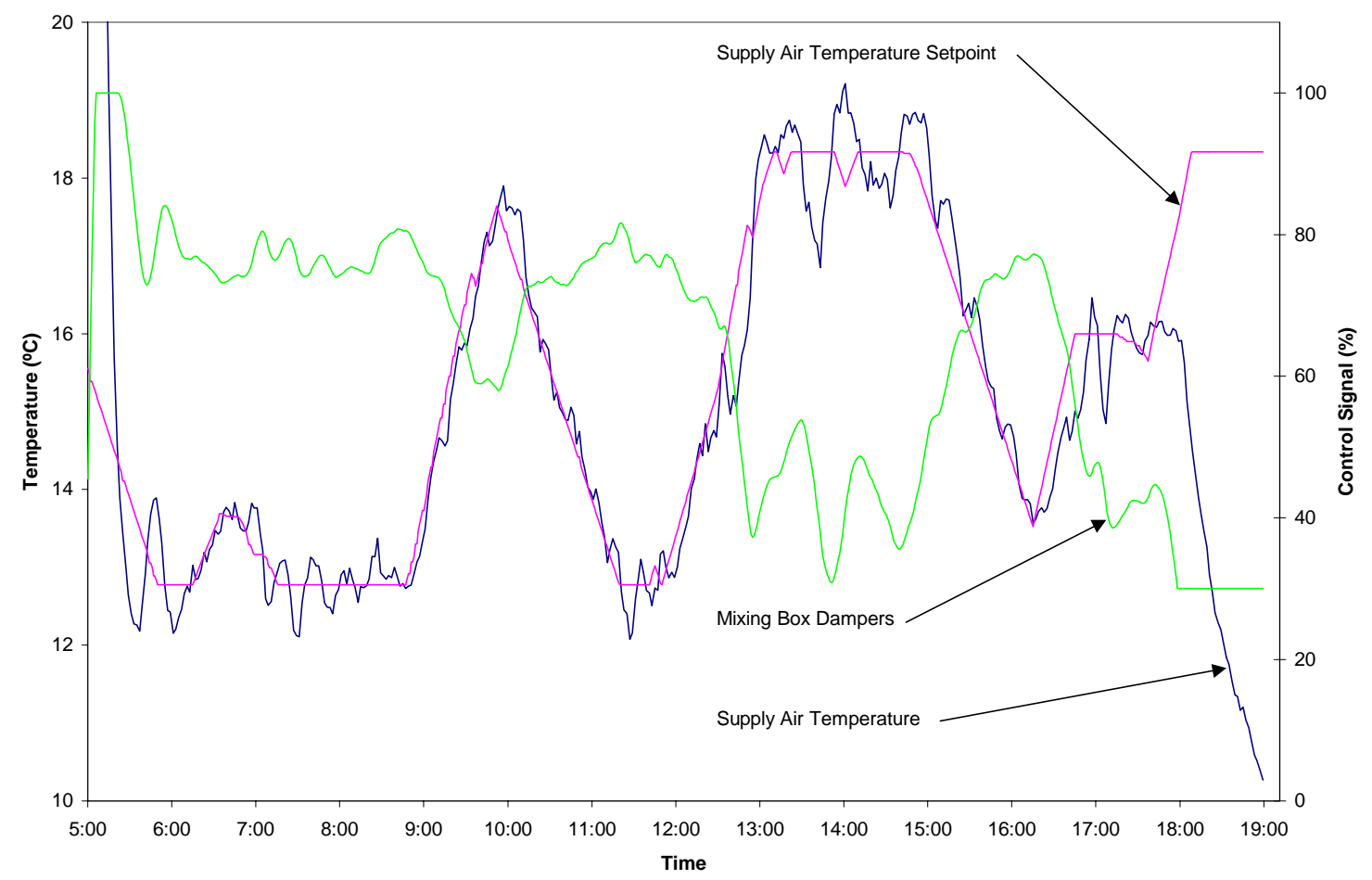

Figure 5.15. Supply Air Temperature Error.

Figure 5.15 shows a plot of temperature and control signal data vs. time of day from the AHU at SITE-3 for the occupied portion of one day. Both stages of heating (not shown) and all four stages of cooling (not shown) remain off while the mixing box dampers modulate to maintain the supply air temperature at its setpoint. This combination of control signals corresponds to Mode 2: cooling with outdoor air. In addition to the set of rules specific to Mode 4, there is a set of rules that apply to all occupied modes of operation (see Table 2.1). One rule which applies to all occupied modes is Rule 25, which states that the supply air temperature should be nearly equal to the supply air temperature setpoint. For most of the day shown, the supply air temperature is nearly equal to the setpoint, but from 17:45 until 19:00, the supply air temperature drifts well below the setpoint. A trendlog showed that the APAR algorithm embedded in the AHU controller had generated a fault report due to Rule 25 late in the day. As shown in Table 2.2, the only possible causes of this fault are either a controller tuning or logic error. Onsite personnel investigated and determined that the fault was not due to either of the possible causes listed by APAR. Instead it was the result of a low supply airflow rate due to a low cooling load. The constant toilet exhaust airflow rate caused the AHU outdoor air fraction to rise despite the mixing box dampers closing to the minimum position. It is unknown whether the AHU controller would have energized the first stage of heating had the condition persisted. 


\subsubsection{SITE-4}

\subsubsection{Hot Water Converter Offline}

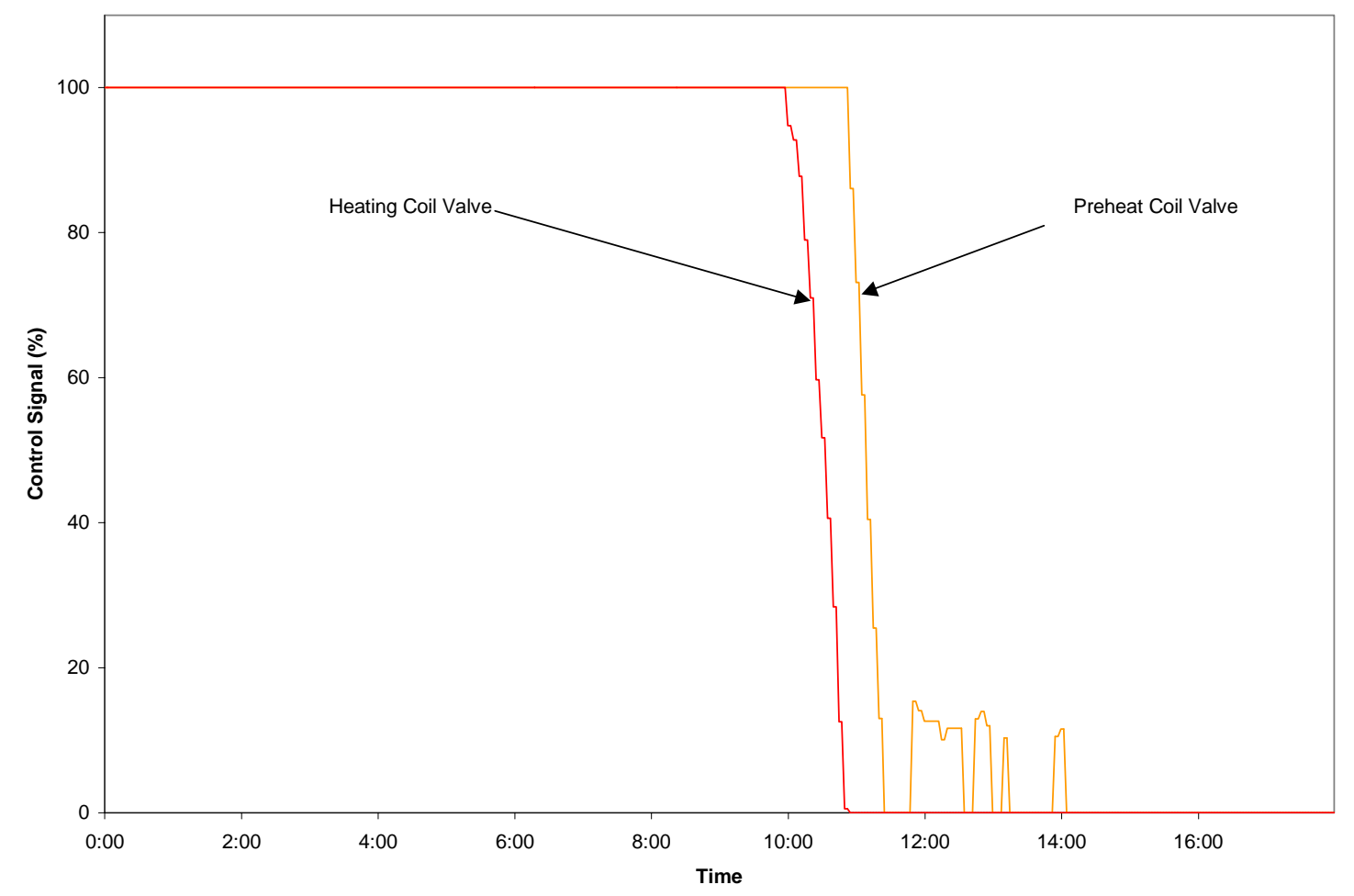

Figure 5.16. Hot Water Converter Offline.

Figure 5.16 shows a plot of control signal data vs. time of day from the AHU at SITE-4. This AHU has a preheat coil and a heating coil, which are sequenced in series to meet the heating load. Relatively small heating loads are met by opening the preheat coil valve only, while the heating coil valve remains closed. As the heating load increases, the preheat coil valve saturates open and the heating coil valve opens to meet the load. Figure 5.16 shows the AHU operating in Mode 1: heating. One of the rules for Mode 1 is Rule 4, which warns that the heating coil valve is saturated fully open. For the first 10 hours of the day shown, both the preheat and heating coil valves are saturated at $100 \%$ open. A trendlog showed that the APAR algorithm embedded in the AHU controller had generated a fault report due to Rule 4. As shown in Table 2.2, the possible causes of this fault are either a supply air temperature sensor error, a stuck or leaking cooling coil valve, a stuck heating coil valve, an undersized heating coil, a fouled heating coil, hot water supply temperature too low, a problem with the hot water circulating pump, or a controller tuning error. Onsite personnel investigated and determined that the fault was due to a steam-to-hot water converter going offline. The converter supplies hot water to the preheat and heating coils of the AHU. When the converter was offline, the hot water supply temperature was too low. Figure 5.16 shows that the fault disappeared when the converter was brought back online at approximately 10:00. 


\subsubsection{Manual Override of Outdoor Air Damper}

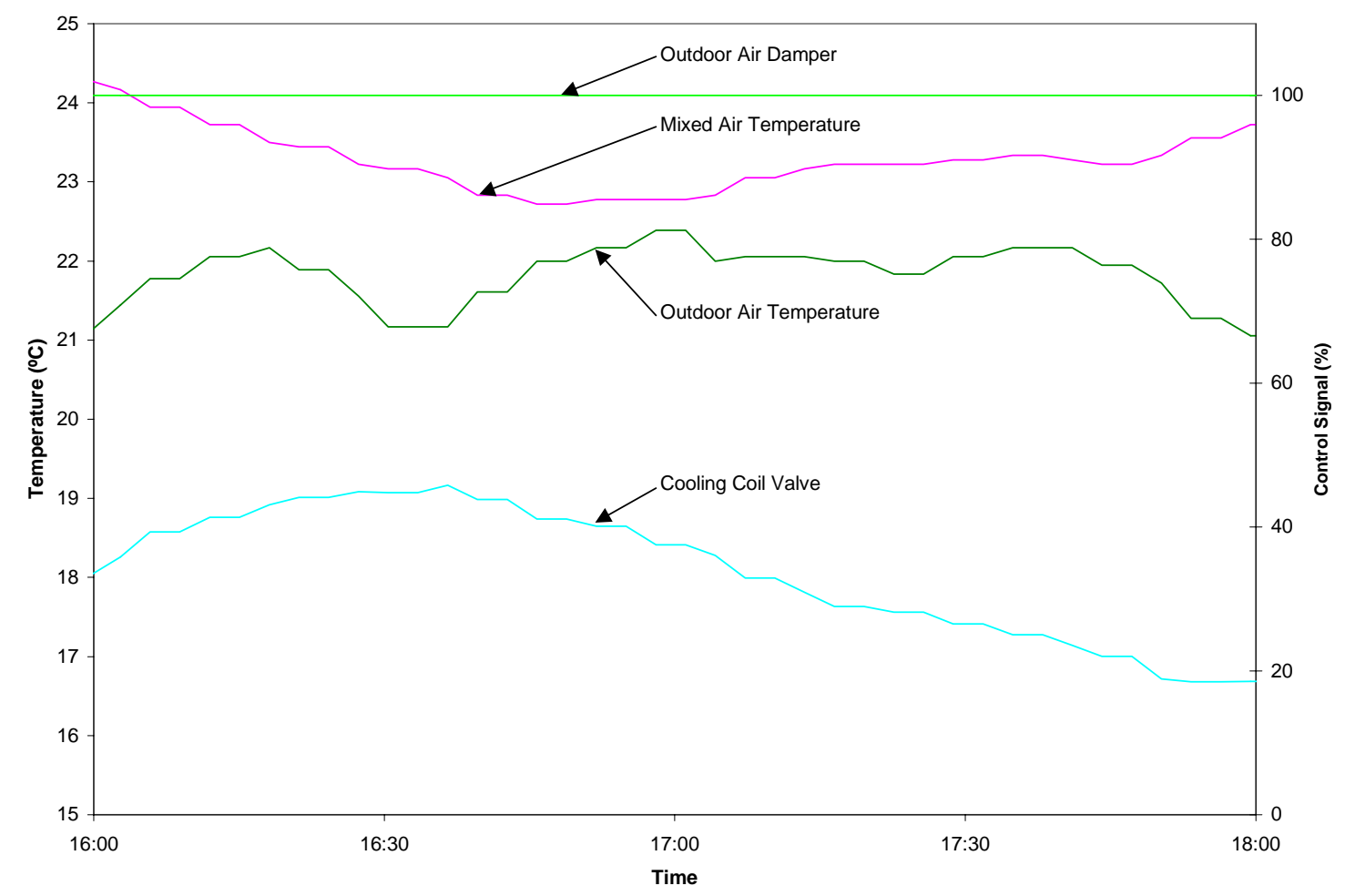

Figure 5.17. Manual Override of Outdoor Air Damper.

Figure 5.17 shows a plot of temperature and control signal data vs. time of day from the AHU at SITE-4. The preheat and heating coil valves (not shown) remain fully closed and the mixing box dampers are positioned for $100 \%$ outdoor air. The cooling coil valve is modulated to meet the cooling load. This combination of control signals corresponds to Mode 3: mechanical cooling with $100 \%$ outdoor air. One of the rules for Mode 3 is Rule 10, which states that the outdoor air and mixed air temperatures should be nearly the same. Figure 5.17 shows that the mixed air temperature is greater than the outdoor air temperature by as much as $3{ }^{\circ} \mathrm{C}$. A trendlog showed that the APAR algorithm embedded in the AHU controller had generated a fault report due to Rule 10. As shown in Table 2.2, the possible causes of this fault are an outdoor or mixed air temperature sensor error or a stuck or leaking mixing box damper. Onsite personnel explained that the fault was due to a manual override of the outdoor air damper which had been made in response to a design flaw. The sequence of operations for this AHU specifies that the outdoor air damper open fully during occupied periods. However, under some weather conditions, the AHU does not have sufficient capacity to meet both the space heating/cooling load and the ventilation load. A manual override keeps the outdoor air damper partially closed, thereby reducing the ventilation load so that the AHU has sufficient capacity to maintain the space temperature and humidity at setpoint. 


\subsubsection{Steam Outage}

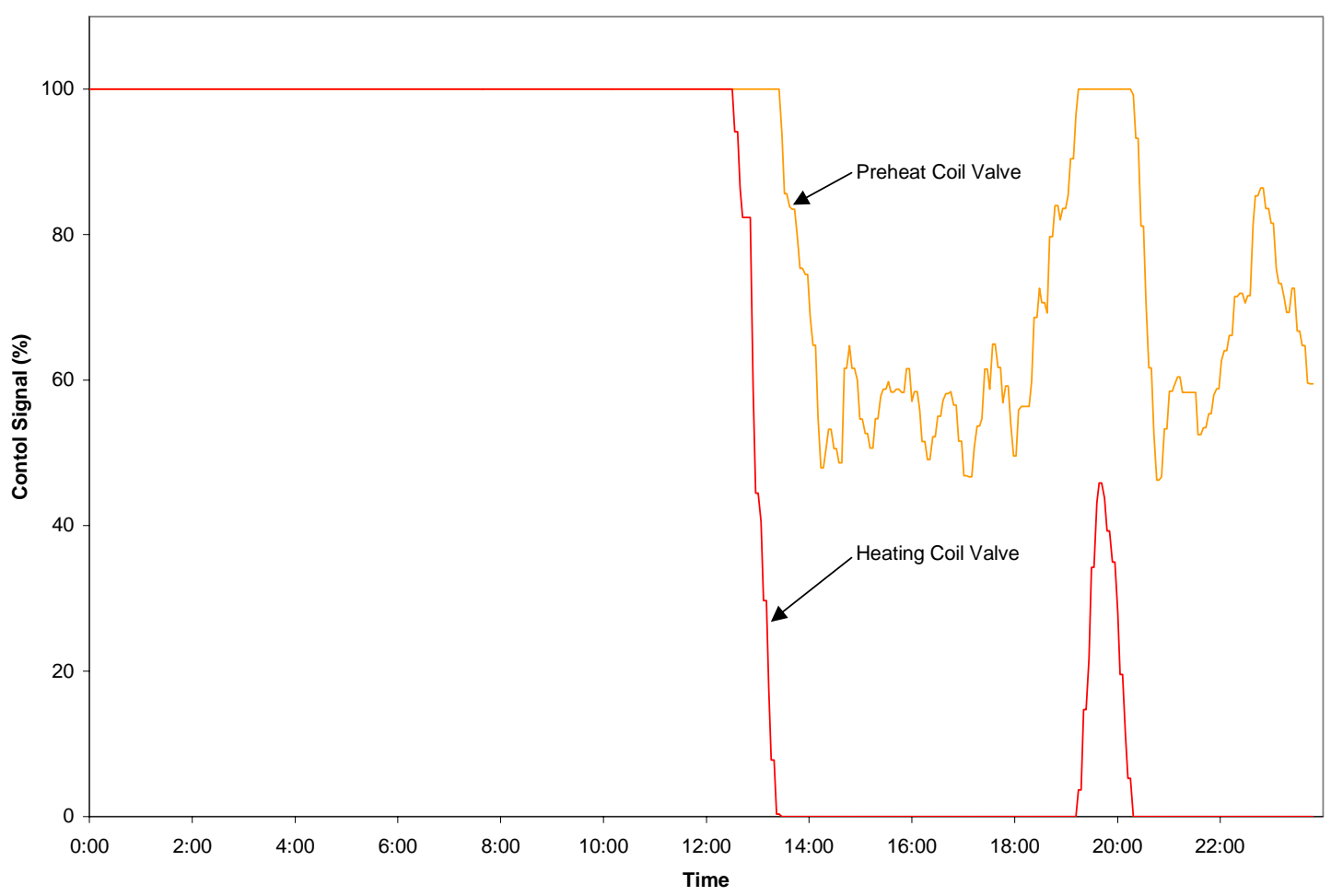

Figure 5.18. Sitewide Steam Outage.

Figure 5.18 shows a plot of temperature and control signal data vs. time of day from the AHU at SITE-4. This AHU has a preheat coil and a heating coil, which are sequenced as described in Section 5.4.1. Figure 5.18 shows the AHU operating in Mode 1: heating. One of the rules for Mode 1 is Rule 4, which warns that the heating coil valve is saturated fully open. For the first 12 hours of the day shown, both the preheat and heating coil valves are saturated at $100 \%$ open. A trendlog showed that the APAR algorithm embedded in the AHU controller had generated a fault report due to Rule 4. As shown in Table 2.2, the possible causes of this fault are either a supply air temperature sensor error, a stuck or leaking cooling coil valve, a stuck heating coil valve, an undersized heating coil, a fouled heating coil, hot water supply temperature too low, a problem with the hot water circulating pump, or a controller tuning error. Onsite personnel investigated and determined that the fault was due to a sitewide steam outage which caused the hot water supply temperature to fall too low. Figure 5.18 shows that the fault disappeared when the steam supply was brought back online at approximately 12:00. 


\subsubsection{Incorrect Cooling Coil Valve Actuator Configuration}

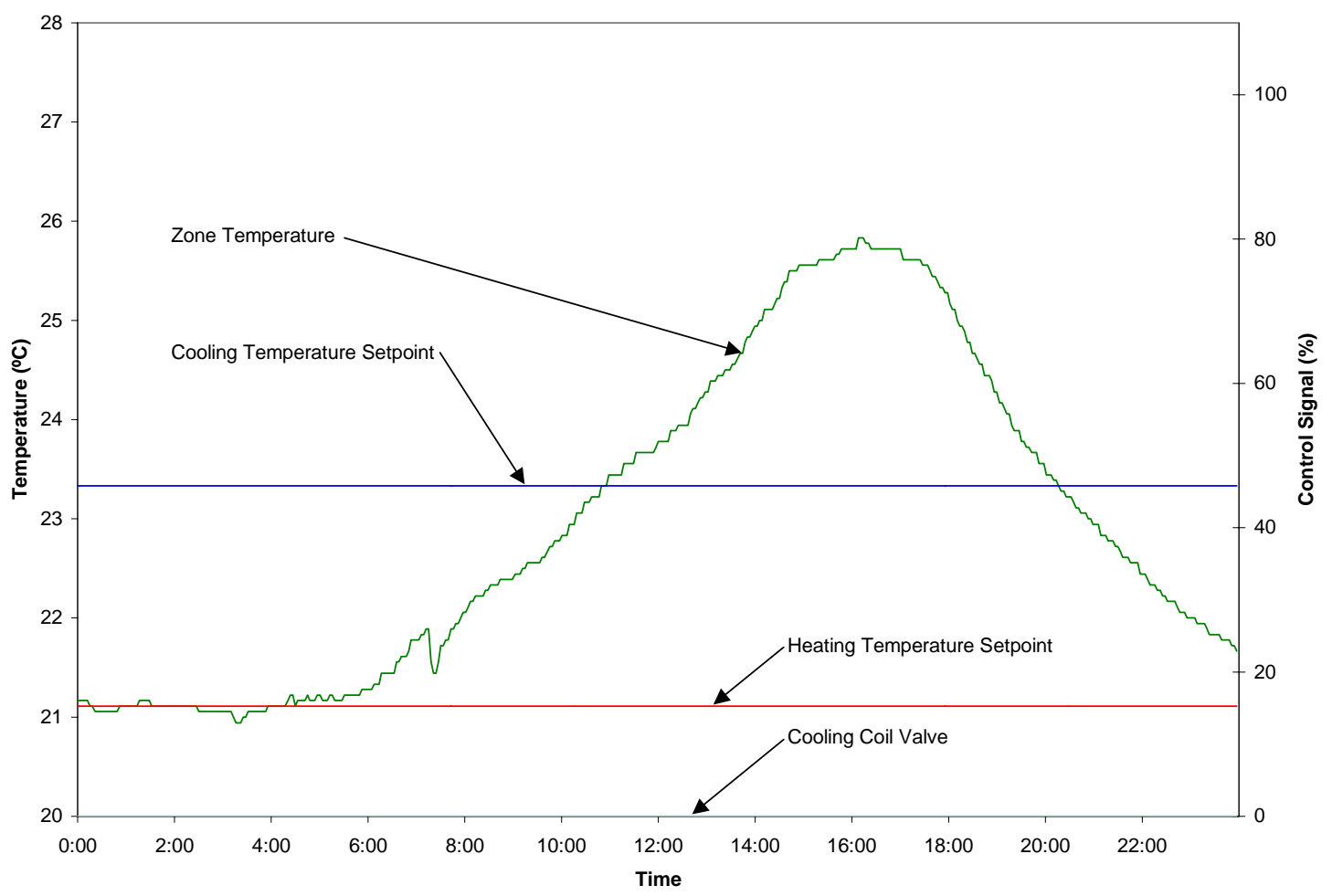

Figure 5.19. Incorrect Cooling Coil Valve Actuator Configuration.

Figure 5.19 shows a plot of temperature and control signal data vs. time of day from the AHU at SITE-4. It shows the AHU operating in Mode 5: unknown mode of operation. One of the rules which applies to all modes of operation is Rule 25, which states that the supply air temperature should be nearly equal to the supply air temperature setpoint. The sequence of operations for this single-zone AHU modulates the cooling coil valve to maintain the zone temperature between the heating and cooling setpoints, so Rule 25 was rewritten to state that the zone temperature should be between the cooling and heating setpoints. Figure 5.19 shows that the zone temperature exceeded the cooling setpoint by as much as $5.5^{\circ} \mathrm{C}$, yet the cooling coil valve remained closed. A trendlog showed that the APAR algorithm embedded in the AHU controller had generated a fault report due to Rule 25. As shown in Table 2.2, the possible causes of this fault are either a controller tuning or logic error. Onsite personnel investigated and determined that the fault was due to an incorrect configuration of the AHU controller output to the cooling coil valve actuator. The controller output was configured for $0 \mathrm{~V}-10 \mathrm{~V}$, but the actuator was $2 \mathrm{~V}-10 \mathrm{~V}$. As a result, the valve remained closed for controller output values from $0 \mathrm{~V}-2 \mathrm{~V}$. The fault was repaired by reconfiguring the controller output for $2 \mathrm{~V}-10 \mathrm{~V}$. 


\subsubsection{SITE-5}

\subsubsection{Simultaneous Mechanical Cooling and Economizing}

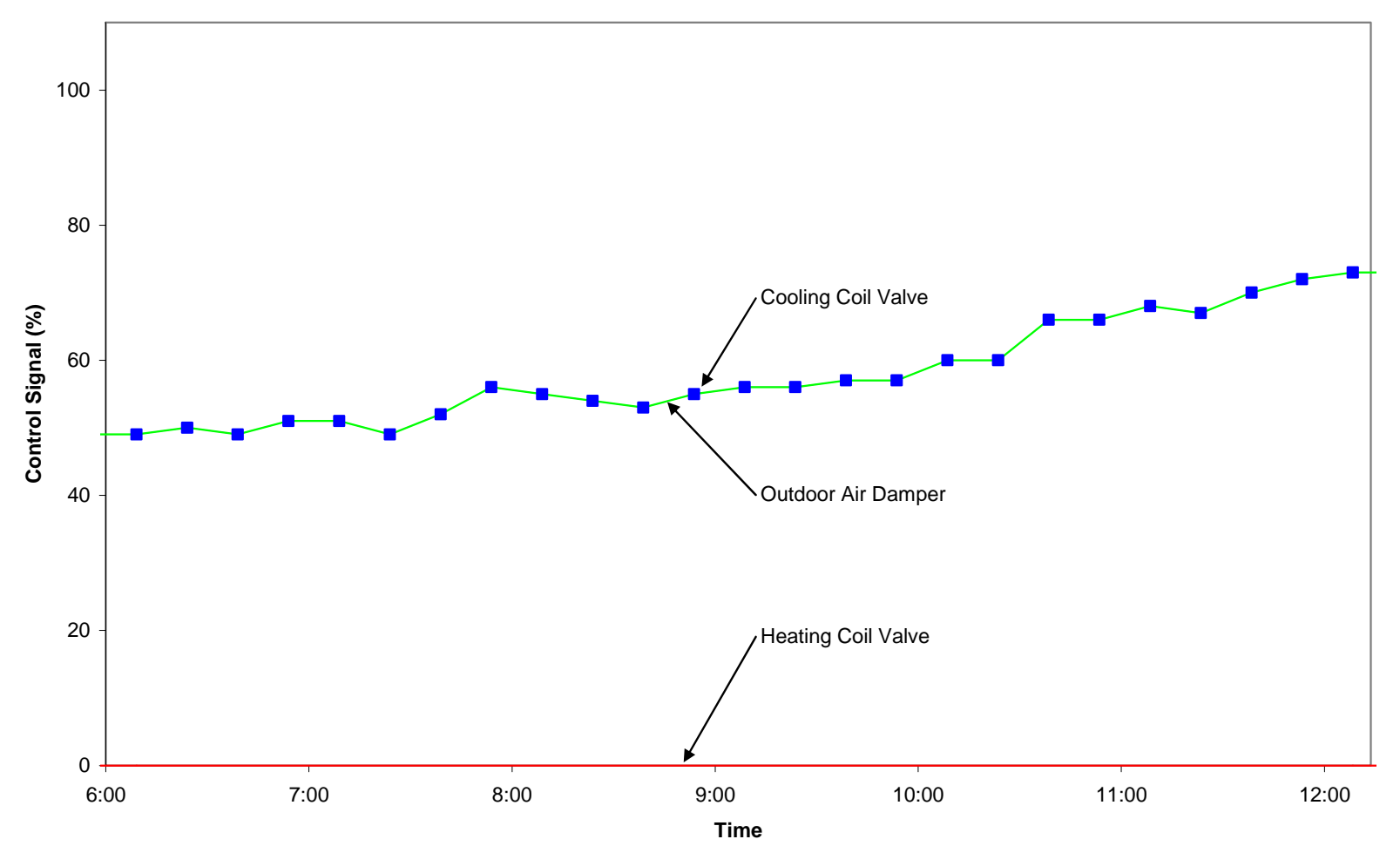

Figure 5.20. Simultaneous Mechanical Cooling and Economizing.

Figure 5.20 shows a plot of control signal data vs. time of day from one of the AHUs at SITE-5; it shows the AHU operating in Mode 5: unknown mode of operation. One of the rules for Mode 5 is Rule 24, which indicates simultaneous mechanical cooling and the economizing. Figure 5.20 shows the cooling coil valve and outdoor air damper move in concert from $50 \%$ to $75 \%$ open. A trendlog showed that the APAR algorithm embedded in the AHU controller had generated a fault report due to Rule 24. As shown in Table 2.2, the possible causes of this fault are a controller tuning or logic (sequencing and scheduling) error. Since this fault was reported for both AHUs at SITE-5, a logic error was the most likely explanation. A review of the control logic revealed that this was the case: the output of the temperature control PID loop was simply sent to the cooling coil valve and outdoor air damper simultaneously. This fault caused an increased load on the chiller and increased chiller run time, both contributing to increased energy consumption. Proper sequencing for conditions that meet the criteria for economizer operation would position the outdoor air damper to maintain the supply air temperature at its setpoint while keeping the cooling coil valve closed, thus meeting the cooling load without using mechanical cooling. If the cooling load is too great, the outdoor air damper will saturate at $100 \%$ open, and the cooling coil valve should then open to maintain the supply air temperature at its setpoint. 


\subsubsection{SITE-6}

\subsubsection{Simultaneous Mechanical Cooling and Economizing}

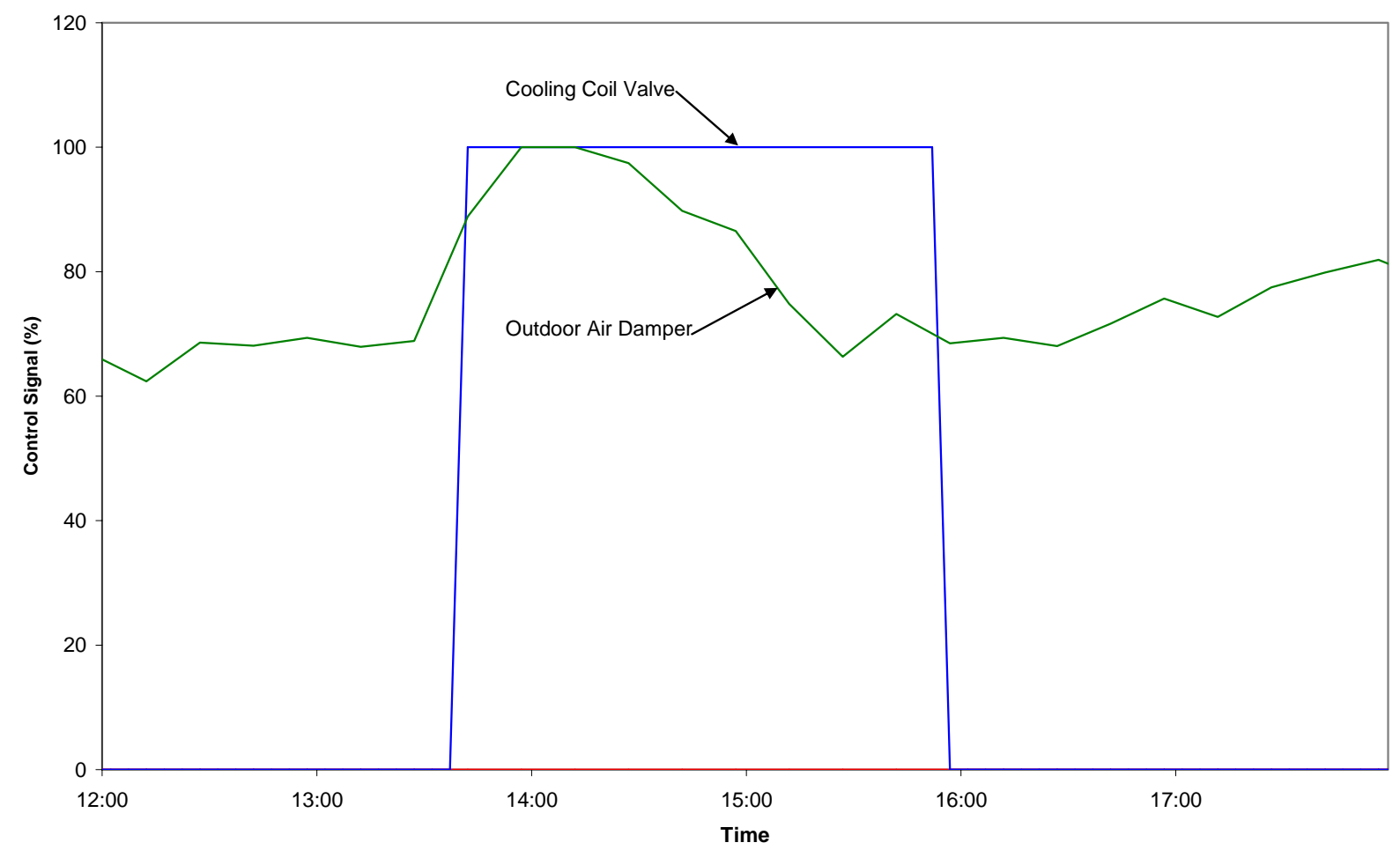

Figure 5.21. Simultaneous Mechanical Cooling and Economizing.

Figure 5.21 shows a plot of control signal data vs. time of day from one of the AHUs at SITE-6; it shows the AHU operating in Mode 5: unknown mode of operation. One of the rules for Mode 5 is Rule 24, which states that the AHU is simultaneously modulating the cooling coil valve and economizer. As shown in Figure 5.21, the cooling coil valve opens while the outdoor air damper is modulating. A trendlog showed that the APAR algorithm embedded in the AHU controller had generated a fault report due to Rule 24. As shown in Table 2.2, the possible causes of this fault are a controller tuning or logic (sequencing and scheduling) error. As in the simultaneous cooling and economizing fault for SITE-5, the AHU sequencing logic was the cause. In this case, two separate PID loops were used to position the cooling coil valve and the outdoor air damper. No interlocks or other logic was present to coordinate outdoor air damper operation with the heating and cooling coil valves. 


\subsubsection{Outdoor Air Temperature Sensor Error}

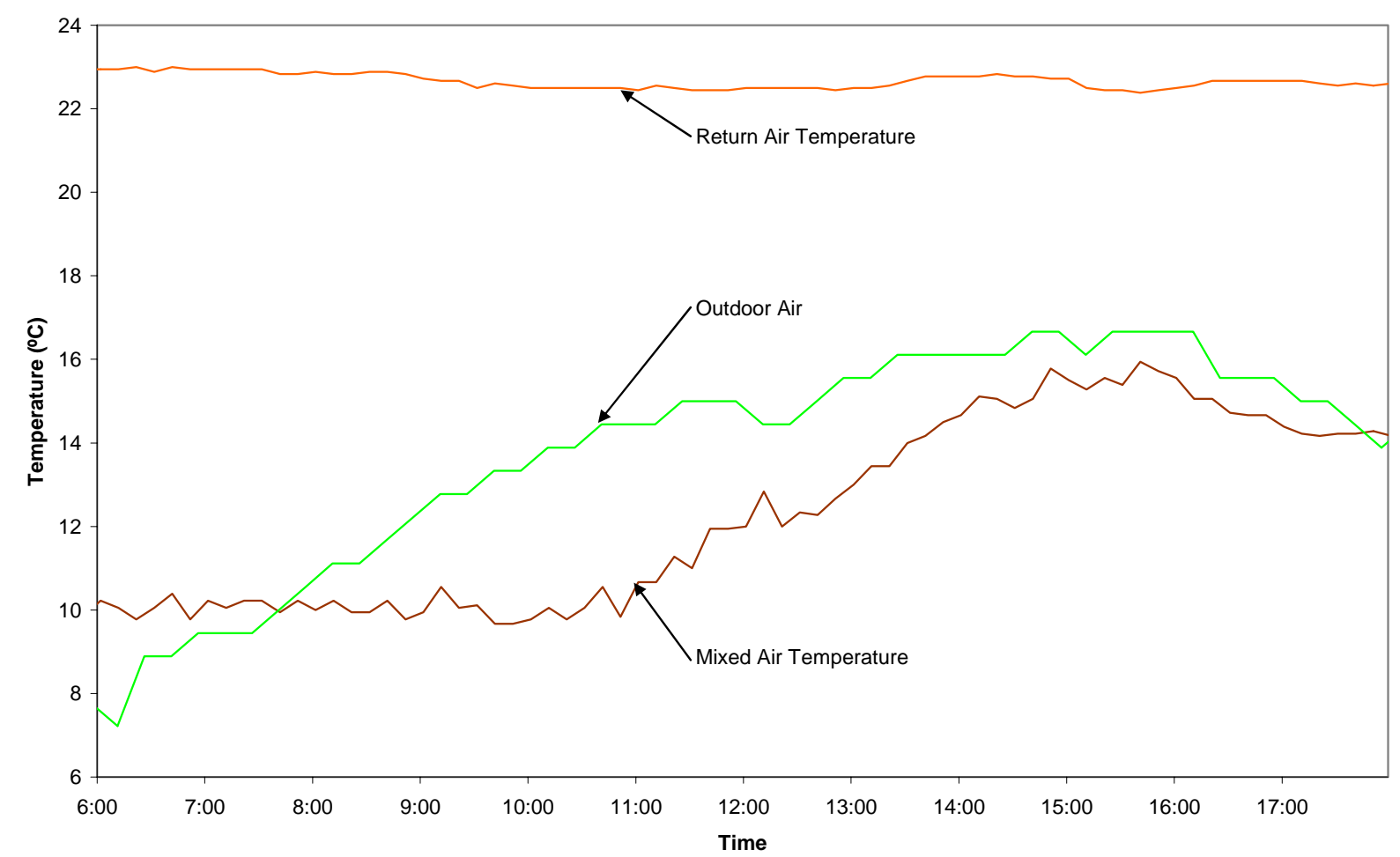

Figure 5.22. Outdoor Air Temperature Sensor Error.

Figure 5.22 shows a plot of temperature data vs. time of day from one of the AHUs at SITE-6. Rules 26 and 27 apply to all modes of operation and state that the mixed air temperature should be between the outdoor air and return air temperatures. Rule 26 checks whether the mixed air temperature is greater than the maximum of the outdoor air and return air temperatures, while Rule 27 checks whether the mixed air temperature is less than the minimum of the outdoor air and return air temperatures. Figure 5.22 shows that the mixed air temperature is less than the minimum of the outdoor air and return air temperatures by as much as $5^{\circ} \mathrm{C}$. A trendlog showed that the APAR algorithm embedded in the AHU controller had generated a fault report due to Rule 27. As shown in Table 2.2, the possible causes of this fault are an outdoor or mixed air temperature sensor error or a stuck or leaking mixing box damper. Onsite personnel investigated and determined that the fault was due to an outdoor air temperature sensor error caused by a difference in temperature between the location of the outdoor air temperature sensor and the AHU's outdoor air intake. 


\subsubsection{VAV Box Controller Hardware Failure}

In one case, high airflow alarms were reported for two of the VAV boxes at SITE-6. A follow up by the maintenance staff determined that both of the VAV box controllers had failed. The controllers were replaced and the alarms did not recur.

\subsubsection{Disconnected VAV Box Supply Air Duct}

Another fault was a low airflow alarm for a VAV box. The maintenance staff determined that the flexible duct connecting the main supply air duct to the inlet of the VAV box had partially slipped from the VAV box inlet connection. The flexible duct was moved into the correct position and secured in place. After this repair, the alarm did not recur.

\subsubsection{VAV Box Damper Actuator Failure}

A high airflow alarm was reported for one of the VAV boxes at SITE-6. A follow up by the maintenance staff determined that the damper actuator shaft was bent. The shaft was replaced and the alarm did not recur.

\subsubsection{Disconnected VAV Box Flow Sensor Tubing}

Another high airflow alarm was reported for another VAV box at SITE-6. In this case, the fault was caused by one of the flexible tubing connections from the velocity probe (flow ring) in the VAV box inlet to the differential pressure sensor on the VAV box controller. The tubing had slipped off of the connection at the controller. The tubing was moved back into the correct position and the alarm did not recur.

\subsubsection{Zone Temperature Sensor Error}

A high zone temperature fault was reported for one of the VAV boxes at SITE-6. A follow up by the maintenance staff determined that the zone temperature sensor was located directly above a computer monitor. The sensor was measuring the temperature of a local "hot spot" rather than the zone temperature. 


\subsubsection{Undersized VAV Box}

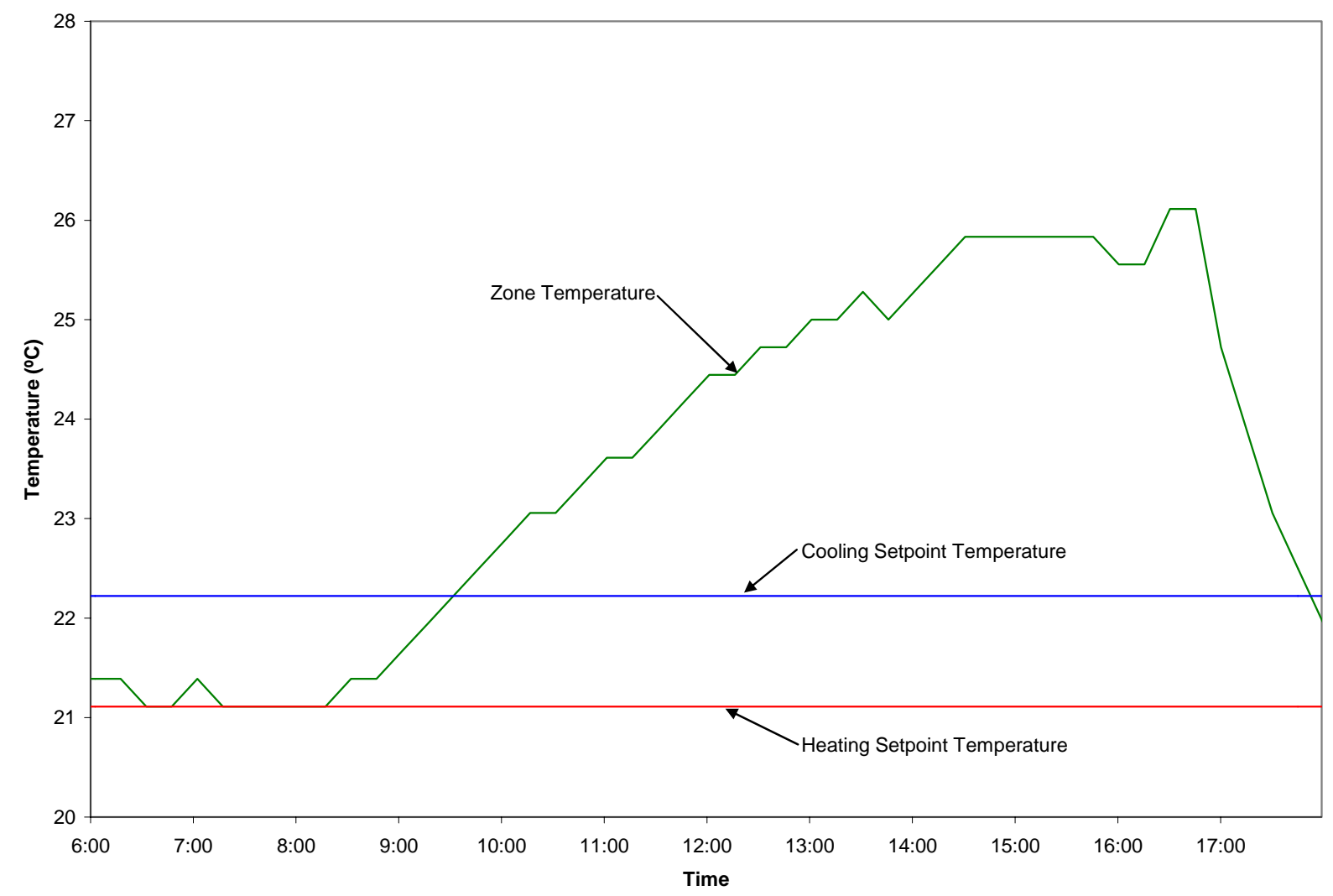

Figure 5.23. Undersized VAV Box.

Figure 5.23 shows a plot of temperature data vs. time of day from one of the VAV boxes at SITE-6. It shows a large positive zone temperature error, since the zone temperature is greater than the cooling setpoint temperature. A trendlog showed that the VPACC algorithm embedded in the VAV box controller reported a high zone temperature alarm. Table 2.3 lists the possible causes of this fault, including a zone temperature sensor error, airflow (DP) sensor error, reheat coil valve or actuator stuck or failed, supply air too warm, a scheduling conflict with the AHU, an undersized VAV box, a tuning problem with the airflow control or zone temperature control PID loop, an inappropriate zone temperature setpoint, a maximum airflow setpoint that is too low, and a sequencing logic error. Onsite personnel investigated and determined that the fault was due to a high solar heat gain to the conditioned space, which is a lobby with large windows. The VAV box is not large enough to provide a sufficient supply airflow rate to meet the load. 


\subsubsection{Undersized Supply Fan}

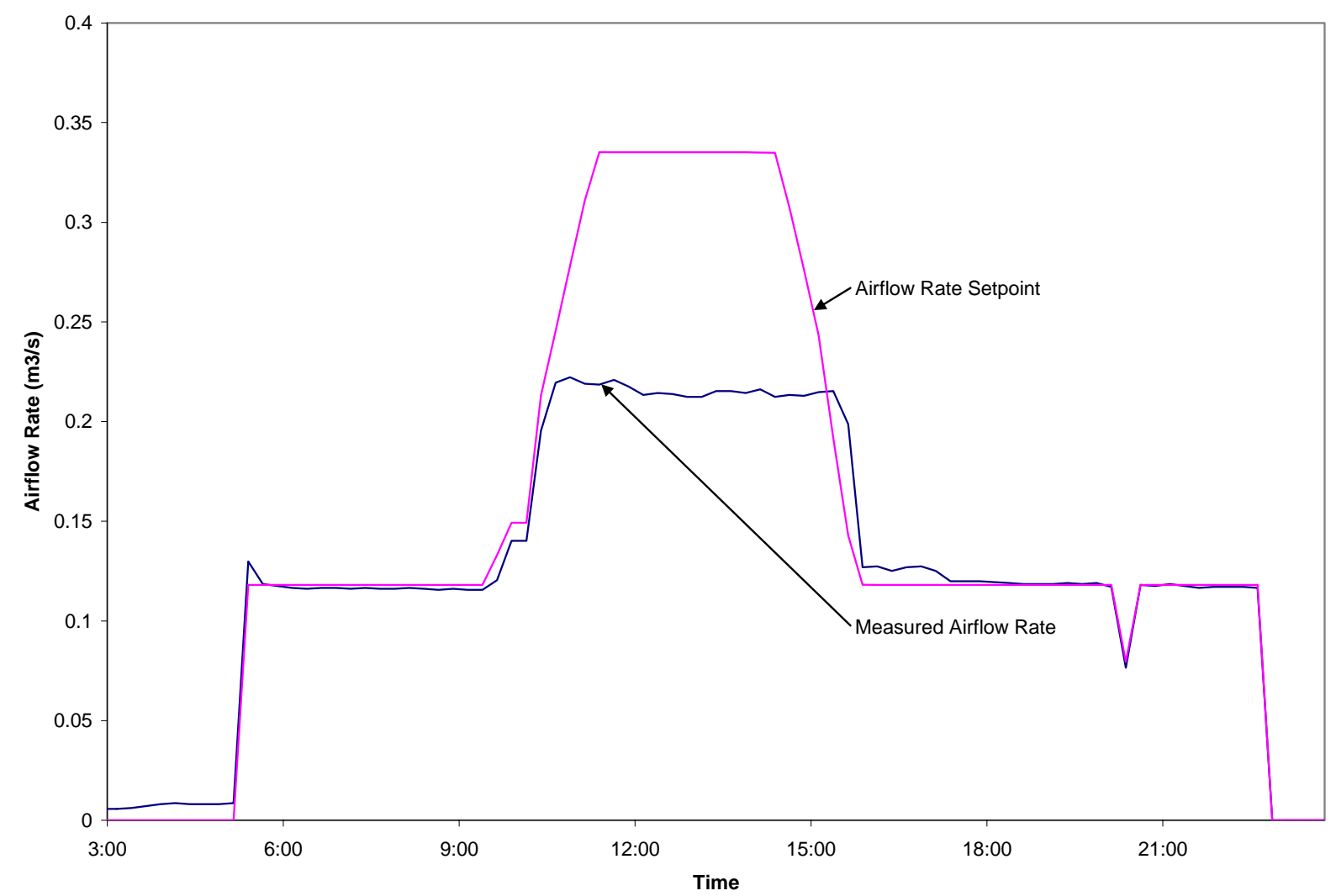

Figure 5.24. Undersized Supply Fan.

Figure 5.24 shows a plot of airflow data vs. time of day from one of the VAV boxes at SITE-6. The plot shows that the measured airflow rate was substantially less than the airflow rate setpoint. A trendlog showed that the VPACC algorithm embedded in the VAV box controller reported a low airflow alarm. Table 2.3 lists the possible causes of this fault, including an airflow (DP) sensor error, a stuck or failed damper or damper actuator, low static pressure in the supply air duct, a scheduling conflict with the AHU, an undersized VAV box, a tuning problem with the airflow control PID loop, a maximum airflow setpoint that is too high, and a sequencing logic error. Onsite personnel investigated and determined that the fault was due to low static pressure in the supply air duct caused by an undersized supply fan in the AHU that serves this VAV box. Figure 5.24 illustrates that early and again later in the day, the airflow rate setpoint was at the minimum and the supply fan was able to maintain sufficient static pressure. When the airflow setpoint increased in the middle of the day, the actual airflow fell below the setpoint as the supply fan was not able to maintain the static pressure at the setpoint. The problem was corrected by replacing the sheaves on the supply fan and motor to increase the fan speed. 


\subsubsection{SITE-7}

\subsubsection{AHU PID Loop Tuning Error}

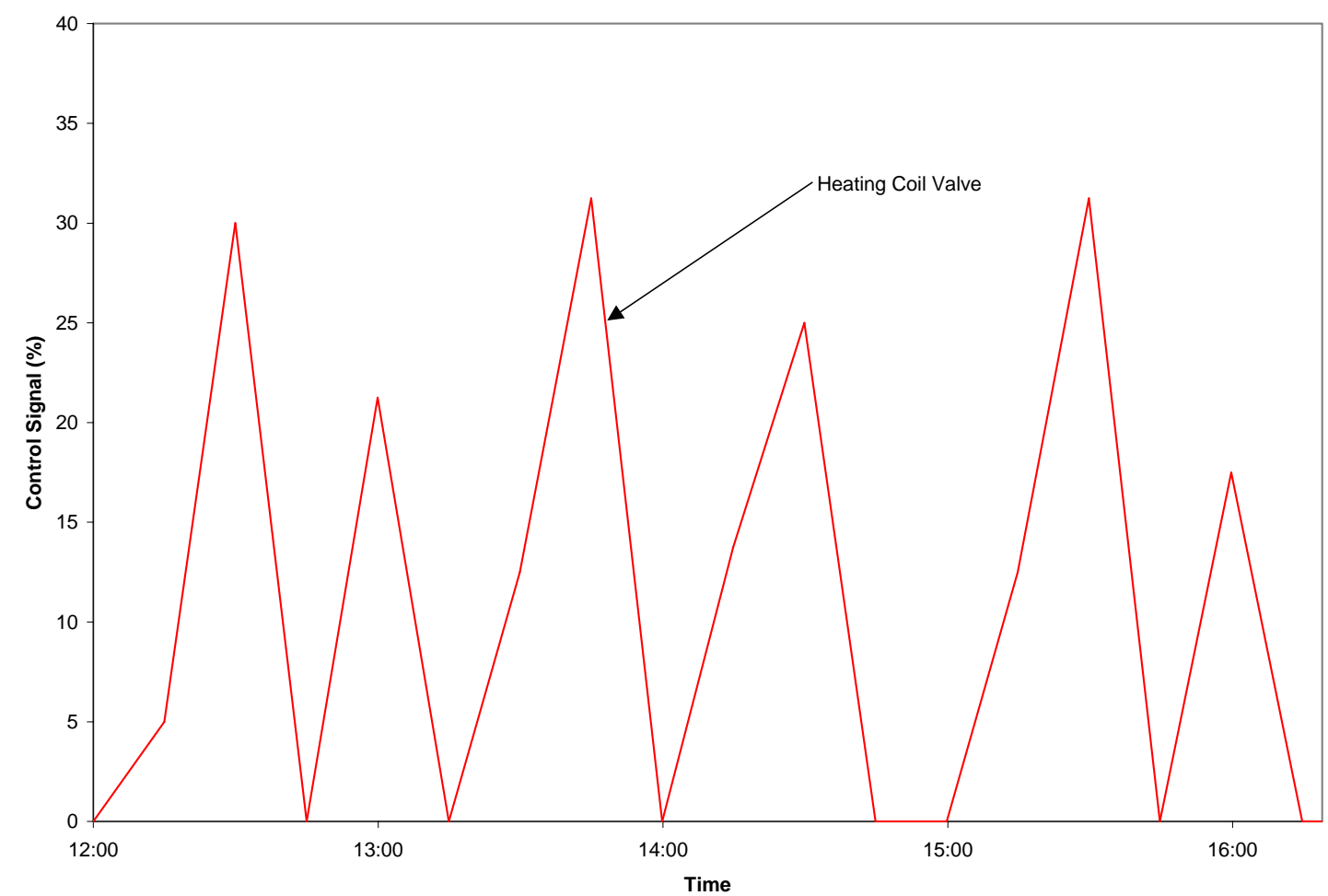

Figure 5.25. AHU PID Loop Tuning Error.

Figure 5.25 shows a plot of control signal data vs. time of day from one of the AHUs at SITE-7. Both stages of DX cooling remain off (not shown) and the economizer is positioned for minimum outdoor air (not shown), while the heating coil valve repeatedly cycles open and closed. The actual rate of valve cycling was observed by the researcher and the maintenance staff to be several times greater than that shown on Figure 5.25. An aliasing effect is present due to the relatively large trendlog sample interval time of $15 \mathrm{~min}$. Whenever the heating coil valve is closed, the AHU is in Mode 5 (unknown mode of operation) and when the heating coil valve is open, the AHU is in Mode 1 (heating). Rule 28, which applies to all modes of operation, counts the number of mode switches per hour. If the count exceeds the threshold (seven mode switches per hour) then a fault has occurred. Although it does not appear so in Figure 5.2, Rule 28 is violated several times on the day shown. A trendlog showed that the APAR algorithm embedded in the AHU controller had generated several fault reports due to Rule 28. As shown in Table 2.2, the possible causes of this fault are a controller or logic error. Onsite personnel investigated and determined that the fault was due to the value of the parameters used to sequence the heating coil valve, stages of DX cooling, and the economizer. 


\subsubsection{SITE-8}

\subsubsection{Zone Temperature Setpoint Too High}

One of the VAV box controllers at SITE-8 reported a low zone temperature alarm. The control contractor investigated and determined that the zone temperature setpoint had been set to an unreasonably high value. This error caused the VAV box to operate in full reheat mode, with the parallel fan running and both stages of reheat energized, during mild spring weather. The setpoint was corrected and the alarms did not recur. 


\section{Summary}

An overall effort was conducted to transfer two FDD methods, APAR and VPACC, from research to commercial use. FDD code was developed using several manufacturers' application programming languages. Various options for communicating the results of the FDD calculations to the building operator were explored, including notification via BAS alarms and automatically generated work orders.

Robust sets of parameters for APAR and VPACC were tabulated to enable the commercial use of these FDD tools without the collection and analysis of trend data from each potential installation. Recommended values for the parameters were determined through trial and error at multiple field test sites and the resulting values were compiled and tabulated. For users who need or prefer to determine site-specific parameters, procedures to do so were developed and documented.

Multiple field sites were established to test APAR and VPACC embedded in commercial HVAC equipment controllers. The test was quite successful: a variety of mechanical and control faults have been detected, diagnosed, and in many cases, repaired.

The viability of deploying FDD as an integral component of the HVAC control system has been demonstrated. Based on feedback from users at the field sites, modifications have been made to enhance the usability and robustness of the FDD tools. In some cases, the local representative of the manufacturer of the control system was involved in the setup and operation of the test site. Feedback from these manufacturers' representatives, who will ultimately be responsible for installing FDD in their customers' buildings, was used to make the installation procedure more time- and resource-efficient and minimize the amount of site-specific configuration required. 


\section{References}

[1] Castro, N.S., Schein, J., Park, C., Galler, M.A., Bushby, S.T., and House, J.M. 2002. Results from Simulation and Laboratory Testing of Air Handling Unit and Variable Air Volume Box Diagnostic Tools. NISTIR 6964. National Institute of Standards and Technology. Gaithersburg, MD.

[2] Schein, J., Bushby, S.T., Castro, N.S., and House, J.M. 2003. Results from Field Testing of Air Handling Unit and Variable Air Volume Box Diagnostic Tools. NISTIR 6994. National Institute of Standards and Technology. Gaithersburg, MD.

[3] Schein, J., Bushby, S.T., and House, J.M. 2003. Results from Laboratory Testing of Embedded Air Handling Unit and Variable Air Volume Box Diagnostic Tools. NISTIR 7036. National Institute of Standards and Technology. Gaithersburg, MD.

[4] Hyvärinen, J. and Kärki, S. (Ed.). 1996. International Energy Agency Building Optimisation and Fault Diagnosis Source Book. Published by Technical Research Centre of Finland, Laboratory of Heating and Ventilation, Espoo, Finland.

[5] House, J.M., Vaezi-Nejad, H., and Whitcomb, J.M., 2001. An Expert Rule Set for Fault Detection in Air-Handling Units. ASHRAE Transactions. Vol. 107, Pt. 1: pp. 858-871.

[6] Schein, J., and House, J.M. 2003. Application of Control Charts for Detecting Faults in Variable-Air-Volume Boxes. ASHRAE Transactions Vol. 109, Part 2.

[7] Ryan, Thomas P., 2000. Statistical Methods for Quality Improvement, $2^{\text {nd }}$ Edition. Wiley and Sons, New York.

[8] Taylor, B.N. and Kuyatt, C.E. 1994. Guidelines for Evaluating and Expressing the Uncertainty of NIST Measurement Results. NIST Technical Note 1297. National Institute of Standards and Technology. Gaithersburg, MD. 


\section{Appendix 1 APAR Pseudocode}

A platform-independent pseudocode implementation of APAR was developed as a programmer's reference:

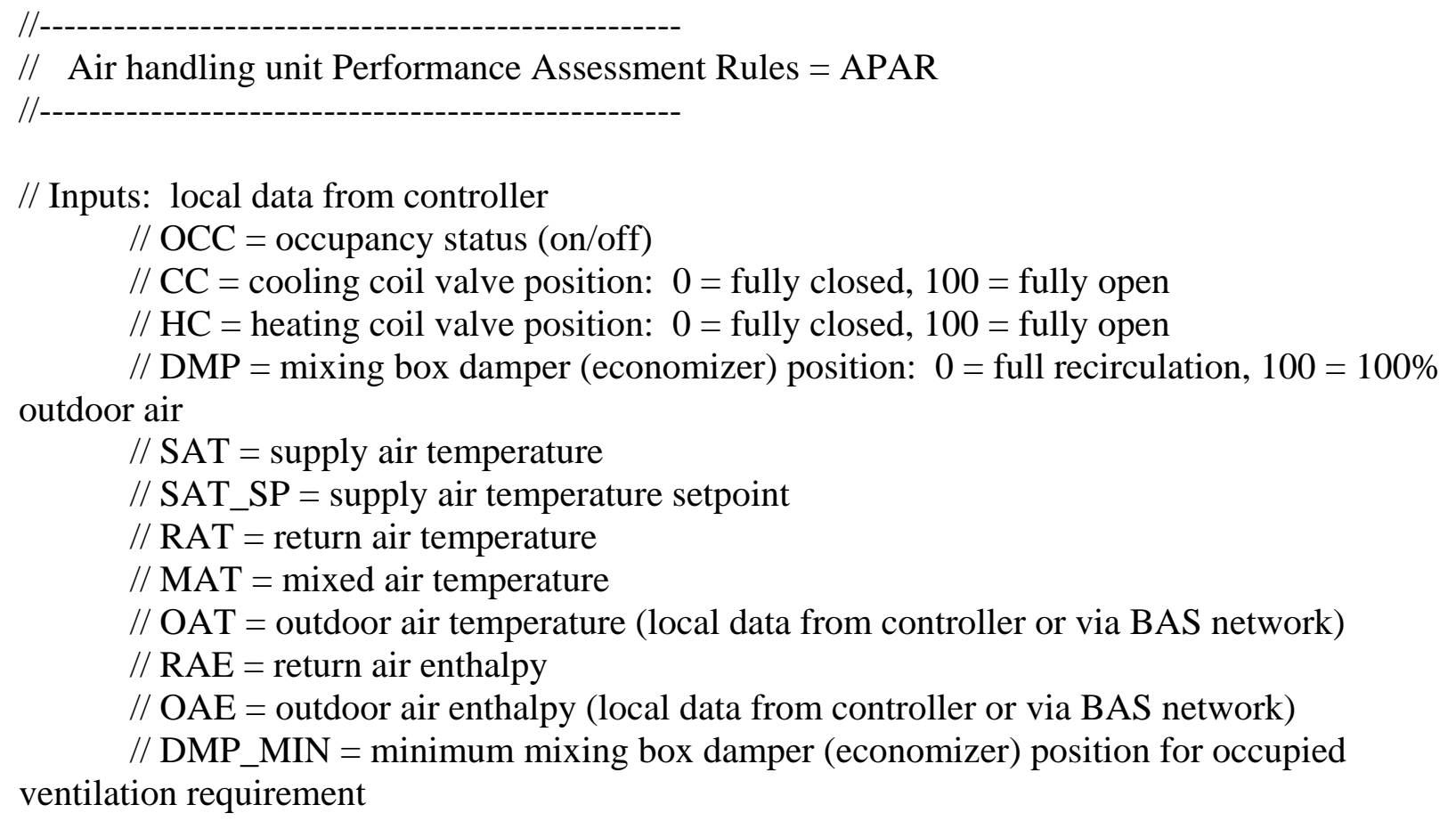

// MODE4_START = Mechanical cooling with minimum outdoor air mode (on/off)

// MODE4_STDY = Mechanical cooling with minimum outdoor air mode steady state (on/off)

// MODE5_START = Unknown mode of operation (on/off)

// MODE5_STDY = Unknown mode of operation steady state (on/off)

// EWMA_RESET = used to reset exponentially weighted moving averages (on/off)

// SAT_AVG = supply air temperature exponentially weighted moving average 

average

//SAT_SP_AVG = supply air temperature setpoint exponentially weighted moving

// RAT_AVG = return air temperature exponentially weighted moving average

// MAT_AVG = mixed air temperature exponentially weighted moving average

// OAT_AVG = outdoor air temperature exponentially weighted moving average

// RAE_AVG = return air enthalpy exponentially weighted moving average

// OAE_AVG = outdoor air enthalpy exponentially weighted moving average

// U_CC_AVG = normalized cooling coil valve position exponentially weighted moving average

// U_HC_AVG = normalized heating coil valve position exponentially weighted moving average

// U_D_AVG = normalized mixing box damper (economizer) position exponentially weighted moving average

// SW_COUNTER = mode switch counter

// VIOL_1 = status of rule 1 , on = fault (rule violated), off = normal

// VIOL_2 = status of rule 2 , on $=$ fault (rule violated), off $=$ normal

// VIOL_3 $=$ status of rule 3 , on $=$ fault (rule violated), off $=$ normal

$/ /$ VIOL_4 $=$ status of rule 4 , on $=$ fault (rule violated), off $=$ normal

// VIOL_5 $=$ status of rule 5 , on $=$ fault (rule violated), off $=$ normal

// VIOL_6 $=$ status of rule 6 , on $=$ fault (rule violated), off $=$ normal

// VIOL_7 $=$ status of rule 7 , on $=$ fault (rule violated), off $=$ normal

// VIOL_8 $=$ status of rule 8 , on $=$ fault (rule violated), off $=$ normal

// VIOL_9 $=$ status of rule 9, on $=$ fault (rule violated), off $=$ normal

// VIOL_10 = status of rule 10, on = fault (rule violated), off $=$ normal

// VIOL_11 = status of rule 11 , on = fault (rule violated), off = normal

// VIOL_12 = status of rule 12, on = fault (rule violated), off $=$ normal

// VIOL_13 = status of rule 13, on = fault (rule violated), off = normal

// VIOL_14 = status of rule 14, on = fault (rule violated), off = normal

// VIOL_15 = status of rule 15, on = fault (rule violated), off $=$ normal

// VIOL_16 = status of rule 16, on = fault (rule violated), off $=$ normal

// VIOL_17 = status of rule 17, on $=$ fault (rule violated), off $=$ normal

// VIOL_18 = status of rule 18, on = fault (rule violated), off $=$ normal

// VIOL_19 = status of rule 19, on = fault (rule violated), off = normal

// VIOL_20 = status of rule 20, on = fault (rule violated), off = normal

// VIOL_21 $=$ status of rule 21 , on $=$ fault (rule violated), off $=$ normal

// VIOL_22 = status of rule 22, on = fault (rule violated), off $=$ normal

// VIOL_23 = status of rule 23, on = fault (rule violated), off $=$ normal

// VIOL_24 = status of rule 24, on = fault (rule violated), off = normal

// VIOL_25 = status of rule 25, on = fault (rule violated), off $=$ normal

// VIOL_26 = status of rule 26, on = fault (rule violated), off $=$ normal

// VIOL_27 = status of rule 27, on = fault (rule violated), off $=$ normal

// VIOL_28 = status of rule 28, on = fault (rule violated), off = normal

// FAULT_CODE_1 = multiplexes VIOL_1 through VIOL_8 into a single 8-bit number

// FAULT_CODE_2 = multiplexes VIOL_9 through VIOL_16 into a single 8-bit number

// FAULT_CODE_3 = multiplexes VIOL_17 through VIOL_24 into a single 8-bit

number 
number

// FAULT_CODE_4 = multiplexes VIOL_25 through VIOL_28 into a single 8-bit

// Static parameters

min_OA_frac = DMP_MIN / $100 / /$ minimum outdoor air fraction 0 to 1

e_hc $=0.02 / /$ heating coil threshold (unitless)

e_cc $=0.02 / /$ cooling coil threshold (unitless)

e_d $=0.02 / /$ mixing box dampers threshold (unitless)

e_f $=0.3 / /$ flow threshold (unitless)

e_h $=1.3 / /$ enthalpy threshold $(\mathrm{kJ} / \mathrm{kg})(3.0 \mathrm{BTU} / \mathrm{lb})$

e_t $=2.0 / /$ temperature threshold (deg C) (3.6 deg F)

sw_max $=7 / /$ maximum mode switches per hour (unitless)

del_t_sf $=1.1 / /$ supply fan temperature rise $(\operatorname{deg} \mathrm{C})(2.0 \mathrm{deg} \mathrm{F})$

del_t_rf $=1.1 / /$ return fan temperature rise $(\operatorname{deg} \mathrm{C})(2.0 \mathrm{deg} \mathrm{F})$

del_t_min $=5.6 / /$ min temperature difference between OA and RA for ventilation rules

(deg C) $(1.0 \operatorname{deg} \mathrm{F})$

lambda $=0.1 / /$ smoothing constant (unitless, value determined elsewhere in program)

occ_dly $=90 \mathrm{~min} / /$ occupancy delay (min)

mode_dly $=60 \mathrm{~min} / /$ mode switch delay $(\mathrm{min})$

rule_dly $=60 \mathrm{~min} / /$ rule delay $(\mathrm{min})$

// allow selective disabling of rules to eliminate nuisance alarms

RULE_1_ENABLE $=$ On

RULE_2_ENABLE $=$ On

RULE_3_ENABLE $=$ On

RULE_4_ENABLE $=$ On

RULE_5_ENABLE $=$ On

RULE_6_ENABLE $=$ On

RULE_7_ENABLE $=$ On

RULE_8_ENABLE $=$ On

RULE_9_ENABLE $=$ On

RULE_10_ENABLE $=$ On

RULE_11_ENABLE $=$ On

RULE_12_ENABLE $=$ On

RULE_13_ENABLE $=$ On

RULE_14_ENABLE $=$ On

RULE_15_ENABLE $=$ On

RULE_16_ENABLE $=$ On

RULE_17_ENABLE $=$ On

RULE_18_ENABLE $=$ On

RULE_19_ENABLE $=$ On

RULE_20_ENABLE $=$ On

RULE_21_ENABLE $=$ On

RULE_22_ENABLE $=$ On

RULE_23_ENABLE $=$ On

RULE_24_ENABLE $=$ On 
RULE_25_ENABLE $=$ On

RULE_26_ENABLE $=$ On

RULE_27_ENABLE $=$ On

RULE_28_ENABLE $=$ On

Do // once every 60 seconds

// Normalize control signals

ucc_norm $=$ CC / 100

uhc_norm $=\mathrm{HC} / 100$

ud_norm = (DMP - DMP_MIN) / (100 - DMP_MIN)

$/ /-$

// Determine mode

$/ /-$

// Mode 99: Unoccupied

If $(\mathrm{OCC}=\mathrm{On})$ For occ_dly Then

MODE99 = Off

Else

$$
\text { MODE99 }=\text { On }
$$

End If

// Mode 1: Heating

If MODE99 = Off And uhc_norm $>$ e_hc And ud_norm $<$ e_d And ucc_norm $<$ e_cc Then

Else

$$
\text { MODE1_START }=\text { On }
$$

End If

MODE1_START $=$ Off

If $($ MODE1_START = On) For mode_dly Then MODE1_STDY $=$ On

Else

End If

$$
\text { MODE1_STDY = Off }
$$

// Mode 2: Cooling with OA

If MODE99 = Off And uhc_norm < e_hc And ud_norm > e_d And ud_norm < $(1$ - e_d $)$ And ucc_norm $<$ e_cc Then MODE2_START $=$ On

Else

$$
\text { MODE2_START }=\text { Off }
$$


End If

If $($ MODE2_START $=$ On) For mode_dly Then MODE2_STDY $=$ On

Else

$$
\text { MODE2_STDY = Off }
$$

End If

// Mode 3: Mechanical Cooling with 100\% OA

If MODE99 = Off And uhc_norm < e_hc And ud_norm > (1 - e_d) And ucc_norm > e_cc Then

$$
\begin{array}{ll}
\text { Else } & \text { MODE3_START }=\text { On } \\
\text { MODE3_START }=\text { Off }
\end{array}
$$

End If

If $($ MODE3_START $=$ On) For mode_dly Then

$$
\text { MODE3_STDY }=\text { On }
$$

Else

$$
\text { MODE3_STDY = Off }
$$

\section{End If}

// Mode 4: Mechanical Cooling with Min OA

If MODE99 = Off And uhc_norm < e_hc And ud_norm < e_d And ucc_norm > e_cc Then

$$
\begin{array}{ll}
\text { Else } & \text { MODE4_START }=\text { On } \\
\text { MODE4_START }=\text { Off }
\end{array}
$$

End If

If $($ MODE4_START $=$ On) For mode_dly Then

$$
\text { MODE4_STDY = On }
$$

Else

$$
\text { MODE4_STDY = Off }
$$

\section{End If}

// Mode 5: Unknown

If MODE99 = Off And MODE1_START $=$ Off And MODE2_START $=$ Off And MODE3_START $=$ Off And MODE4_START $=$ Off Then

$$
\text { MODE5_START }=\text { On }
$$

Else

$$
\text { MODE5_START }=\text { Off }
$$

End If

If $($ MODE5_START $=$ On) For mode_dly Then MODE5_STDY $=$ On 
Else

MODE5_STDY = Off

End If

// Mode Switch Counter

One Shot: If MODE1_START $=$ On Then SW_COUNTER $=$ SW_COUNTER +1

One Shot: If MODE2_START $=$ On Then SW_COUNTER $=$ SW_COUNTER +1

One Shot: If MODE3_START $=$ On Then SW_COUNTER $=$ SW_COUNTER +1

One Shot: If MODE4_START $=$ On Then SW_COUNTER $=$ SW_COUNTER +1

One Shot: If MODE5_START $=$ On Then SW_COUNTER $=$ SW_COUNTER +1

Calculate exponentially weighted moving averages

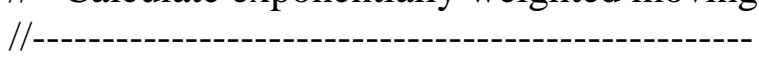

// Reset exponentially weighted moving averages upon mode switch

One Shot: If MODE1_START = On Then EWMA_RESET $=$ On

One Shot: If MODE2_START $=$ On Then EWMA_RESET $=$ On

One Shot: If MODE3_START $=$ On Then EWMA_RESET $=$ On

One Shot: If MODE4_START $=$ On Then EWMA_RESET $=$ On

One Shot: If MODE5_START $=$ On Then EWMA_RESET $=$ On

// Supply Air Temperature

If EWMA_RESET = On Then

SAT_AVG $=$ SAT

Else

End If

$$
\text { SAT_AVG }=(\text { SAT } * \text { lambda })+(\text { SAT_AVG } *(1-\text { lambda }))
$$

// Supply Air Temperature Setpoint

If EWMA_RESET = On Then

SAT_SP_AVG $=$ SAT_SP

Else

End If

$$
\text { SAT_SP_AVG }=\left(S A T \_S P * \text { lambda }\right)+\left(S A T \_S P \_A V G *(1-\text { lambda })\right)
$$

// Return Air Temperature

If EWMA_RESET = On Then

RAT_AVG $=$ RAT

Else

End If

$$
\text { RAT_AVG }=(\text { RAT } * \text { lambda })+(\text { RAT_AVG } *(1-\text { lambda }))
$$

// Mixed Air Temperature 


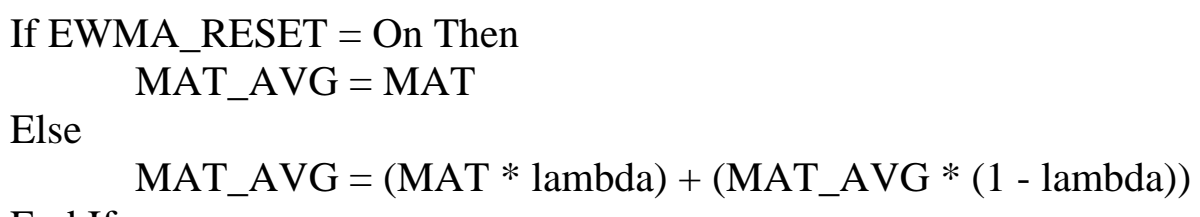

End If

// Outside Air Temperature

If EWMA_RESET $=$ On Then

$$
\text { OAT_AVG }=\text { OAT }
$$

Else

End If

$$
\text { OAT_AVG }=(\mathrm{OAT} * \text { lambda })+\left(\mathrm{OAT} \_\mathrm{AVG} *(1-\text { lambda })\right)
$$

// Return Air Enthalpy

If EWMA_RESET = On Then

RAE_AVG $=$ RAE

Else

End If

$$
\mathrm{RAE} \_\mathrm{AVG}=(\mathrm{RAE} * \text { lambda })+\left(\mathrm{RAE} \_\mathrm{AVG} *(1-\text { lambda })\right)
$$

// Outdoor Air Enthalpy

If EWMA_RESET $=$ On Then

OAE_AVG $=$ OAE

Else

End If

$$
\text { OAE_AVG }=(\mathrm{OAE} * \text { lambda })+\left(\mathrm{OAE} \_A V G *(1-\text { lambda })\right)
$$

// Normalized Cooling Coil Control Signal

If EWMA_RESET $=$ On Then

U_CC_AVG = ucC_norm

Else

End If

$$
\text { U_CC_AVG }=(\text { ucc_norm * lambda })+(\text { U_CC_AVG * }(1 \text { - lambda }))
$$

// Normalized Heating Coil Control Signal

If EWMA_RESET $=$ On Then

Else

$$
\text { U_HC_AVG = uhc_norm }
$$

End If

$$
\text { U_HC_AVG }=(\text { uhc_norm } * \text { lambda })+(\text { U_HC_AVG * }(1-\text { lambda }))
$$

// Normalized Mixing Box Damper Control Signal

If EWMA_RESET $=$ On Then

Else

$$
\text { U_D_AVG = ud_norm }
$$

$$
\text { U_D_AVG }=(\text { ud_norm * lambda })+(\text { U_D_AVG * }(1 \text { - lambda }))
$$


End If

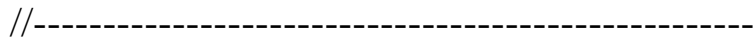

// Evaluate rules

//---------------------------------------------------------

// Mode 1: Heating

// Rule 1: In heating mode, SAT should be > MAT

If (RULE_1_ENABLE $=$ On And MODE1_STDY $=$ On And SAT_AVG $<$ MAT_AVG

+ del_t_sf - e_t) $=$ On For rule_dly Then

VIOL_1 $=$ On

Else

VIOL_1 = Off

End If

// Rule 2: Outdoor air fraction too low or too high

If (RULE_2_ENABLE = On And MODE1_STDY = On And Abs (RAT_AVG -

OAT_AVG) > del_t_min And (Abs ((MAT_AVG - RAT_AVG) / (OAT_AVG - RAT_AVG)) ) min_OA_frac $>$ e_f $)=$ On For rule_dly Then

VIOL_2 = On

Else

VIOL_2 = Off

End If

// Rule 3: Heating coil valve saturated fully open and persistent SAT error exists

If $($ RULE_3_ENABLE = On And MODE1_STDY = On And Abs $(1-$ U_HC_AVG $)<$ e_hc And SAT_SP_AVG -SAT_AVG > e_t) = On For rule_dly Then

VIOL_3 $=$ On

Else

End If

$$
\text { VIOL_3 = Off }
$$

// Rule 4: Heating coil valve saturated fully open, if heating load increases SAT will drift from setpoint

If (RULE_4_ENABLE = On And MODE1_STDY = On And VIOL_3 = Off And Abs (1 - U_HC_AVG) $<$ e_hc) $=$ On For rule_dly Then

$$
\text { VIOL_4 = On }
$$

Else

End If

$$
\text { VIOL_4 = Off }
$$

// Mode 2: Cooling with OA

// Rule 5: OAT too warm for cooling with OA 
If $($ RULE_5_ENABLE $=$ On And MODE2_STDY $=$ On And OAT_AVG >

SAT_SP_AVG - del_t_sf + e_t $)=$ On For rule_dly Then

VIOL_5 $=$ On

Else

End If

$$
\text { VIOL_5 = Off }
$$

// Rule 6: SAT should be $<$ RAT

If (RULE_6_ENABLE $=$ On And MODE2_STDY $=$ On And SAT_AVG $>$ RAT_AVG del_t_rf + e_t $)=$ On For rule_dly Then

VIOL_6 $=$ On

Else

End If

$$
\text { VIOL_6 = Off }
$$

// Rule 7: SAT and MAT should be nearly the same

If (RULE_7_ENABLE = On And MODE2_STDY = On And Abs (SAT_AVG - del_t_sf

- MAT_AVG) $>$ e_t) $=$ On For rule_dly Then

Else

$$
\text { VIOL_7 }=\text { On }
$$

End If

$$
\text { VIOL_7 = Off }
$$

// Mode 3: Mechanical cooling with 100\% OA

// Rule 8: OAT too cool for mech clg with $100 \%$ OA

If $($ RULE_8_ENABLE $=$ On And MODE3_STDY = On And OAT_AVG <

SAT_SP_AVG - del_t_sf - e_t) = On For rule_dly Then

Else

$$
\text { VIOL_8 }=\text { On }
$$

End If

$$
\text { VIOL_8 = Off }
$$

// Rule 9: OAE too high for mech clg with 100\% OA, rule will vary depending on AHU sequencing as follows:

// 1. Is economizer enabled based on temperature or enthalpy?

$/ / 2$. Is economizer enabled based on return or fixed changeover condition?

If (RULE_9_ENABLE $=$ On And MODE3_STDY = On And OAE_AVG $>$ RAE_AVG $\left.+\mathrm{e} \_\mathrm{h}\right)=$ On For rule_dly Then

$$
\text { VIOL_9 = On }
$$

Else

End If

$$
\text { VIOL_9 = Off }
$$

// Rule 10: OAT and MAT should be nearly the same 
If (RULE_10_ENABLE = On And MODE3_STDY = On And Abs (OAT_AVG -

MAT_AVG) $>$ e_t $)=$ On For rule_dly Then

$$
\text { VIOL_10 = On }
$$

Else

End If

$$
\text { VIOL_10 = Off }
$$

// Rule 11: SAT should be $<$ MAT

If (RULE_11_ENABLE $=$ On And MODE3_STDY $=$ On And SAT_AVG $>$ MAT_AVG + del_t_sf + e_t $)=$ On For rule_dly Then VIOL_11 = On

Else

End If

$$
\text { VIOL_11 = Off }
$$

// Rule 12: SAT should be $<$ RAT

If $($ RULE_12_ENABLE $=$ On And MODE3_STDY $=$ On And SAT_AVG $>$ RAT_AVG - del_t_rf + e_t) $=$ On For rule_dly Then

Else

$$
\text { VIOL_12 = On }
$$

End If

$$
\text { VIOL_12 = Off }
$$

// Rule 13: Cooling coil valve saturated fully open and persistent SAT error exists

If (RULE_13_ENABLE = On And MODE3_STDY = On And Abs $(1$ - U_CC_AVG) $<$ e_cc And SAT_AVG - SAT_SP_AVG > e_t $=$ = On For rule_dly Then

$$
\text { VIOL_13 = On }
$$

Else

End If

$$
\text { VIOL_13 = Off }
$$

// Rule 14: Cooling coil valve saturated fully open, if cooling load increases SAT will drift from setpoint

If (RULE_14_ENABLE $=$ On And MODE3_STDY = On And VIOL_13 = Off And Abs $(1$ - U_CC_AVG) $<$ e_cc) $=$ On For rule_dly Then

$$
\text { VIOL_14 = On }
$$

Else

End If

$$
\text { VIOL_14 = Off }
$$

// Mode 4: Mechanical cooling with minimum OA

// Rule 15: OAE too low for mech clg with min OA, rule will vary depending on AHU sequencing as follows:

// 1. Is economizer enabled based on temperature or enthalpy?

// 2. Is economizer enabled based on return or fixed changeover condition? 
If $($ RULE_15_ENABLE $=$ On And MODE4_STDY $=$ On And OAE_AVG $<$ RAE_AVG - e_h) = On For rule_dly Then

VIOL_15 = On

Else

End If

$$
\text { VIOL_15 = Off }
$$

// Rule 16: SAT should be $<$ MAT

If (RULE_16_ENABLE $=$ On And MODE4_STDY $=$ On And SAT_AVG $>$ MAT_AVG + del_t_sf + e_t $)=$ On For rule_dly Then

Else

$$
\text { VIOL_16 = On }
$$

\section{End If}

$$
\text { VIOL_16 = Off }
$$

// Rule 17: SAT should be < RAT

If $($ RULE_17_ENABLE $=$ On And MODE4_STDY $=$ On And SAT_AVG $>$ RAT_AVG - del_t_rf + e_t $)=$ On For rule_dly Then

VIOL_17 = On

Else

End If

$$
\text { VIOL_17 = Off }
$$

// Rule 18: \%OA too low or too high

If (RULE_18_ENABLE $=$ On And MODE4_STDY = On And Abs (RAT_AVG OAT_AVG) > del_t_min And (Abs ((MAT_AVG - RAT_AVG) / (OAT_AVG - RAT_AVG)) ) min_OA_frac $>$ e_f $)=$ On For rule_dly Then

Else

$$
\text { VIOL_18 = On }
$$

End If

$$
\text { VIOL_18 = Off }
$$

// Rule 19: Cooling coil valve saturated fully open and persistent SAT error exists

If $($ RULE_19_ENABLE = On And MODE4_STDY = On And Abs $(1-$ U_CC_AVG $)<$ e_cc And SAT_AVG - SAT_SP_AVG > e_t $)=$ On For rule_dly Then

$$
\text { VIOL_19 = On }
$$

Else

End If

$$
\text { VIOL_19 = Off }
$$

// Rule 20: Cooling coil valve saturated fully open, if cooling load increases SAT will drift from setpoint

If (RULE_20_ENABLE = On And MODE4_STDY = On And VIOL_19 = Off And Abs $(1$ - U_CC_AVG $)<$ e_cc $)=$ On For rule_dly Then

$$
\text { VIOL_20 = On }
$$

Else 


$$
\text { VIOL_20 = Off }
$$

End If

// Mode 5: Unknown mode simultaneously

// Rule 21: htg coil and clg coil valves and mixing box damper all modulating

If (RULE_21_ENABLE $=$ On And MODE5_STDY $=$ On And U_HC_AVG $>$ e_hc And U_D_AVG $>$ e_d And U_D_AVG $<(1$ - e_d) And U_CC_AVG $>$ e_cc $)=$ On For rule_dly Then VIOL_21 = On

Else

End If

$$
\text { VIOL_21 = Off }
$$

// Rule 22: htg coil and clg coil valves modulating simultaneously

If (RULE_22_ENABLE $=$ On And MODE5_STDY = On And U_HC_AVG $>$ e_hc And

U_CC_AVG > e_cc) $=$ On For rule_dly Then

$$
\text { VIOL_22 = On }
$$

Else

$$
\text { VIOL_22 = Off }
$$

End If

// Rule 23: htg coil valve and mixing box damper modulating simultaneously

If (RULE_23_ENABLE $=$ On And MODE5_STDY = On And U_HC_AVG $>$ e_hc And U_D_AVG $>$ e_d) $=$ On For rule_dly Then

$$
\text { VIOL_23 = On }
$$

Else

End If

$$
\text { VIOL_23 = Off }
$$

// Rule 24: clg coil valve and mixing box damper modulating simultaneously

If $($ RULE_24_ENABLE $=$ On And MODE5_STDY $=$ On And U_D_AVG $>$ e_d And

U_D_AVG $<(1$ - e_d $)$ And U_CC_AVG $>$ e_cc $)=$ On For rule_dly Then

$$
\text { VIOL_24 = On }
$$

Else

End If

$$
\text { VIOL_24 = Off }
$$

// Rules that apply to multiple modes

// Rule 25: persistent SAT error exists

If (RULE_25_ENABLE $=$ On And $($ MODE1_STDY $=$ On Or MODE2_STDY $=$ On Or MODE3_STDY $=$ On Or MODE4_STDY $=$ On Or MODE5_STDY $=$ On) And Abs (SAT_AVG -SAT_SP_AVG) $>$ e_t $=$ On For rule_dly Then

$$
\text { VIOL_25 = On }
$$

Else 


\section{End If}

$$
\text { VIOL_25 = Off }
$$

// Rule 26: MAT should be between RAT and OAT (MAT too great)

If $($ RULE_26_ENABLE $=$ On And $($ MODE1_STDY = On Or MODE2_STDY = On Or MODE3_STDY $=$ On Or MODE4_STDY = On Or MODE5_STDY = On) And MAT_AVG > Max (RAT_AVG, OAT_AVG) + e_t) = On For rule_dly Then

$$
\text { VIOL_26 }=\text { On }
$$

Else

End If

$$
\text { VIOL_26 = Off }
$$

// Rule 27: MAT should be between RAT and OAT (MAT too low)

If (RULE_27_ENABLE $=$ On And $($ MODE1_STDY $=$ On Or MODE2_STDY $=$ On Or MODE3_STDY $=$ On Or MODE4_STDY = On Or MODE5_STDY = On) And MAT_AVG < Min (RAT_AVG, OAT_AVG) - e_t) = On For rule_dly Then

$$
\text { VIOL_27 }=\text { On }
$$

Else

$$
\text { VIOL_27 = Off }
$$

End If

// Rule 28: Too many mode switches

If (RULE_28_ENABLE = On And SW_COUNTER > sw_max) Then

Else

$$
\text { VIOL_28 }=\text { On }
$$

End If

$$
\text { VIOL_28 = Off }
$$

$/ /-$

// Multiplex binary rule violations into analog fault codes

// Only necessary if fault code trend logs are desired

// Assumes 8-bit integers, therefore 8 faults per code

$/ /-$

FAULT_CODE_1 $=0$

If VIOL_1 = On Then

End If

$$
\text { FAULT_CODE_1 = FAULT_CODE_1 }+1
$$

If VIOL_2 = On Then

End If

$$
\text { FAULT_CODE_1 = FAULT_CODE_1 + } 2
$$

If VIOL_3 = On Then

End If

$$
\text { FAULT_CODE_1 = FAULT_CODE_1 }+4
$$

If VIOL_4 = On Then

FAULT_CODE_1 = FAULT_CODE_1 +8 
End If

If VIOL $5=$ On Then

End If

FAULT_CODE_1 $=$ FAULT_CODE_1 +16

If VIOL_6 = On Then

FAULT_CODE_1 $=$ FAULT_CODE_1 +32

End If

If VIOL_7 = On Then

FAULT_CODE_1 = FAULT_CODE_1 + 64

End If

If VIOL_8 $=$ On Then

End If

FAULT_CODE_1 $=$ FAULT_CODE_ $1+128$

FAULT_CODE_2 $=0$

If VIOL_9 = On Then

End If

FAULT_CODE_2 $=$ FAULT_CODE_2 +1

If VIOL_10 = On Then

End If

FAULT_CODE_2 $=$ FAULT_CODE_2 +2

If VIOL_11 $=$ On Then

FAULT_CODE_2 $=$ FAULT_CODE_2 +4

End If

If VIOL_12 = On Then

End If

FAULT_CODE_2 $=$ FAULT_CODE_2 +8

If VIOL_13 = On Then

End If

FAULT_CODE_2 = FAULT_CODE_2 + 16

If VIOL_14 = On Then

FAULT_CODE_2 $=$ FAULT_CODE_2 +32

End If

If VIOL_15 $=$ On Then

FAULT_CODE_2 $=$ FAULT_CODE_2 +64

End If

If VIOL_16 = On Then

End If

FAULT_CODE_2 =FAULT_CODE_2 + 128

FAULT_CODE_3 $=0$

If VIOL_17 $=$ On Then

End If

FAULT_CODE_3 $=$ FAULT_CODE_3 +1

If VIOL $18=$ On Then

FAULT_CODE_3 $=$ FAULT_CODE_3 +2 
End If

If VIOL_19= On Then

End If

FAULT_CODE_3 $=$ FAULT_CODE_3 +4

If VIOL_20 $=$ On Then

End If

FAULT_CODE_3 $=$ FAULT_CODE_3 +8

If VIOL_21 = On Then

FAULT_CODE_3 $=$ FAULT_CODE_3 +16

End If

If VIOL_22 $=$ On Then

End If

FAULT_CODE_3 $=$ FAULT_CODE_3 +32

If VIOL_23 = On Then

End If

FAULT_CODE_3 $=$ FAULT_CODE_3 +64

If VIOL $24=$ On Then

FAULT_CODE_3 $=$ FAULT_CODE_3 +128

End If

FAULT_CODE_4 $=0$

If VIOL_25 = On Then

FAULT_CODE_4 $=$ FAULT_CODE_4 +1

End If

If VIOL_26 = On Then

End If

FAULT_CODE_4 = FAULT_CODE_4 + 2

If VIOL_27 $=$ On Then

FAULT_CODE_4 = FAULT_CODE_4 + 4

End If

If VIOL_28 Then

End If

FAULT_CODE_4 $=$ FAULT_CODE_ $4+8$

End Do // once every 60 seconds

$/ /-$

Do // once every 60 minutes

One Shot: SW_COUNTER $=0 / /$ reset mode switch counter End Do // once every 60 minutes 


\section{Appendix 2 VPACC Pseudocode}

A platform-independent pseudocode implementation of VPACC was developed as a programmer's reference:

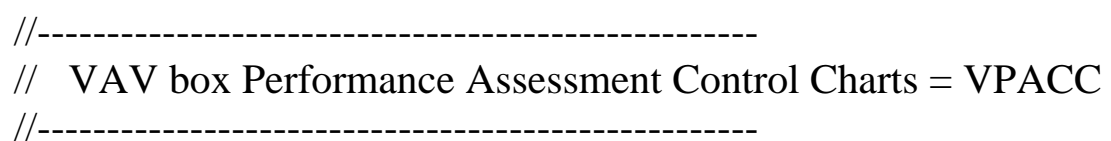

// Inputs: local data from controller

// OCC = occupancy status (on/off)

$/ /$ ZONE_TEMP = zone temperature sensor

// HSP = heating setpoint temperature

$/ / \mathrm{CSP}=$ cooling setpoint temperature

// FLOW = air flow rate (DP) sensor

// FLOW_SP = air flow rate setpoint

// MAX_FLOW = VAV box maximum airflow rate

$/ /$ RHC = reheat coil valve position: 0 = fully closed, 100 = fully open

// DAT = discharge air temperature

// AHU_SAT = air handling unit supply air temperature (via BAS network)

// VPACC variables

// steady = zone occupied and steady-state conditions exist (on/off)

// reset = timer to periodically reset CUSUMs

// temp_err = zone temperature error

// airflow_err = zone airflow error

// dat_err = discharge air temperature error

// norm_temp_err $=$ normalized zone temperature error

// norm_airflow_err = normalized zone airflow error

// norm_dat_err = normalized discharge air temperature error

// TEMP_S = positive cumulative sum for the zone temperature error

// TEMP_T = negative cumulative sum for the zone temperature error

// AIRFLOW_S = positive cumulative sum for the zone airflow error

// AIRFLOW_T = negative cumulative sum for the zone airflow error

// ABS_AIRFLOW_S = absolute value cumulative sum for the zone airflow error

// DAT_S = positive cumulative sum for the discharge air temperature error

// DAT_T = negative cumulative sum for the discharge air temperature error

hi_temp_err_enable $=$ On $/ /$ allows selective disabling of zone temperature error to eliminate nuisance alarms

lo_temp_err_enable $=$ On $/ /$ allows selective disabling of zone temperature error to eliminate nuisance alarms

hi_airflow_err_enable $=$ On $/ /$ allows selective disabling of zone airflow error to eliminate nuisance alarms

lo_airflow_err_enable $=$ On $/ /$ allows selective disabling of zone airflow error to eliminate nuisance alarms 
abs_airflow_err_enable $=$ On $/ /$ allows selective disabling of zone airflow error to eliminate nuisance alarms

hi_dat_err_enable $=$ On // allows selective disabling of discharge air temperature error to eliminate nuisance alarms

lo_dat_err_enable $=$ On // allows selective disabling of discharge air temperature error to eliminate nuisance alarms

// Static parameters

temp_err_exp $=0.0$ deg C $(0.0$ deg F $) / /$ expected zone temperature error

temp_err_stdev $=0.6$ deg C (1.0 deg F) // expected zone temperature variation

airflow_err_exp $=0 *$ MAX_FLOW // expected zone airflow error (same units as

MAX_FLOW)

airflow_err_stdev $=0.02 *$ MAX_FLOW // expected zone airflow variation (same units as MAX_FLOW)

dat_err_exp = 1.1 deg C (2.0 deg F) // expected discharge air temperature error

dat_err_stdev $=1.1$ deg C (2.0 deg F) // expected discharge air temperature variation

slack_parameter $=3$ (unitless)

alarm_limit $=1000$ (unitless)

occ_dly = $90 \mathrm{~min} / /$ occupancy delay (min)

rst_int $=360 \mathrm{~min} / /$ CUSUM reset interval (min)

// Delay for quasi-steady state conditions

If OCC $=$ On For occ_dly Then

steady $=\mathrm{ON}$

Do // once every rst_int

One Shot: reset $=$ ON $/ /$ periodically reset CUSUMs

End Do

Else

steady $=$ OFF

reset $=\mathrm{OFF}$

End If

Do // once every 60 seconds

If steady = On And reset = OFF // perform VPACC calculations

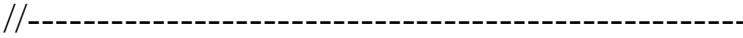

// Compute process errors

$/ /$

// Compute temperature error

If temp_err_enable $=$ On Then

If ZONE_TEMP $>$ CSP Then

temp_err $=$ ZONE_TEMP - CSP 
ElseIf ZONE_TEMP $<$ HSP Then

temp_err = ZONE_TEMP - HSP

Else

temp_err $=0$

End If

Else

End If

temp_err $=0$

// Compute airflow error

If airflow_err_enable $=$ On Then

airflow_err $=$ FLOW - FLOW_SP

Else

End If

airflow_err $=0$

// Compute discharge air temperature error

If (dat_er_enable $=$ On) And $(\mathrm{RHC}=0)$ Then

dat_err = DAT - AHU_SAT

Else

dat_err $=0$

End If

|/---------------------------------------------------------

// Normalize process errors

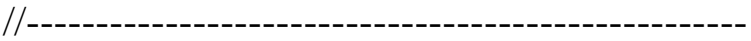

// Normalize temperature error

norm_temp_err $=$ (temp_err - temp_err_exp) / temp_err_stdev

// Normalize airflow error

norm_airflow_err = (airflow_err - airflow_err_exp) / airflow_err_stdev

// Normalize discharge air temperature error

norm_dat_err $=$ (dat_err - dat_err_exp) / dat_err_stdev

// Compute cumulative sums

//-------------------------------------------------------

// Calculate temperature cumulative sums

TEMP_S = Max (0, norm_temp_err - slack_parameter + TEMP_S $)$

TEMP_T $=$ Max $(0,-1 *$ norm_temp_err - slack_parameter + TEMP_T $)$

// Calculate airflow cumulative sums

AIRFLOW_S = Max (0, norm_airflow_err - slack_parameter + AIRFLOW_S) 


\author{
ABS_AIRFLOW_S) \\ // Calculate dat cumulative sums \\ // Check for alarm conditions \\ //---------------------------------------------------------- \\ If TEMP_S > alarm_limit Then

$$
\text { HI_TEMP_ALARM }=\text { On }
$$ \\ Else \\ End If \\ HI_TEMP_ALARM = Off \\ If TEMP_T $>$ alarm_limit Then \\ LO_TEMP_ALARM $=$ On \\ Else \\ LO_TEMP_ALARM $=$ Off \\ End If \\ If AIRFLOW_S > alarm_limit Then \\ HI_AIRFLOW_ALARM = On \\ Else \\ End If \\ HI_AIRFLOW_ALARM = Off \\ If AIRFLOW_T > alarm_limit Then

$$
\text { LO_AIRFLOW_ALARM = On }
$$ \\ Else \\ End If \\ LO_AIRFLOW_ALARM = Off \\ If ABS_AIRFLOW_S > alarm_limit Then \\ ABS_AIRFLOW_ALARM $=$ On \\ Else \\ End If \\ ABS_AIRFLOW_ALARM = Off \\ If DAT_S > alarm_limit Then

$$
\text { HI_DAT_ALARM = On }
$$ \\ Else \\ End If \\ HI_DAT_ALARM = Off \\ If $\mathrm{DAT}_{-} \mathrm{T}>$ alarm_limit Then

$$
\text { LO_DAT_ALARM = On }
$$ \\ Else

$$
\text { LO_DAT_ALARM = Off }
$$

AIRFLOW_T $=$ Max $(0,-1 *$ norm_airflow_err - slack_parameter + AIRFLOW_T)

ABS_AIRFLOW_S = Max (0, Abs (norm_airflow_err) - slack_parameter +

DAT_S = Max (0, norm_dat_err - slack_parameter + DAT_S $)$

DAT_T $=$ Max $(0,-1 *$ norm_dat_err - slack_parameter + DAT_T $)$ 
End If

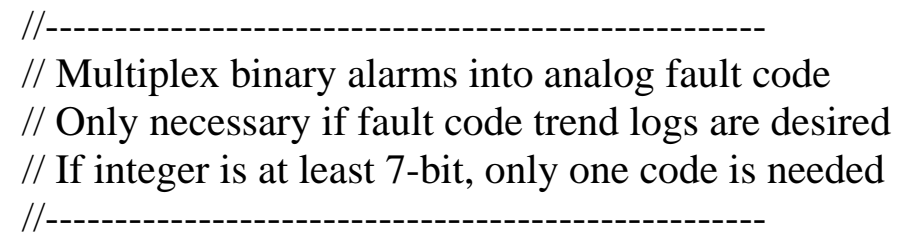

FAULT_CODE $=0$

If HI_TEMP_ALARM $=$ On Then

FAULT_CODE $=$ FAULT_CODE +1

End If

$\begin{aligned} \text { If LO_TEMP_ALARM } & =\text { On Then } \\ \text { FAULT_CODE } & =\text { FAULT_CODE }+2\end{aligned}$

End If

If HI_AIRFLOW_ALARM = On Then

FAULT_CODE $=$ FAULT_CODE +4

End If

If LO_AIRFLOW_ALARM $=$ On Then

FAULT_CODE $=$ FAULT_CODE +8

End If

If ABS_AIRFLOW_ALARM $=$ On Then

FAULT_CODE $=$ FAULT_CODE + 16

End If

If HI_DAT_ALARM $=$ On Then

End If

FAULT_CODE $=$ FAULT_CODE +32

If LO_DAT_ALARM = On Then

End If

FAULT_CODE $=$ FAULT_CODE + 64

Else // Quasi-steady state conditions do not exist, do not perform VPACC calculations
temp_err $=0$
airflow_err $=0$
dat_err $=0$
norm_temp_err $=0$
norm_airflow_err $=0$
norm_dat_err $=0$
TEMP_S $=0$
TEMP_T $=0$
AIRFLOW_S $=0$
AIRFLOW_T $=0$
ABS_AIRFLOW_S $=0$
DAT_S $=0$
DAT_T $=0$ 

HI_TEMP_ALARM $=$ Off
LO_TEMP_ALARM $=$ Off
HI_AIRFLOW_ALARM $=$ Off
LO_AIRFLOW_ALARM = Off
ABS_AIRFLOW_ALARM $=$ Off
HI_DAT_ALARM $=$ Off
LO_DAT_ALARM $=$ Off
FAULT_CODE $=0$
DIAGNOSTIC_CODE_1 $=0$
DIAGNOSTIC_CODE_2 $=0$
DIAGNOSTIC_CODE_3 $=0$

End If

//------------------------------------------------------------

End Do // once every 60 seconds 